\title{
CORRELAÇÃO INTRACLASSE DE PEARSON PARA PARES REPETIDOS - COMPARAÇÃO ENTRE DOIS ESTIMADORES
}

\section{Denise Pimentel Bergamaschi}

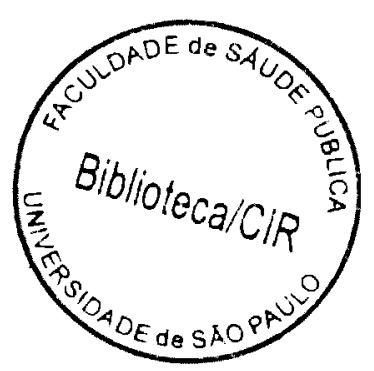

Tese de Doutorado apresentada ao Departamento de Epidemiologia da Faculdade de Saúde Pública da Universidade de São Paulo para obtenção do grau de Doutor.

Area de concentração: Epidemiologia

Orientador: JOSÉ MARIA PACHECO DE SOUZA 
Autorizo, exclusivamente para fins acadêmicos e científicos, a reprodução total ou parcial desta tese, por processos fotocopiadores.

Assinatura:

Data:

$38596 / 99$ doc 
PARA DAVID, JÚLIA E MATEUS 


\section{AGRADECIMENTOS}

Os meus agradecimentos ao Prof. JOSÉ MARIA PACHECO DE SOUZA pela valiosa orientação prestada, por me ensinar a gostar do tema objeto desta tese, pela paciência infinita, pelas oportunidades propiciadas e, especialmente, pelas lições de vida oferecidas. Não tenho dúvidas de que ter sido sua orientanda foi um grande privilégio

Aos professores Clóvis de Araújo Peres, Jorge Oishi, Jair Lício Ferreira dos Santos, Nilza Nunes da Silva e Suzana Alves de Moraes pelas valiosas contribuições dadas para a elaboração desse trabalho.

À minha mãe e irmãos pelo apoio recebido

Às professoras Maria do Rosário Dias de Oliveira Latorre, Sabina Léa Davidson Gotlieb e Suely Godoy Agostinho Gimeno pela amizade, estímulos, constante apoio e inúmeras sugestões

Às professoras Maria Lúcia de Moura Soboll e Márcia de Almeida Furquim pela amizade e constante apoio.

Aos professores e funcionários da Estatística do Departamento de Epidemiologia da Faculdade de Saúde Pública pela amizade e apoio recebidos durante todo o desenvolvimento deste trabalho

Às bibliotecárias da Faculdade de Saúde Pública e, em especial, Maria Lúcia de Faria Ferraz pela revisão bibliográfica.

Aos amigos Ana Maria, Bernadette, Cláudia, Gizelton, Mary, Maria Lúcia e Regina pelo apoio, discussões e constantes estímulos recebidos

À CAPES pela bolsa de estudos concedida

À Fundação Nacional de Saúde, em especial à Coordenação Regional de São Paulo, por ter me liberado, permitido a realização deste trabalho. 


\section{Resumo}

Bergamaschi DP. Correlação intraclasse de Pearson para pares repetidos comparação entre dois estimadores. São Paulo; 1999. [Tese de Doutorado - Faculdade de Saúde Pública da USP]

Objetivo. Comparar, teórica e empiricamente, dois estimadores do coeficiente de correlação intraclasse momento-produto de Pearson para pares repetidos $\rho_{l}$. O primeiro é o estimador "natural", obtido mediante a correlação momento-produto de Pearson para membros de uma mesma classe $\left(r_{I}\right)$ e o segundo, obtido como função de componentes de variância (icc). Métodos. Comparação teórica e empírica dos parâmetros e estimadores. A comparação teórica envolve duas definições do coefíciente de correlação intraclasse $\rho_{l}$ como medida de confiabilidade $\left(\rho_{I}=\frac{\operatorname{Cov}(X, Y)}{\sigma_{Y} \sigma_{Y}}\right.$ e $\rho_{I}=\frac{\sigma_{a}^{2}}{\sigma_{a}^{2}+\sigma_{e}^{2}}$ ), para o caso de duas réplicas, assim como uma apresentação da técnica de análise de variância e a definição e interpretação dos estimadores $r_{1}$ e icc. A comparação empírica é realizada mediante um estudo de simulação Monte Carlo com a geração de pares de valores correlacionados segundo o coeficiente de correlação intraclasse, momentoproduto de Pearson para pares repetidos. Os pares de valores são distribuídos segundo uma distribuição Normal bivariada, com valores do tamanho da amostra e da correlação intraclasse previamente fixados em: $n=15,30$ e 45 e $\rho_{I}=\{0 ; 0,15 ; 0,30 ; 0,45 ; 0,60$; $0,75 ; 0,9\}$ Resultados. Comparando-se o vício e o erro quadrático médio dos estimadores, bem como as amplitudes dos intervalos de confiança, tem-se como resultado que o vício de icc foi sempre menor que o vício de $r_{f}$, mesmo ocorrendo com o erro quadrático médio. Conclusões. O icc é um estimador melhor, principalmente para $n$ pequeno (por exemplo 15). Para valores maiores de $n$ (30 ou mais), os estimadores produzem resultados iguais até a segunda casa decimal.

Descritores: Dois estimadores da correlação intraclasse de Pearson para pares repetidos. Simulação Monte Carlo. 


\section{SUMMARY}

Bergamaschi DP. Correlação intraclasse de Pearson para pares repetidos - comparação entre dois estimadores. São Paulo; 1999. [Pearson's pairwise correlation coefficient - two estimators] São Paulo (BR); 1999 [Tese de Doutorado - Faculdade de Saúde Pública da USP]

Objective. This thesis presents and compares, theoretically and empirically, two estimators of the intraclass correlation coefficient $\rho_{l}$, defined as Pearson's pairwise intraclass correlation coefficient. The first is the "natural" estimator, obtained by Pearson's moment-product correlation for members of one class $\left(r_{l}\right)$ while the second was obtained as a function of components of variance (icc). Methods. Theoretical and empirical comparison of the parameters and estimators are performed. The theoretical comparison involves two definitions of the intraclass correlation coefficient $\rho_{l}$ as a measure of reliability $\left(\rho_{I}=\frac{\operatorname{Cov}(X, Y)}{\sigma_{X} \sigma_{Y}} e \rho_{I}=\frac{\sigma_{a}^{2}}{\sigma_{a}^{2}+\sigma_{e}^{2}}\right)$, for two repeated measurements in the same class and the presentation of the technique of analysis of variance, as well as for the definition and interpretation of the estimators $r_{l}$ and icc. The empirical comparison was carried out by means of a Monte Carlo simulation study of pairs of correlated values according Pearson's pairwise correlation. The pairs of values follow a normal bivariate distribution, with correlation values and sample size previously fixed: $n=15,30$ e 45 and $\rho_{l}=\{0 ; 0,15 ; 0,30 ; 0,45 ; 0,60 ; 0,75 ; 0,9\}$. Results. Bias and mean square error for the estimators were compared as well as the range of the intervals of confidence. The comparison shows that the bias of icc is always smaller than of $r_{l}$. This also applies to the mean square error. Conclusions. The icc is a better estimator, especially for $n$ less than or equal to 15. For larger samples sizes ( $n 30$ or more), the estimators produce results that are equal to the second decimal place.

Descriptors: - Two estimators of Pearson's pairwise correlation coefficient. Monte Carlo study. 


\section{ÍNDICE}

RESUMO

SUMMARY

1 - INTRODUÇÃO

1.1 - Variabilidade de medições

1.2 - Avaliação da confiabilidade $\quad 8$

$\begin{array}{ll}1.3 \text { - Medidas de confiabilidade } & 9\end{array}$

1.3.1 - Correlação intraclasse momento-produto de Pearson para 9 pares repetidos

1.3.2 - Correlação intraclasse como função de componentes de 13 variância

2 - OBJETIVOS

2.1 - Objetivo geral

$\begin{array}{ll}2.2 \text { - Objetivos específicos } & 16\end{array}$

3 - METODOLOGIA $\quad 17$

3.1 - Análise de variância com um fator aleatório 17

3.1.1 - Partição da soma de quadrados $\quad 20$

3.1 .2 - Estimação pontual dos componentes da variância $\quad 21$

3.2 - Correlação intraclasse momento-produto de Pearson para pares 23 repetidos $\left(\rho_{I}\right)$

3.2.1 - Definição de $\rho_{I}$

3.2 .2 - Limites de variação de $\rho_{I} \quad 26$

3.2 .3 - Comparação entre estimadores da correlação interclasse $(r) \quad 27$ e da correlação intraclasse para pares repetidos $\left(r_{l}\right)$

$\begin{array}{ll}3.2 .4 \text { - Transformação de } r \mathrm{em} \mathrm{z} & 28\end{array}$

3.2 .5 - Estimatimador de $\rho_{I}$ por ponto e por intervalo 30

3.3 - Correlação intraclasse $\left(\rho_{I}\right)$ como função de componentes de 31 variância

3.3.1.- Definição de $\rho_{l}$

3.3.2 - Limites de variação de $\rho_{I} \quad 32$

3.3.3 - Estimatimador de $\rho_{I}$ por ponto e por intervalo 32

3.4 - Comparação entre $r_{I}$ e icc 34

3.5 - Estudo de simulação Monte Carlo 37

3.6 - Critérios para escolha do melhor estimador $\quad 42$ 
4 - RESULTADOS E COMENTÁRIOS 43

4.1 - Estudo Monte Carlo 43

4.2 - Estimadores de $\rho_{1}: r_{1}$ e $i c c \quad 43$

4.3 - Viés de $r_{I}$ e de icc 49

4.4 - Erro quadrático médio de $r_{I}$ e icc

4.5 - Estimação de $\rho_{I}$ por intervalo $\quad 55$

5 - DisCuSSÃO 61

6 - CONCLUSÕES

7- REFERÊNCIAS BIBLIOGRÁFICAS

ANEXOS

Anexo 1 Definição de erro, viés e erro quadrático médio

Anexo 2 Sensibilidade e especificidade

Anexo 3 Modelo de efeitos aleatórios para um fator

Anexo4 Definição de confiabilidade em termos de concordância

Anexo 5 Correlação intraclasse de pearson estimada pela anova

Anexo 6 Equações geradoras de números pseudo-aleatórios, do gerador kiss - stata

Anexo 7 Programa computacional utilizado no estudo monte carlo

Anexo 8 Estudo da distribuição dos valores gerados

Anexo 9 Diferenças entre os valores médios de $r_{l}$ e icc

Anexo 10 Viés e erro quadrático médio de $r_{l}$ e icc

Anexo 11 Eficiência relativa de icc

Anexo 12 Amplitude dos intervalos de confiança.

Número de vezes que os Intervalos de Confiança abrangem o parâmetro

Anexo 13 Aplicação 


\section{LISTA DE FIGURAS}

Figura 1 - Concentrações (\%) de amônia, em experimento realizado por quatro técnicos, com seis determinações por técnico

Figura 2A - Dispersão dos pontos $\{X, Y\}$

Figura 2B- Dispersão dos pontos $\{Y, X\}$

Figura 3 - Dispersão dos pontos $\left\{X, X^{\prime}\right\}$

Figura 4a - Simulação de 2.000 amostras de tamanho $n=15$ e coeficientes de correlação intraclasse $\rho_{I}=\{0 ; 0,15 ; 0,30 ; 0,45 ; 0,60 ; 0,75 ; 0,90\}$. Valores médios de $r_{l}$, e icc

Figura 4b - Simulação de 2.000 amostras de tamanho $n=30$ e coeficientes de correlação intraclasse $\rho_{I}=\{0 ; 0,15 ; 0,30 ; 0,45 ; 0,60 ; 0,75 ; 0,90\}$. Valores médios de $r_{l}$, e icc

Figura 4c- Simulação de 2.000 amostras de tamanho $n=45$ e coeficientes de correlação intraclasse $\rho_{I}=\{0 ; 0,15 ; 0,30 ; 0,45 ; 0,60 ; 0,75 ; 0,90\}$. Valores médios de $r_{l}$, e icc

Figura 5 - Simulação de 2.000 amostras de tamanho $n=15,30$ e 45 e coeficientes de correlação intraclasse $\rho_{I}=\{0 ; 0,15 ; 0,30 ; 0,45 ; 0,60 ; 0,75 ; 0,90\}$. Diferença entre os valores médios de icc e $r_{l}$.

Figura 6 - Simulação de 2.000 amostras de tamanho $n=15,30$ e 45 e coeficientes de correlação intraclasse $\rho_{I}=\{0 ; 0,15 ; 0,30 ; 0,45 ; 0,60 ; 0,75 ; 0,90\}$. Razão entre os logaritmos naturais dos valores médios absolutos de icc e $r_{I}$.

Figura 7 - Simulação de 2.000 amostras de tamanho $n=15,30$ e 45 e coeficientes de correlação intraclasse $\rho_{J}=\{0 ; 0,15 ; 0,30 ; 0,45 ; 0,60 ; 0,75 ; 0,90\}$. Diferença entre os desvios padrão de icc e $r_{I}$.

Figura 8 - Simulação de 2.000 amostras de tamanho $n=15,30$ e 45 e coeficientes de correlação intraclasse $\rho_{l}=\{0 ; 0,15 ; 0,30 ; 0,45 ; 0,60 ; 0,75 ; 0,90\}$. Razão entre os desvios padrão de icc e $r_{I}$. 
Figura 9a - Simulação de 2.000 amostras de tamanho $n=15$ e coeficientes de correlação intraclasse $\rho_{I}=\{0 ; 0,15 ; 0,30 ; 0,45 ; 0,60 ; 0,75 ; 0,90\}$. Valores do viés de $r_{I}$ (viesri) e do viés de icc (viesicc)

Figura 9b - Simulação de 2.000 amostras de tamanho $n=30$ e coeficientes de correlação intraclasse $\rho_{I}=\{0 ; 0,15 ; 0,30 ; 0,45 ; 0,60 ; 0,75 ; 0,90\}$. Valores do viés de $r_{I}$ (viesri) e do viés de icc (viesicc)

Figura 9c- Simulação de 2.000 amostras de tamanho $n=45$ e coeficiente de correlação intraclasse $\rho_{I}=\{0 ; 0,15 ; 0,30 ; 0,45 ; 0,60 ; 0,75 ; 0,90\}$. Valores do viés de $r_{I}$ (viesri) e do viés de $i c c$ (viesicc)

Figura 10a - Simulação de 2.000 amostras de tamanho $n=15$ e coeficientes de correlação intraclasse $\rho_{I}=\{0 ; 0,15 ; 0,30 ; 0,45 ; 0,60 ; 0,75 ; 0,90\}$. Valores do quociente entre o viés dos estimadores $r_{I}$ e icc e $\rho_{I}$.

Figura 10b - Simulação de 2.000 amostras de tamanho $n=30$ e coeficientes de correlação intraclasse $\rho_{I}=\{0 ; 0,15 ; 0,30 ; 0,45 ; 0,60 ; 0,75 ; 0,90\}$. Valores do quociente entre o viés dos estimadores $r_{I}$ e icc e $\rho_{I}$.

Figura 10c - Simulação de 2.000 amostras de tamanho $n=45$ e coeficientes de correlação intraclasse $\rho_{I}=\{0 ; 0,15 ; 0,30 ; 0,45 ; 0,60 ; 0,75 ; 0,90\}$. Valores do quociente entre o viés dos estimadores $r_{I}$ e icc e $\rho_{I}$.

Figura 1 la - Simulação de 2.000 amostras de tamanho $n=15$ e coeficientes de correlação intraclasse $\rho_{I}=\{0 ; 0,15 ; 0,30 ; 0,45 ; 0,60 ; 0,75 ; 0,90\}$. Valores dos erros quadráticos médios de $r_{I}$ (eqmri) e de $i c c$ (eqmicc)

Figura 1lb - Simulação de 2.000 amostras de tamanho $n=30$ e coeficientes de correlação intraclasse $\rho_{I}=\{0 ; 0,15 ; 0,30 ; 0,45 ; 0,60 ; 0,75 ; 0,90\}$. Valores dos erros quadráticos médios de $r_{I}$ (eqmri) e de icc (eqmicc)

Figura 11c - Simulação de 2.000 amostras de tamanho $n=45$ e coeficientes de correlação intraclasse $\rho_{I}=\{0 ; 0,15 ; 0,30 ; 0,45 ; 0,60 ; 0,75 ; 0,90\}$. Valores dos erros quadráticos médios de $r_{I}$ (eqmri) e de icc (eqmicc)

Figura 12 - Simulação de 2.000 amostras de tamanho $n=45$ e coeficientes de correlação intraclasse $\rho_{I}=\{0 ; 0,15 ; 0,30 ; 0,45 ; 0,60 ; 0,75 ; 0,90\}$. Diferenças entre os erros quadráticos médios de $r_{I}$ (eqmri) e de icc (eqmicc)

Figura 13 - Simulação de 2.000 amostras de tamanho $n=15,30$ e 45 e coeficientes de correlação intraclasse $\rho_{I}=\{0 ; 0,15 ; 0,30 ; 0,45 ; 0,60 ; 0,75 ; 0,90\}$. Valores dos quocientes entre os erros quadráticos médios de $r_{I}$ (eqmri) $\mathrm{e}$ de $i c c$ (eqmicc) 
Figura 14a - Simulação de 2.000 amostras de tamanho $n=15,30$ e 45 e coeficientes de correlação intraclasse $\rho_{I}=\{0 ; 0,15 ; 0,30 ; 0,45 ; 0,60 ; 0,75 ; 0,90\}$. Valores das amplitudes médias dos intervalos de confiança de $95 \%$ de $\rho_{I}$, estimados por $r_{I}$

Figura 14b - Simulação de 2.000 amostras de tamanho $n=15,30$ e 45 e coeficientes de correlação intraclasse $\rho_{I}=\{0 ; 0,15 ; 0,30 ; 0,45 ; 0,60 ; 0,75 ; 0,90\}$. Valores das amplitudes médias dos intervalos de confiança de $95 \%$ de $\rho_{I}$, estimados por $i c c$

Figura 15- Simulação de 2.000 amostras de tamanho $n=15,30$ e 45 e coeficientes de 56 correlação intraclasse $\rho_{I}=\{0 ; 0,15 ; 0,30 ; 0,45 ; 0,60 ; 0,75 ; 0,90\}$. Diferenças entre as amplitudes médias dos intervalos de confiança de $95 \%$ de $\rho_{I}$, estimados por $r_{I}$ e icc.

Figura 16a - Simulação de 2.000 amostras de tamanho $n=15$ e coeficientes de correlação intraclasse $\rho_{I}=\{0 ; 0,15 ; 0,30 ; 0,45 ; 0,60 ; 0,75 ; 0,90\}$. Percentual de vezes que o parâmetro $\rho_{I}$ está contido no intervalo de confiança de $95 \%$ de $\rho_{I}$, estimados por $r_{I}$ e $i c c$.

Figura 16b - Simulação de 2.000 amostras de tamanho $n=30$ e coeficientes de 56 correlação intraclasse $\rho_{I}=\{0 ; 0,15 ; 0,30 ; 0,45 ; 0,60 ; 0,75 ; 0,90\}$. Percentual de vezes que o parâmetro $\rho_{I}$ está contido no intervalo de confiança de $95 \%$ de $\rho_{I}$.

Figura 16c - Simulação de 2.000 amostras de tamanho $n=45$ e coeficientes de correlação intraclasse $\rho_{I}=\{0 ; 0,15 ; 0,30 ; 0,45 ; 0,60 ; 0,75 ; 0,90\}$. Percentual de vezes que o parâmetro $\rho_{I}$ está contido no intervalo de confiança de $95 \%$ de $\rho_{I}$. 


\section{LISTA DE TABELAS}

Tabela 1 - Concentrações (\%) de amônia em experimento realizado por quatro técnicos, com seis determinações por técnico

Tabela 2 - Número de dobras cutâneas de impressões digitais de todos os dedos, de ambas as mãos, de 12 pares de gêmeas idênticas

Tabela 3 - Pares originais e pares repetidos, em ordem inversa

$\begin{array}{llr}\text { Tabela } 4 \text { - Estrutura geral de observações repetidas } & 20\end{array}$

Tabela 5 - ANOVA para o modelo de efeitos aleatórios com um fator 22

Tabela 6 - Simulação de 2.000 amostras de tamanho $n=15,30$ e 45 e coeficientes de correlação intraclasse $\rho_{I}=\{0 ; 0,15 ; 0,30 ; 0,45 ; 0,60 ; 0,75 ; 0,90\}$. Média, desvio padrão e valores mínimo e máximo de $r_{I}$

Tabela 7 - Simulação de 2.000 amostras de tamanho $n=15,30$ e 45 e coeficientes de correlação intraclasse $\rho_{I}=\{0 ; 0,15 ; 0,30 ; 0,45 ; 0,60 ; 0,75 ; 0,90\}$. Média, desvio padrão e valores mínimo e máximo de icc.

\section{LISTA DE QUADROS}

Quadro 1 - Resumo dos conceitos relacionados à variabilidade de dados e relação entre eles

Quadro 2 - Procedimentos do estudo Monte Carlo e respectivos comandos no STATA

Quadro 3 - Características teóricas dos parâmetros $\quad 58$

Quadro 4 - Características empíricas dos estimadores a partir da simulação de 2.000 amostras de pares de valores correlacionados segundo coeficientes de correlação intraclasse e tamanho de amostras fixadas 


\section{INTRODUÇ̃̃o}

\section{1 - Variabilidade de medições}

Em ciências biomédicas e exatas, mensuração pode ser definida como a "atribuição de números a objetos ou eventos". Uma definição mais ampla, que pode ser aplicada também na área de ciências sociais, é aquela que define mensuração como "o processo de associar conceitos abstratos a indicadores empíricos" (Carmines e Zeller 1979).

A escolha das características a serem mensuradas, assim como, o método de mensuração são importantes, não apenas porque cada tipo de variável possibilita diferentes graus de informação, mas, principalmente, porque algumas descrevem, de uma forma mais apurada, a natureza do evento sob estudo. Por exemplo, medições de bilirrubina caracterizam melhor funções hepáticas do que a presença de icterícia.

Uma vez escolhida a forma de se medir a característica sob interesse, o investigador depara-se com o fato de que sempre existe um certo grau de incerteza, associado a resultados diretos ou indiretos de medições (Dunn 1992). Segundo Carmines e Zeller (1979), “a meta de medições livres de erro, apesar de almejada, nunca é alcançada, em qualquer área de investigação científica"; assim, é pouco provável que duas seqüências de medições da mesma característica, realizadas no mesmo indivíduo, produzam exatamente os mesmos resultados.

$\mathrm{Na}$ área médica ou de saúde, não é raro serem obtidas informações clínicas e laboratoriais sobre indivíduos enfermos ou sobre doenças com resultados dispares. Isto ocorre devido tanto a variações biológicas, como ao processo de mensuração, ou, ainda, a ambos. 
As fontes de variação biológica podem ser explicadas, basicamente, por dois motivos: pessoas diferentes possuem características intrínsecas diferentes e uma mesma pessoa pode reagir diferentemente, em ocasiões distintas. As variações devidas ao processo de mensuração são comuns e podem ser causadas por falha mecânica, pela falta de padronização de equipamentos ou de examinadores ou, ainda, devido ao acaso, que desempenha, também, um papel importante como fonte de variação entre medidas. Um exemplo é a situação onde em um exame radiológico do tórax, uma lesão pode estar escondida por uma sombra de uma costela e, portanto, não ser detectada. Num segundo exame, uma mudança mínima na posição do paciente pode revelar a lesão.

\section{Erros de medida}

A descrição de erros de medida envolve a utilização de modelos matemáticos. Assim, para variáveis contínuas, pode-se supor uma amostra de $n$ indivíduos representados por $\boldsymbol{u}=1,2, \ldots, n$. Supondo-se que $x_{u}$ representa o valor observado de uma variável, para um indivíduo $u$ e $T_{u}$ representa o verdadeiro valor da medida, o modelo clássico que descreve a observação $x_{u}$ é

$$
x_{u}=T_{u}+e_{u}
$$

onde

$e_{u}$ representa o erro aleatório associado à observação $x_{u}$ (Cochran 1968).

Assim, qualquer observação particular $x_{u}$ não será igual a seu verdadeiro valor $T_{u}$ porque existe, associado a ela, um erro aleatório $e_{u}$.

Imaginando-se a situação onde são realizadas observações repetidas (réplicas), em um mesmo individuo, utilizando-se sempre o mesmo instrumento, onde o subscrito $t$ representa a réplica, pode-se escrever

$$
x_{u t}=T_{u}+e_{u t}
$$

Neste caso, para um dado indivíduo $u$, tanto $x_{u t}$ como $e_{u t}$ possuem uma distribuição de probabilidades, sendo que $T_{u}$ é fixo para cada indivíduo. 
Dado que podem ocorrer tanto erros positivos como negativos, com magnitudes semelhantes, os valores observados são distribuidos simetricamente ao redor do verdadeiro valor. Espera-se que, para grandes amostras, a média dos erros seja igual a zero, porque os valores positivos são compensados pelos negativos. Neste modelo mais simples, os erros possuem variância constante. São, ainda, não correlacionados com o verdadeiro valor da medida; para indivíduos diferentes os erros também são não correlacionados, o mesmo ocorrendo com o erro entre diferentes réplicas, num mesmo indivíduo. A definição formal de erro é apresentada no Anexo 1.

São dois os tipos de erros: erros aleatórios e erros sistemáticos (Caulcutt e Boddy 1983, Cochran 1968).

Erros aleatórios são irregulares e imprevisíveis; resultam de várias pequenas causas independentes e estão presentes em todas as medições. Quando observações repetidas são realizadas, os erros aleatórios resultam em variabilidade. Se não existisse o erro aleatório, as medidas repetidas seriam todas iguais

O erro sistemático, se presente, afeta toda a seqüencia de medições. Se o erro sistemático for fixo, as medições serão aumentadas (ou diminuidas) pela mesma magnitude. Se, o erro sistemático for relativo, as medições serão aumentadas (ou diminuídas) por uma percentagem.

No momento da tomada da medida ou do registro do dado, podem ocorrer, ainda, valores errados, cujas magnitudes são muito acima ou muito abaixo das demais observações, não se encaixando em nenhum padrão de erro associado a uma situação particular. Estes valores são referidos na literatura como erros grosseiros ("gross errors") ou valores aberrantes ("outlier values") sendo identificados em programas de análise estatística para microcomputadores, segundo critérios específicos de cada programa 


\section{Vício e precisão}

Vício ou viés refere-se à situação na qual o método estatístico utilizado não estima, como intencionado, a quantidade que tem que ser estimada

Utilizando-se notação algébrica, define-se a estatística $T$ como estimador não viciado do parâmetro $\theta$ se $E(T)=\theta$, onde $E$ representa a esperança matemática. $\mathrm{O}$ anexo 1 apresenta a definição formal de viés

Precisão de um conjunto de dados refere-se ao grau de proximidade dos valores (entre si), sendo uma característica interna de um conjunto de observações. É medida pela variância, definida como $E(T-E(T))^{2}$.

Acurácia refere-se ao grau de proximidade destes valores em relação ao "verdadeiro" valor da quantidade que está sendo medida. O conceito de acurácia envolve o conceito de viés e está relacionado a um valor externo. Por exemplo, um termômetro, que consistentemente mede uma determinada temperatura como sendo cinco graus acima do verdadeiro valor, pode ser considerado um instrumento preciso, porque a variabilidade é zero (todos os valores lidos são iguais). Neste caso o instrumento é preciso mas não acurado (Fisher DL, Van Belle G 1993, Zar JH 1996)

Para efeitos de exemplificação considere-se a situação onde quatro técnicos realizam seis determinações de concentração de amônia contida em uma solução. Os resultados obtidos, bem como a média aritmética e o desvio padrão das observações de cada técnico, são apresentados na tabela 1 e figura 1 (Caulcutt e Boddy 1983).

Tabela 1 - Concentraçōes (\%) de amònia em experimento realizado por quatro técnicos. com seis determinações por técnico.

\begin{tabular}{ccccccccc}
\hline Técnico & \multicolumn{3}{c}{ determinaçóes de concentração de amônia (\%) } & \multicolumn{2}{c}{ média (\%) } & desvio padrão (\%) \\
\hline A & 20.2 & 19.9 & 20.1 & 20.4 & 20.2 & 20.4 & 20.20 & 0.190 \\
$B$ & 19.9 & 20.2 & 19.5 & 20.4 & 20.6 & 19.4 & 20.00 & 0.486 \\
C & 20.6 & 20.5 & 20.7 & 20.6 & 20.8 & 21.0 & 20.70 & 0.179 \\
$D$ & 20.1 & 19.9 & 20.2 & 19.9 & 21.1 & 20.0 & 20.20 & 0.456 \\
\hline
\end{tabular}

Fonte : Caulcutt e Boddy 1983

\footnotetext{
1 "Verdadeiro" valor é altendido. aqui. como um valor hipotáico. que seria obtido taso o instrumonto de medida losse perterto.
} 
A comparação das médias dos técnicos permite explorar a existência de viés e a comparação dos desvios padrão fornece, por sua vez, uma idéia da precisão das observações.

As médias dos técnicos $A, B$ e $D$ são parecidas, o que não ocorre com a média do técnico $C$. Conclui-se que, possivelmente, cada uma das seis determinações do técnico $C$ possui um erro sistemático. Pode-se dizer que $C$ exibe um vício fixo dado que suas concentrações possuem um erro sistemático fixo.

Os desvios padrão de $B$ e $D$ são maiores do que os de $\boldsymbol{A}$ e $C$; então, $\boldsymbol{A}$ e $\boldsymbol{C}$ são mais precisos. Se por um lado os valores de $B$ estão dispersos igualmente, por outro, $D$ produz um valor aberrante revelando um possível erro grosseiro (figura 1). $C$ tem a melhor precisão, o mesmo ocorreria com $D$, caso o valor aberrante não fosse considerado. Dos quatro técnicos, $\boldsymbol{A}$ parece ser o mais bem treinado porque apresenta boa precisão, sem vício. $D$ também o seria, caso não fosse considerado o valor aberrante entre sua medições. Apesar da precisão de $C$ ser menor, ele apresenta um vício maior do que o de $\boldsymbol{A}$.

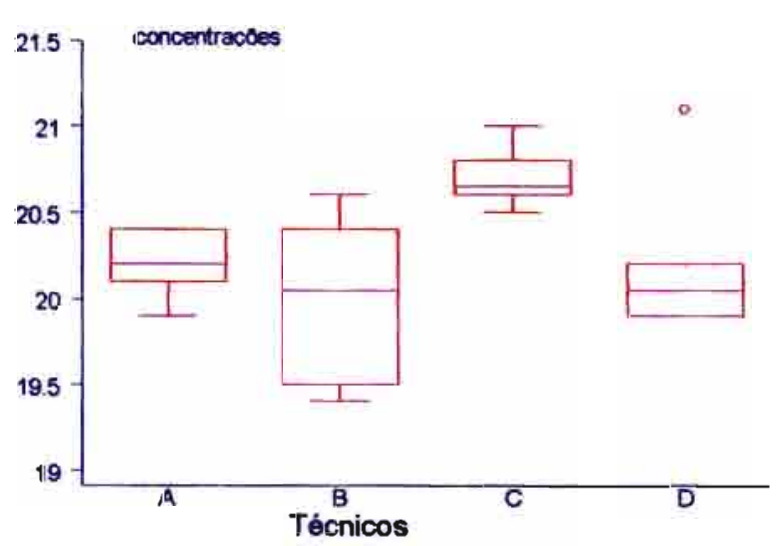

Figura 1 - Concentraçð̃es (\%) de amônia em experimento realizado por quatro técnicos, com seis determinaçđes por técnico. 


\section{Validade e confiabilidade}

Nos campos da pesquisa experimental e empírica, surgem duas questões relacionadas à qualidade dos dados: como pode-se estar seguro de que se está medindo de fato o fenômeno de interesse? E, ainda, qual a possibilidade de se repetir os resultados, caso o experimento seja realizado novamente?

Relacionado à primeira questão, tem-se o conceito de validade ("validity") e à segunda, o de confiabilidade ("reliability"). Na literatura médica, estes conceitos são utilizados como sinônimos de acurácia e precisão, respectivamente (Douglass CW 1993).

Validade e viés estão relacionados a quanto um teste mede o que ele tem que medir e refletem quanto o teste está correto. Confiabilidade e precisão estão relacionados à possibilidade de repetição de medições por um mesmo observador ou por observadores diferentes.

Tem-se uma observação válida quando esta corresponde ao estado verdadeiro do fenômeno que está sendo medido (Fletcher HR et al. 1991).

Este conceito refere-se tanto aos indivíduos que estão sendo estudados (validade interna), como à possibilidade de generalização dos resultados do estudo (validade externa).

A quantificação da validade é feita através da comparação entre os resultados obtidos e um padrão, utilizando-se medidas ou indices especificos tais como os índices de especificidade e sensibilidade, definidos no Anexo 2.

Com respeito à confiabilidade, diz-se que dados são confiáveis quando é possível obter-se os mesmos resultados de um experimento, caso este seja repetido, sob condições experimentais semelhantes (Burt C 1955). Confiabilidade está, assim, relacionada ao grau de concordância entre observações repetidas, realizadas para um mesmo indivíduo. 


\section{Repetibilidade e reprodutibilidade}

Se os resultados obtidos apresentarem o mesmo valor, pode-se dizer que os dados são repetíveis ou reprodutiveis.

Julgou-se importante apresentar aqui os conceitos de repetibilidade e reprodutibilidade, muitas vezes utilizados indistintamente, sendo, de fato, semelhantes, porém com aplicações distintas (Caulcutt e Boddy 1983).

Repetibilidade ("repeatability") é utilizada em situações homogêneas, e está relacionada ao grau de concordância entre resultados sucessivos, obtidos mediante o uso de um mesmo método, em material de teste idêntico, sob as mesmas condições experimentais.

O conceito de reprodutibilidade ("reproducibility") é aplicado em situações heterogêneas que envolvem medições realizadas em laboratórios diferentes, ou com operadores que usam equipamentos, ou até mesmo métodos, diferentes.

O quadro 1 contém um esquema resumo das relações entre os conceitos apresentados.

Quadro 1 - Resumo dos conceitos relacionados à variabilidade de dados e relação entre eles

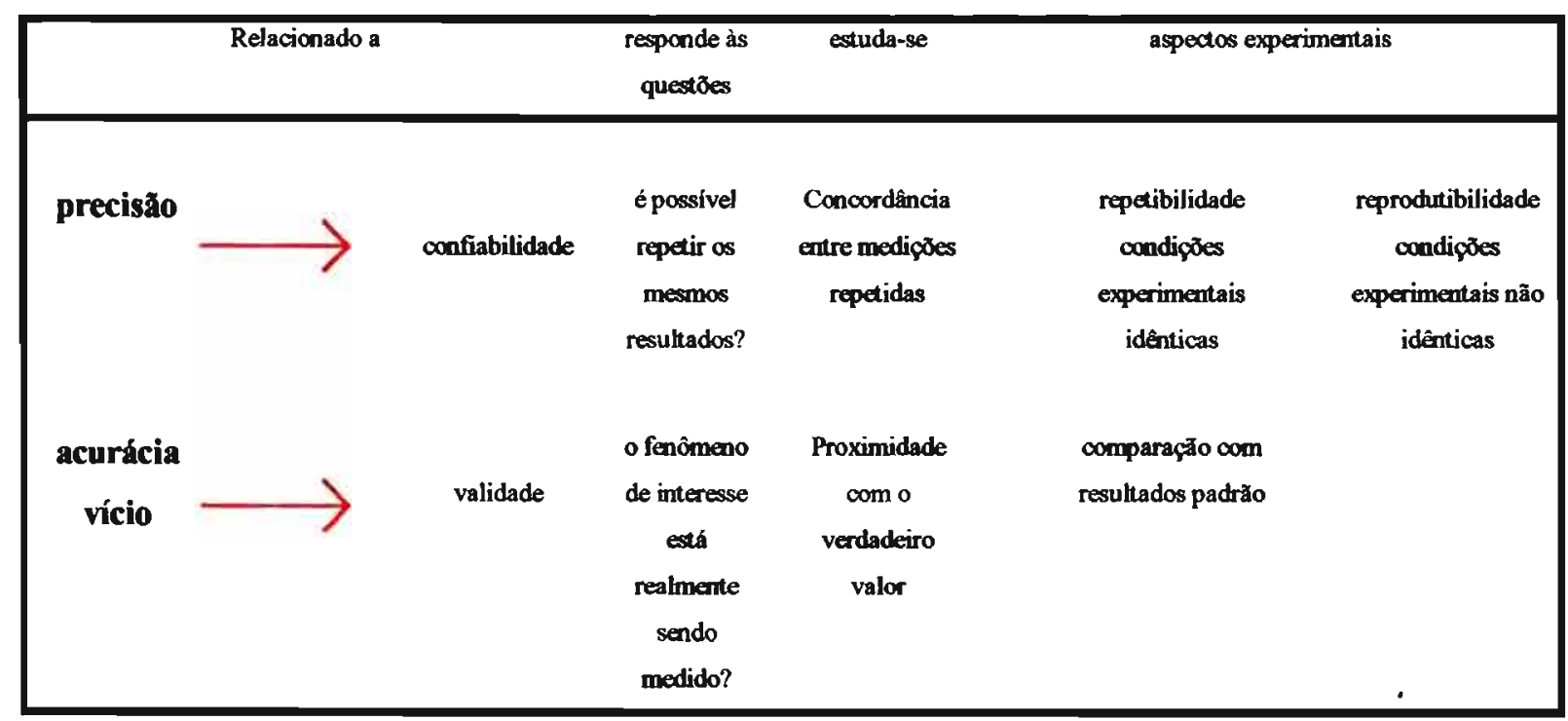


Dados confiáveis não são necessariamente válidos, ou seja, um equipamento pode produzir resultados semelhantes sempre que for utilizado com um mesmo indivíduo - dizse que o equipamento é preciso (confiável); entretanto, se, em média, os resultados estão afastados do verdadeiro valor, diz-se que o equipamento produz dados viciados ou viesados (Fletcher et al. 1991).

A avaliação da confiabilidade de dados é feita, normalmente, mediante a utilização de medidas de dispersão ou funções matemáticas destas. A formulação matemática destas medidas dependerá de aspectos tais como a natureza das variáveis de interesse e o plano experimental adotado que revela as fontes de variação existentes.

Considerando-se a existência de medidas estatísticas que permitem a avaliação da confiabilidade de dados e o beneficio em termos de ganho na qualidade, a avaliação da confiabilidade é fortemente recomendada. Isto pode ser feito durante o estudo piloto de uma pesquisa, utilizando-se um pequeno número de unidades amostrais (Fleiss JL 1986, Gimeno SGA, Souza PJM 1997).

Deve-se salientar, ainda, que a utilização de dados não confiáveis pode interferir em resultados de estimativas de medidas e em resultados de testes de hipótese, podendo induzir o pesquisador a conclusões erradas (Fleiss JL 1986, Peres CA, Ching TH 1994 , Ching TH 1995).

\section{2- Avaliação da Confiabilidade}

Como apresentado anteriormente, a confiabilidade de um teste está relacionada à quantidade de variação existente nos resultados, quando o teste é repetido sob condições experimentais semelhantes. Confiabilidade está, então, relacionada à questão: se um teste é repetido, até que ponto os resultados são concordantes?

Deve-se a Gauss, no início do século XIX, a idéia de se estimar a precisão de uma quantidade, com base em uma série de medidas repetidas. Wissler, em 1901, sugeriu que a precisão de um teste podia ser estimada por meio de ensaios correlacionados, originando outro coeficiente de confiabilidade (Burt C 1955). 
O outro coeficiente de confiabilidade (Burt C 1955) é proposto em termos da concordância entre observações repetidas, computando-se a correlação entre as duas séries de medições obtidas de forma idêntica, para um instrumento específico, utilizado sob condições experimentais idênticas (Anexo 4).

\section{3 - Medidas de confiabilidade}

São várias as medidas utilizadas na avaliação de confiabilidade (Dunn G 1992).

Nesta sessão será apresentada a utilização da correlação intraclasse como medida de confiabilidade calculada com base em $r_{l}$ e $i c c$, a título ilustrativo.

A definição dos parâmetros e respectivos estimadores são apresentados no capitulo referente à metodologia.

\subsection{1 - Correlação intraclasse (momento-produto) de Pearson, para pares repetidos}

O coeficiente de correlação intraclasse foi utilizado por Fisher, em 1925, como uma medida estatística aplicada em genética quantitativa e, mais especificamente, no estudo de semelhanças entre membros de uma mesma família.

Fisher (1925) distingue a correlação interclasse da correlação intraclasse, com base em uma situação onde é de interesse avaliar a correlação entre n' pares de irmãos, propondo duas abordagens para o problema.

A primeira consiste em dividir os irmãos em duas classes de idade (mais velhos e mais jovens) e calcular a média e o desvio padrão de cada classe, obtendo-se a correlação (momento-produto) de Pearson entre as classes, denominada, para efeitos de distinção, correlação interclasse (simbolizada por $\rho$, quando populacional e $r$, amostral). Se $X$ e $Y$ são as variáveis aleatórias de interesse, por exemplo, altura para os irmãos mais velhos e mais novos, respectivamente, então a correlação (momento-produto) de Pearson é dada por 


$$
\rho=\frac{\operatorname{cov}(X, Y)}{\sigma_{X} \sigma_{Y}}
$$

A segunda alternativa é aplicada quando a distinção entre os irmãos é irrelevante para os objetivos do estudo. Neste caso, ter-se-ia uma única classe, podendo-se calcular a média e o desvio padrão comuns a todas as observações. A composição dos pares de valores, para o cálculo da correlação, é neste caso, diferente.

Sendo $X$ a variável primeiro membro do par e $Y$ a variável segundo membro do par, não existiria motivo para se considerar um determinado membro da família como sendo $X$ ou $Y$. Exemplificando, se em uma familia ocorre o par $\{1,60 ; 1,45\}$ para o irmão mais velho e o mais novo, respectivamente, com a falta de relevância da divisão em classe segundo idade, o par $\{1,45 ; 1,60\}$ se torna, também, um par possível.

Assim, nesta abordagem, cada membro da família é considerado em primeiro lugar no par, resultando que, para $n$ indivíduos numa família $i$, para $i=1, \ldots, k$, cada membro é considerado ( $n-1)$ vezes, em primeiro lugar no par, o que resulta em um total, por família, de $N=n(n-1)$ pares de valores. Sendo o número total de pares de observações, para todas as familias, dado por $k \times N$.

Para $n=2$, dois indivíduos por familia, cada irmão aparecerá em primeiro lugar no par 1 vez, o número de pares possíveis por família é $2(2-1)=2$ e o número total de pares, para $k=12$ é $k \times N=12 \times 2=24$.

Considerar cada um dos irmãos em primeiro lugar, em associação com outro irmão tomado em segundo lugar, é equivalente a utilizar-se, para cada família, os pares de valores originais $\{X, Y\}$ e seus respectivos pares em ordem inversa $\{Y, X\}$, obtendo-se um novo conjunto de dados formado por $2 k$ pares de valores. É sobre este novo conjunto de dados que a correlação momento produto de Pearson $(\rho)$ é calculada. Quando isto é feito, $\rho$ é denominado uma correlação intraclasse, com notação $\rho_{I}$, para valores populacionais e $r_{I}$, para valores amostrais, dado que todos os irmãos foram tratados como se pertencessem à mesma classe, possuindo a mesma média e o mesmo desvio padrão. Esta é a abordagem adequada para o estudo de confiabilidade 
Para efeitos de exemplo, considere-se os dados de Newman, Freeman, e Holzinger, citados em Snedecor e Cochran (1967), referentes à comparação entre 12 pares de irmãs gêmeas idênticas, para as quais observou-se o número de dobras cutâneas dos dedos de ambas as mãos. Os dados são apresentados na tabela 2.

Tabela 2: Número de dobras cutâneas de impressões digitais de todos os dedos, de ambas as mãos, de 12 pares de gêmeas idênticas

\begin{tabular}{|c|c|c|c|c|c|c|c|c|}
\hline par & \multicolumn{2}{|c|}{$\begin{array}{c}\text { dobras cutineas } \\
\text { por pesson }\end{array}$} & par & \multicolumn{2}{|c|}{$\begin{array}{l}\text { dobras cutiness } \\
\text { por pesson }\end{array}$} & par & \multicolumn{2}{|c|}{$\begin{array}{l}\text { dobras cutiness } \\
\text { por pesson }\end{array}$} \\
\hline 1 & 71 & 71 & 5 & 76 & 70 & 9 & 114 & 113 \\
\hline 3 & 105 & 99 & 7 & 114 & 113 & 11 & 75 & 83 \\
\hline 4 & 115 & 114 & 8 & 57 & 44 & 12 & 76 & 72 \\
\hline
\end{tabular}

Fonte: Snedecor e Cochran 1967

O exemplo é utilizado, originalmente, no estudo de semelhança entre irmãs, onde a solução é dada pela segunda abordagem proposta por Fisher (1925). Entretanto, para efeitos comparativos, serão apresentadas ambas as soluções. Nesta aplicação será seguida a nomenclatura adotada por Fisher (1925), onde o número de pares é representado por $n^{\prime}$.

\section{Correlação interclasse}

Supondo-se que os $n^{\prime}=12$ pares de valores são compostos por duas classes de idade, $X$ sendo irmãs mais jovens e $Y$, irmãs mais velhas, a correlação interclasse é dada por $r=0,97$. O cálculo é feito para $n^{\prime}=12$ pares de valores, aplicando-se a fórmula (2).

As figuras 2A e 2B apresentam a dispersão dos pares $\{X, Y\}$.

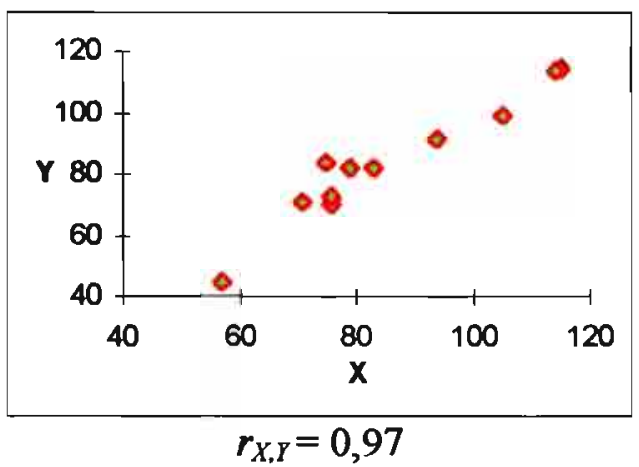

Figura 2A- Dispersão dos pontos $\{X, Y\}$ 


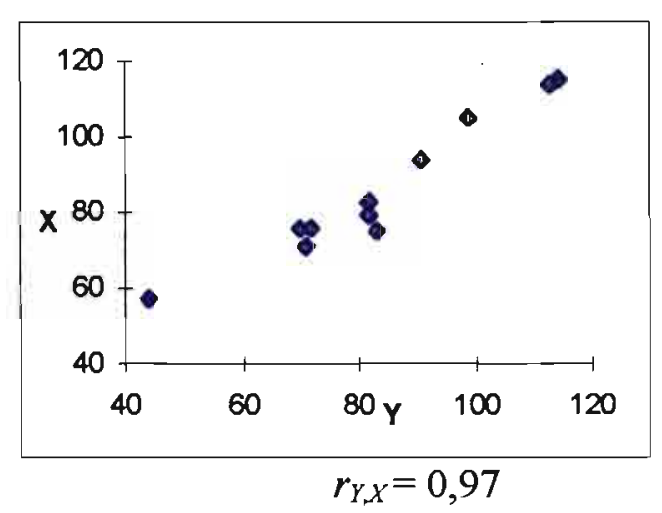

Figura 2B- Dispersão dos pontos $\{Y, X\}$

Correlação intraclasse (momento produto) de Pearson, para pares repetidos

Nesta situação, não é necessário dividir as irmãs em classes de idade, dado que o interesse do investigador reside na busca de semelhanças entre os membros dos pares, com respeito ao número de dobras cutâneas, independente da ordem de nascimento.

Para tanto, constroem-se os pares repetidos $\{X, Y\}$ e $\{Y, X\}$, obtendo-se o novo conjunto de dados, formado, agora, por $2 n^{\prime}=24$ pares $\left\{X, X^{\prime}\right\}$, apresentados na tabela 3 .

Tabela 3 - pares originais e pares repetidos em ordem inversa

\begin{tabular}{crrrrr}
\hline par & $\mathbf{X}$ & $\mathbf{X}^{\prime}$ & par & $\mathbf{X}$ & $\mathbf{X}^{\prime}$ \\
\hline $\mathbf{1}$ & $\mathbf{7 1}$ & 71 & $\mathbf{7}$ & 114 & 113 \\
$\mathbf{1}$ & 71 & 71 & 7 & 113 & 114 \\
$\mathbf{2}$ & $\mathbf{7 9}$ & 82 & $\mathbf{8}$ & 57 & 44 \\
$\mathbf{2}$ & 82 & 79 & $\mathbf{8}$ & 44 & 57 \\
$\mathbf{3}$ & 105 & 99 & $\mathbf{9}$ & 114 & 113 \\
$\mathbf{3}$ & 99 & 105 & $\mathbf{9}$ & 113 & 114 \\
$\mathbf{4}$ & 115 & 114 & $\mathbf{1 0}$ & 94 & 91 \\
$\mathbf{4}$ & 114 & 115 & $\mathbf{1 0}$ & 91 & 94 \\
$\mathbf{5}$ & 76 & 70 & $\mathbf{1 1}$ & 75 & 83 \\
$\mathbf{5}$ & 70 & 76 & $\mathbf{1 1}$ & 83 & 75 \\
$\mathbf{6}$ & 83 & 82 & $\mathbf{1 2}$ & 76 & 72 \\
$\mathbf{6}$ & 82 & 83 & $\mathbf{1 2}$ & 72 & 76 \\
\hline
\end{tabular}

Calculando-se a correlação (momento-produto) de Pearson, para o novo conjunto de 24 pares de observações, obtém-se a correlação intraclasse $r_{I}=0,96$. A figura 3 apresenta a dispersão do novo conjunto de dados. 


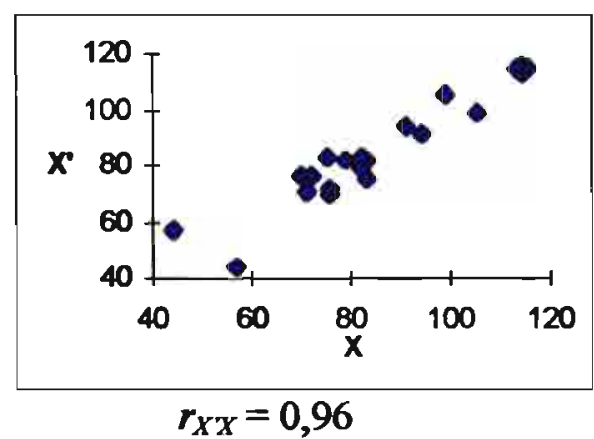

Figura 3- Dispersão dos pontos $\left\{X, X^{\prime}\right\}$

\subsection{2 - Correlação intraclasse como função de componentes de variância}

Fisher (1925) definiu, também, a correlação intraclasse como uma função de variâncias. A idéia básica é quantificar a importância relativa dos fatores que causam variação nos valores observados. Com este objetivo, o coeficiente de correlação intraclasse foi definido da seguinte forma ${ }^{2}$ :

"tomemos uma quantidade composta de duas partes independentes $e$ normalmente distribuidas; que $A$ seja a variância da primeira parte, e $B$ a da segunda parte; então é fácil ver que a variância da quantidade total é $A+B$. Considere uma amostra de n' valores da primeira parte, e a cada um destes, acrescente uma amostra de $k$ valores da segunda parte, tomando uma nova amostra de $\boldsymbol{k}$ em cada caso. Então temos $\boldsymbol{n}$ ' famílias com $\boldsymbol{k}$ valores em cada familia. Na população infinita da qual estes são retirados, a correlação entre pares de membros da mesma familia será

$$
\rho=\frac{A}{A+B}
$$

De tal conjunto de $n$ 'k valores nós podemos produzir estimadores dos valores de $A$ e $B$, ou, em outras palavras, nós podemos decompor a variância nas partes

\footnotetext{
2 tradução do original
} 
derivadas das duas causas; a correlação intraclasse será meramente a fração da variância total devida à causa comım a todos na mesma familia. $O$ valor de $B$ pode ser estimado diretamente, dado que a variação dentro de cada família se deve unicamente a esta causa."

Vale ressaltar que $\rho$, definido em (2), está sendo representado no presente trabalho por $\rho_{I}$

Comentando-se a definição apresentada por Fisher e tomando-se como base o exemplo citado anteriormente, tem-se um conjunto de $n^{\prime}=12$ pares de valores provenientes de famílias que possuem irmãs gêmeas, pode-se explicar a variabilidade dos dados segundo duas fontes de variação: devida a diferenças entre pares (de família para família) e devida à cada irmã dentro de cada par (dentro de família). Se $A$ constitui a variância devida ao par (causa comum a todos na mesma família), e $B$ a variância devida ao individuo (réplica, dentro de uma mesma família), então a variância total dos dados é fornecida por $A+B$

Para a amostra de $n^{\prime}$ familias $\left(n^{\prime}=12\right)$, sorteia-se uma amostra de $k$ indivíduos $(k=2)$ para cada família. Como o objetivo do estudo é investigar a semelhança entre as irmãs, comparando-se o número de dobras cutâneas, calcula-se a correlação intraclasse, segundo a equação (2), que representa a porção da variância total devida à diferença entre famílias.

Se a variação entre famílias é pequena, então a variância total será em grande parte devida à variação dentro de familias. Neste caso a correlação intraclasse será pequena, próxima de zero. Entretanto, se a variação dentro de famílias é pequena, a variação total será devida em sua maior parte à variação entre famílias, fazendo com que a correlação se aproxime do valor um. Esta segunda situação indica que as observações dentro de cada par são semelhantes.

Este mesmo raciocínio é aplicado no estudo de confiabilidade, sendo que a semelhança entre os valores dentro de um par indicam que os dados são confiáveis, porque são passiveis de serem repetidos. 
Uma forma possível de se estimar a correlação intraclasse definida em (2) é mediante a associação da medida a um modelo matemático, mediante a aplicação da técnica de Análise de Variância (ANOVA), que será vista com detalhe no capítulo referente a metodologia. No exemplo acima, o valor da estimativa da correlação intraclasse (icc), mediante a técnica da ANOVA, é $i c c=0,97$.

Vê-se que $r_{I}$ e icc são praticamente iguais, diferindo na segunda casa decimal. A semelhança de resultados destes estimadores já havia sido verificada na prática, com outros conjuntos de dados, fazendo com que surgisse a questão sobre sua igualdade, do ponto de vista teórico e empírico. Esta questão constitui a motivação principal para o desenvolvimento deste trabalho. 


\section{2 - OBJetivos}

\section{1 - Objetivo geral}

O objetivo geral deste trabalho é comparar, mediante abordagens teórica e empírica, dois estimadores do coeficiente de correlação intraclasse $\left(\rho_{l}\right)$, definido como a correlação momento-produto de Pearson para pares repetidos.

\section{2 - Objetivos especificos}

- apresentar a técnica de análise de variância $(A N O V A)$ com um fator aleatório;

- apresentar duas definições da correlação intraclasse: segundo a correlação de Pearson para pares repetidos $\left(\rho_{I}=\frac{\operatorname{Cov}(X, Y)}{\sigma_{X} \sigma_{Y}}\right)$ e como função de componentes de variância $\left(\rho_{l}=\frac{\sigma_{a}^{2}}{\sigma_{a}^{2}+\sigma_{e}^{2}}\right)$;

- apresentar o estimador "natural" de $\rho_{l}$, correlação intraclasse de Pearson para pares repetidos $\left(r_{l}\right)$ e o estimador da correlação como função de componentes de variância, coeficiente de correlação intraclasse (icc), estimado pela $A N O V A$;

- comparar o vício e erro quadrático médio dos estimadores mediante um estudo Monte Carlo. 


\section{3 - Metodologia}

\section{1 - Análise de Variância, com um fator aleatório}

A técnica da Análise de Variância (ANOVA), proposta por Fisher (1925), permite decompor a variabilidade total existente em determinado conjunto de dados, nas fontes de variação e, sob certas condiçôes, testar a significância estatística da diferença entre médias

A técnica foi inicialmente proposta para a comparação de médias e adaptada, posteriormente, para estimar os componentes de variância. Fisher (1925) apresentou a técnica em termos de somas de quadrados de diferenças entre médias observadas, sendo que, nas décadas mais recentes, as idéias subjacentes à análise de variância têm sido apresentadas em termos de modelos lineares. Uma classe destes modelos é a família de modelos de efeitos aleatórios, que será utilizada para estimação da correlação intraclasse como função de componentes de variância.

Para facilitar o entendimento da terminologia a ser adotada e a apresentação do modelo, apresenta-se um exemplo retirado de Searle et al. (1992).

Supõe-se que uma nova forma de insulina injetável está sendo testada em 15 clínicas, escolhidas aleatoriamente, no Estado de Nova York. Se a clínica $i$ tem $\boldsymbol{n}_{i}$ pacientes participando do ensaio, $y_{1}$ representa a resposta do paciente $j$, na clínica $i$, para $j=1, \ldots, n$. O nível de açúcar no sangue dos pacientes constitui a variável resposta, $Y$, quantitativa contínua

$\mathrm{Na}$ análise de variância, os dados são classificados em termos de fatores e cada categoria individual de classificação constitui o nivel do fator, também denominado classe do fator. $O$ interesse principal está concentrado em quanto os diferentes niveis de um fator afetam a variável resposta. 
No exemplo, a variável clínica constitui o fator. Cada clínica constitui um nível do fator. Neste caso, o fator é aleatório, dado que a amostra de clínicas observadas provem de uma população de clínicas. Assim, as conclusões obtidas com base na amostra poderão ser inferidas para a população. Somente faria sentido comparar-se as 15 clínicas entre si se o fator fosse fixo e, neste caso, os resultados seriam relativos somente às clínicas estudadas. No exemplo, o fator clínica possui quinze níveis.

\section{Modelo}

Para a situação descrita acima, um modelo possível é

$$
E\left(y_{i j}\right)=\mu+\alpha_{i}
$$

onde

$y_{i j}$ representa a observação do paciente $j$ na clínica $i$,

$E$ representa a esperança matemática,

$\mu$ é o nivel médio geral de açúcar no sangue na população de pacientes,

$\alpha$, é o efeito no nível de açúcar no sangue dos pacientes sob tratamento, na clínica $i$.

$\mathrm{O}$ efeito de clínica é uma variável aleatória distribuída de forma independente e idêntica, por clínica, com média zero e mesma variância $\sigma_{a}^{2}$, ou, $\alpha_{i} \sim i . d . d .\left(0, \sigma_{a}^{2}\right) \forall i$.

Estas pressuposições do modelo podem ser escritas como

$$
\begin{aligned}
& E\left(\alpha_{i}\right)=0 \quad \forall \mathrm{i}, \\
& \operatorname{var}\left(\alpha_{i}\right)=E / \alpha_{i}-E(\alpha) I^{2}=E\left(\alpha_{i}^{2}\right)=\sigma_{a}^{2}, \\
& \operatorname{cov}\left(\alpha_{i}, \alpha_{k}\right)=0 \forall \mathrm{i} \neq \mathrm{k}
\end{aligned}
$$

Definindo-se o resíduo (erro aleatório) como

$$
e_{\eta j}=y_{1}-E\left(y_{1 j}\right)=y_{1 !}-\left(\mu+\alpha_{1}\right) \text {, }
$$

obtém-se a equação que descreve o modelo aleatório com um fator:

$$
y_{i j}=\mu+\alpha_{i}+e_{i j},
$$


Neste modelo, os erros se distribuem segundo uma variável aleatória com média zero e variância $\sigma_{e}^{2}$, ou seja, $E\left(e_{i j}\right)=0$ e $\operatorname{var}\left(e_{l l}\right)=E\left(e_{\eta j}^{2}\right)=\sigma_{e}^{2}$.

Os erros são independentes entre si e independentes dos $\alpha_{i}$ e, como conseqüência, tem-se

$$
\begin{aligned}
& \operatorname{cov}\left(e_{l y}, e^{\prime} y^{\prime}\right)=0 \text { para } \forall \mathrm{i}, \mathrm{i}^{\prime} \mathrm{e} \mathrm{j}, \mathrm{j}^{\prime} \text { exceto para } \mathrm{i}=\mathrm{i}^{\prime} \mathrm{e} \mathrm{j}=\mathrm{j}^{\prime}, \mathrm{e} \\
& \operatorname{cov}\left(e_{y}, \alpha_{k}\right)=0 \text { para } \forall \mathrm{i}, \mathrm{j} \text { e k }
\end{aligned}
$$

Assim, para os mesmos valores de $i, i^{\prime}, j, j^{\prime}$ e $k$

$$
E\left(e_{i y}, \boldsymbol{e}_{i^{\prime} j^{\prime}}\right)=0 \text { e } E\left(e_{l j}, \alpha_{k}\right)=0
$$

Tendo-se, então,

$$
\begin{aligned}
& \operatorname{var}\left(y_{\eta !}\right)=\operatorname{var}\left(\mu+\alpha_{i}+e_{i !}\right), \text { que é igual a } \\
& \operatorname{var}\left(y_{y}\right)=\sigma_{y}^{2}=\sigma_{a}^{2}+\sigma_{e}^{2}
\end{aligned}
$$

Para este modelo, tem-se que as observações dentro de uma mesma clínica (mesma classe) possuem covariância dada por

$$
\begin{aligned}
& \operatorname{cov}\left(y_{l y}, y_{i h}\right)=E\left\{\left(y_{i j}-\mu\right)\left(y_{i h}-\mu\right)\right\}=E\left\{\left(\alpha_{i}+\varepsilon_{l y}\right)\left(\alpha_{i}+\varepsilon_{i h}\right)\right\}, \text { para } \mathrm{j} \neq \mathrm{h} \\
& \operatorname{cov}\left(y_{i !}, y_{i h}\right)=E\left(\alpha_{i}^{2}\right)=\sigma_{a}^{2}
\end{aligned}
$$

Assim, $\sigma_{a}^{2}$ é a covariância entre todos os possiveis pares de valores em uma mesma clínica, ou seja, é a covariância intraclasse.

Dado que as clínicas são independentes, a covariância entre observações de classes (clinicas) diferentes é igual a zero, ou seja

$$
\operatorname{cov}\left(y_{\eta}, y_{h j}\right)=0 \text { para } \mathrm{i} \neq \mathrm{h}
$$

De (3), tem-se a variação total decomposta em dois componentes: variação entre clínicas (devida a diferenças entre classes) e variação dentro de clínicas (devida a diferenças entre as observações repetidas dentro do fator, também chamada erro 
experimental), respectivamente representados por $\sigma_{a}^{2}$ - variação entre, e $\sigma_{e}^{2}$ - variação do erro ou resíduo

O Anexo 3 apresenta um resumo das características do modelo de efeitos aleatórios, para um fator.

\subsection{1 - Partição da Soma de Quadrados}

Para efeitos de ilustração, supõe-se uma situação geral que segue um modelo de efeitos aleatórios com um fator. $\mathrm{O}$ fator possui $k$ classes e são realizadas $n$ observações repetidas, por classe, totalizando $N-n k$ observações. A tabela 4 apresenta esta situação geral.

Tabela 4 - Estrutura geral de observações repetidas

\begin{tabular}{ccccccc}
\hline classes & \multicolumn{7}{c}{ réplicas } \\
\cline { 2 - 7 } & $\mathbf{1}$ & $\mathbf{2}$ & $\ldots$ & $\mathrm{j}$ & $\ldots$ & $\mathbf{n}$ \\
\hline $\mathbf{1}$ & $\mathrm{y}_{11}$ & $\mathrm{y}_{12}$ & $\ldots$ & $\mathrm{y}_{1 \mathrm{i}}$ & $\ldots$ & $\mathrm{y}_{1 \mathbf{n}}$ \\
$\mathbf{2}$ & $\mathrm{y}_{21}$ & $\mathrm{y}_{22}$ & $\ldots$ & $\mathrm{y}_{2,}$ & $\ldots$ & $\mathrm{y}_{2 \mathbf{n}}$ \\
$\mathbf{3}$ & $\mathrm{y}_{31}$ & $\mathrm{y}_{32}$ & $\ldots$ & $\mathrm{y}_{3 \mathrm{i}}$ & $\ldots$ & $\mathrm{y}_{3 \mathbf{n}}$ \\
$\cdot$ & $\ldots$ & & & & & \\
$\dot{\mathbf{i}}$ & $\ldots$ & & & & & \\
$\cdot$ & $\mathrm{y}_{\mathrm{i} 1}$ & $\mathrm{y}_{\mathrm{i} 2}$ & $\ldots$ & $\mathrm{y}_{\mathrm{ij}}$ & $\ldots$ & $\mathrm{y}_{\mathrm{in}}$ \\
$\dot{\mathbf{k}}$ & $\ldots$ & & & & & \\
\hline
\end{tabular}

As estimativas das médias para a classe $i\left(\bar{y}_{i}\right)$ e da média geral $\left(\bar{y}_{. .}\right)$são dadas por $\bar{y}_{i .}=\frac{\sum_{j=1}^{n} y_{i j}}{n}$ e $\bar{y}_{. .}=\frac{\sum_{i=1}^{k} \sum_{j=1}^{n} y_{i j}}{k n}=\frac{\sum_{i=1}^{n} \bar{y}_{i .}}{k}$ para $i=1,2, \ldots, k ; j=1,2, \ldots, n$

Iniciando-se com a identidade $\left(\mathrm{y}_{\mathrm{ij}}-\bar{y}_{. .}\right)=\left(\mathrm{y}_{\mathrm{ij}}-\bar{y}_{\mathrm{i} .}\right)+\left(\overline{\mathrm{y}}_{\mathrm{i}}-\overline{\mathrm{y}}_{. .}\right)$, elevando-se ao quadrado ambos os lados e somando-se para todo $i$ e $j$, obtém-se a forma quadrática onde a soma de quadrados total (SQT) pode ser decomposta em duas parcelas correspondentes às fontes de variação do modelo: a soma de quadrados devida ao fator (SQA) e a soma de quadrados devida ao erro experimental (SQR). Assim, $S Q T=S Q Q A+S Q R$. 
Algebricamente, tem-se

$$
\underbrace{\sum_{i=1}^{k} \sum_{j=1}^{n}\left(y_{l j}-\bar{y}\right)^{2}}_{\text {Soma de Quadrado Total (SQT) }}=\underbrace{\sum_{i=1}^{k} \sum_{j=1}^{n}\left(\bar{y}_{i}-\bar{y}_{.}\right)^{2}}_{\text {Soma de Quadrado Entre (SQA) }}+\underbrace{\sum_{i=1}^{k} \sum_{j=1}^{n}\left(y_{i j}-\bar{y}_{t}\right)^{2}}_{\text {Soma de Quadrado Dentro (SOR) }}
$$

O termo da esquerda é a soma de quadrados dos desvios de todas as observações em relação à média geral. A $S Q Q A$, também denominada Soma de Quadrados Entre, é a soma dos quadrados dos desvios das médias das classes em relação à média geral das observações, $\bar{y}$. A $S Q R$, também denominada Soma de Quadrados Dentro, é a soma dos quadrados dos desvios das observações na classe $i$ em relação a $\bar{y}_{i}$.

As Somas de Quadrados são variáveis aleatórias independentes e distribuídas, segundo Fisher (1925), como múltiplos da distribuição $\chi^{2}$, com, respectivamente, $(k-1)$ e $k(n-1)$ graus de liberdade. Assim, tem-se

$$
\begin{aligned}
& S Q A-\left(n \sigma^{2}{ }_{a}+\sigma^{2}{ }_{e}\right) \chi_{k}^{2} 1 \\
& S() R-\sigma_{e}^{2} \chi_{i k}^{2}
\end{aligned}
$$

Define-se o Quadrado Médio como a razão entre as Somas de Quadrados e os respectivos graus de liberdade. Assim, o Quadrado Médio de $A(Q M A)$ e o Quadrado Médio de $R(Q M R)$ são dados por $Q M A=\frac{S Q A}{(k-1)}$ e $Q M R=\frac{S Q R}{k(n-1)}$

A razão entre $Q M A$ e $Q M R$, produz a estatística $F=\frac{Q M A}{Q M R}$, que segue, sob $H_{b}: \sigma_{a}^{2}=0$, uma distribuição $F_{\text {central, }}$ com $(k-l)$ e $k(n-l)$ graus de liberdade e sob a hipótese alternativa, $H_{a}: \sigma_{a}^{2} \neq 0$, segue uma distribuição proporcional à $F_{\text {Central }}$.

\subsection{2 - Estimação pontual dos componentes da variância}

A técnica da análise de variância (ANOVA) permite estimar os componentes de variância $\sigma_{a}^{2}$ e $\sigma_{c}^{2}$, com base na hipótese de normalidade, obtendo-se estimadores não 
viesados e de variância uniformemente mínima destes componentes. Estes estimadores são dados pela esperança matemática dos quadrados médios.

Teorema 1 (Searle 1971) Seja $\chi_{\mathrm{r}}^{2}$ uma variável com distribuição $\chi^{2}$ central, com $r$ graus de liberdade; então $\mathrm{E}\left(\chi_{\mathrm{r}}^{2}\right)=\mathrm{r}, \operatorname{Var}\left(\chi_{\mathrm{r}}^{2}\right)=2 \mathrm{r}$

Portanto,

$$
\begin{aligned}
& E(Q M A)=E\left(\frac{S Q A}{k-1}\right)=E\left(\frac{n \sigma_{a}^{2}+\sigma_{e}^{2}}{k-1} \chi_{k-1}^{2}\right)=n \sigma_{a}^{2}+\sigma_{e}^{2} \\
& \mathrm{E}(\mathrm{QMR})=\mathrm{E}\left(\frac{\mathrm{SQR}}{\mathrm{N}-\mathrm{k}}\right)=\mathrm{E}\left(\frac{\sigma_{\mathrm{e}}^{2}}{\mathrm{~N}-\mathrm{k}} \chi_{\mathrm{N}-\mathrm{k}}^{2}\right)=\sigma_{\mathrm{e}}^{2}
\end{aligned}
$$

Os estimadores de $\sigma_{\mathrm{e}}^{2}$ e $\sigma_{a}^{2}$, obtidos pela ANOVA são, portanto:

$$
\begin{aligned}
& \hat{\sigma}_{e}^{2}=Q M R \\
& \hat{\sigma}_{a}^{2}=\frac{Q M A-\underline{Q M R}}{n}
\end{aligned}
$$

A tabela 5 resume as expressões algébricas da análise de variância para o modelo de efeitos aleatórios com um fator e mesmo número de observações em cada classe.

Tabela 5 - ANOVA para o modelo de efeitos aleatórios com um fator

\begin{tabular}{ccccc}
\hline $\begin{array}{c}\text { Fonte de } \\
\text { Variação } \\
\text { F.V. }\end{array}$ & $\begin{array}{c}\text { Graus de } \\
\text { Liberdade } \\
\text { G.L. }\end{array}$ & $\begin{array}{c}\text { Soma de } \\
\text { Quadrados } \\
\text { SQ }\end{array}$ & $\begin{array}{c}\text { Quadrado Médio } \\
\text { QM }\end{array}$ & $\begin{array}{c}\text { Esperança do } \\
\text { Quadrado Médio } \\
\text { E(QM) }\end{array}$ \\
\hline $\begin{array}{c}\text { entre classes } \\
\text { (entre clínicas) } \\
\text { (A) }\end{array}$ & $k-1$ & $S Q A$ & $\mathrm{QMA}=\frac{\mathrm{SQA}}{\mathrm{k}-1}$ & $n \sigma_{a}^{2}+\sigma_{e}^{2}$ \\
$\begin{array}{c}\text { dentro de classes } \\
\text { (dentro de clinica) } \\
\text { (resíduo) } \\
(\mathrm{R})\end{array}$ & $N-k$ & $S Q R$ & $\mathrm{QMR}=\frac{\mathrm{SQR}}{\mathrm{N}-\mathrm{k}}$ & $\sigma_{e}^{2}$ \\
\hline
\end{tabular}




\section{2-Correlação intraclasse momento-produto de Pearson para PARES REPETIDOS $\left(\rho_{l}\right)$}

\subsection{1- Definição de $\rho_{I}$}

A correlação intraclasse $\left(\rho_{I}\right)$ tem sido utilizada em várias áreas de investigação: em epidemiologia, como medida do grau de semelhança entre características ambientais, ou relativas à saúde; em genética, no estudo de hereditariedade de populações (plantas ou animais); em psicologia, na teoria de confiabilidade, onde observações obtidas por mais de um avaliador são comparadas; em amostragem, como medida de heterogeneidade entre elementos de um mesmo grupo (Silva NN 1998, Moraes AS e Souza JMP 1998).

O tratamento de dados relativos ao estudo de semelhanças entre irmãos, utilizando pares de observações repetidos, remonta a Galton. Em 1886, com base em 783 irmãos, de 295 famílias, Galton considerou todos os possíveis pares de irmãos, em cada família. A abordagem aparentemente não obteve o resultado esperado porque foram cometidos alguns erros de tabulação, sendo que alguns irmãos foram considerados, na construção dos pares, em número errado de vezes (Stigler SM 1995).

Pearson, em 1896, propôs o coeficiente de correlação intraclasse para pares repetidos, cabendo a Fisher, em 1925, a proposta do coeficiente de correlação intraclasse, como função de componentes de variância, aplicado em genética, no estudo de semelhança entre membros de uma mesma família (Stigler SM 1995, Keen KJ 1996).

Pearson propôs a estimação da correlação entre irmãos utilizando a correlação momento-produto sobre o conjunto de dados contendo todos os possíveis pares de irmãos. Este estimador ficou conhecido como pairwise intraclass correlation coefficient, traduzido neste trabalho como coeficiente de correlação para pares repetidos (Keen KL 1996).

Adotando-se a nomenclatura seguida por Fisher (1925), a definição da correlação intraclasse é feita com base em uma situação onde $n$ ' pares de irmãos são mensurados segundo uma determinada característica. Supondo-se o par $\{X, Y\}$ onde $X$ representa a observação para o primeiro irmão e $Y$ a observação para o segundo irmão, não existe nenhum motivo para que um irmão seja $X$ ou $Y$, fazendo com que cada irmão possa ser 
considerado em primeiro lugar no par, indistintamente. Isto faz com que seja necessário considerar o par $\{X, Y\}$ e o mesmo par em ordem inversa $\{Y, X\}$.

Denominando-se $Y$ a primeira posição no par e $Y$, a segunda, resulta que cada irmão aparece duas vezes, uma como $Y$ e outra como $Y$ ', totalizando $2 n$ ' pares de observações. Pode-se, então, calcular a média e a variância de $Y$ e $Y^{\prime}$, que serão iguais, dado que são relativas a um mesmo conjunto de dados. A correlação intraclasse é obtida mediante o cálculo da correlação (momento produto) de Pearson para o novo conjunto de dados.

A definição da correlação intraclasse para pares repetidos, dada por Fisher (1925) é feita de modo amostral, como segue:

"se $y_{1}, y_{l}^{\prime} ; y_{2}, y_{2}^{\prime} ; \ldots ; y_{n}, y_{n}^{\prime}$ são os $(n=2 n$ ') pares de valores obtidos, calcula-se

$$
\begin{aligned}
& \bar{y}=\frac{1}{2 n^{\prime}} \sum_{i}^{n}\left(y_{i}+y_{i}^{\prime}\right), \\
& s^{2}=\frac{1}{2 n^{\prime}}\left\{\sum_{i=1}^{n}\left(y_{i}-\bar{y}\right)^{2}+\sum_{i=1}^{n}\left(y_{i}^{\prime}-\bar{y}\right)^{2}\right\}, \\
& r=\frac{1}{n^{\prime} s^{2}} \sum_{i=1}^{n}\left\{\left(y_{i}-\bar{y}\right)\left(y_{i}^{\prime}-\bar{y}\right)\right\}
\end{aligned}
$$

Quando isto é feito, (para 2n' pares de observações), $r$ é diferenciado como uma correlação intraclasse, desde que todos os irmãos foram tratados como pertencendo à mesma classe, tendo a mesma média e mesmo desvio padrão".

Substituindo-se (7) em (8) obtém-se a correlação intraclasse amostral para duas observações por família.

$$
r=\frac{2 \sum_{i}^{n}\left\{\left(y_{i}-\bar{y}\right)\left(y_{i}^{\prime}-\bar{y}\right)\right\}}{\sum_{i=1}^{n}\left(y_{i}-\bar{y}\right)^{2}+\sum_{i=1}^{n}\left(y_{i}^{\prime}-\bar{y}\right)^{2}}
$$


Utilizando-se uma abordagem diferente do exposto acima (Kendall e Stuart 1947), supor $k$ familias com 2 elementos por familia. A j-ésima observação do i-ésimo indivíduo é representada por $y_{i j}$.

Obtendo-se, para a família $i(i=1, \ldots, k)$, os pares $\left\{y_{i,}, y_{i h}\right\}$ e, em ordem inversa, o par $\left\{y_{i h}, y_{i j}\right\}$, para $j=1,2$ e $h=1,2$, tem-se que cada individuo aparece $n(n-1)$ vezes no par, e, no total $n \times k$ vezes. Tomando-se a primeira observação do par como variável $X$ e a segunda como variável $Y$, tem-se que a média de $X$ é igual à média de $Y$, o mesmo ocorrendo com as variâncias, ou seja,

$$
\begin{aligned}
& \bar{X}=\bar{Y}=\mu=\frac{1}{n k} \sum_{i=1}^{k}\left\{\left(n_{i}-1\right) \sum_{j=1}^{2} y_{i j}\right\} \\
& \operatorname{Var}(X)=\operatorname{Var}(Y)=\sigma^{2}=\frac{1}{n k} \sum_{i=1}^{k}\left\{\left(n_{i}-I\right) \sum_{j=1}^{2}\left(y_{i j}-\mu\right)^{2}\right\}, \mathrm{e} \\
& \operatorname{Cov}(X, Y)=\frac{1}{n k} \sum_{i=1}^{k} \sum_{\substack{j, h \\
j \neq h}}^{2}\left(y_{i j}-\mu\right)\left(y_{i h}-\mu\right) \\
& =\frac{1}{n k}\left\{\sum_{i=1}^{k} \sum_{j, h=1}^{2}\left(y_{i j}-\mu\right)\left(y_{i h}-\mu\right)-\sum_{i=1}^{k} \sum_{j=1}^{2}\left(y_{i j}-\mu\right)^{2}\right. \\
& \left.=\frac{1}{n k}\left\{\sum_{i=1}^{k} I \sum_{i=1}^{2}\left(y_{i j}-\mu\right)\right]^{2}-\sum_{i=1}^{k} \sum_{j=1}^{2}\left(y_{i j}-\mu\right)^{2}\right\} \\
& =\frac{1}{n k}\left\{\sum_{i=1}^{k} n_{i}^{2}\left(\mu_{i}-\mu\right)^{2}-\sum_{i=1}^{k} \sum_{j=1}^{2}\left(y_{i j}-\mu\right)^{2}\right\}
\end{aligned}
$$

onde $\mu_{i}$ é a média da i-ésima classe.

Aplicando-se (10) e (11) em (1), tem-se

$$
\rho_{1}=\frac{\sum_{i=1}^{k} n_{i}^{2}(\mu-\mu)^{2}-\sum_{i=1}^{k} \sum_{j=1}^{2}\left(y_{i j}-\mu\right)^{2}}{\sum_{i=1}^{k}\left(n_{i}-1\right) \sum_{j=1}^{n}\left(y_{i j}-\mu\right)^{2}}
$$


Considerando que $\frac{l}{k} \sum_{i=1}^{k}\left(\mu_{i}-\mu\right)^{2}=\sigma_{a}^{2}$ é a variância das médias entre as classe e considerando-se $\boldsymbol{n}_{i}=\boldsymbol{n}$ individuos por classe, pode-se escrever a correlação intraclasse como

$$
\rho_{I}=\frac{n^{2} k \sigma_{a}^{2}-n k \sigma^{2}}{(n-1) n k \sigma^{2}}=\frac{1}{(n-1)}\left(\frac{n \sigma_{a}^{2}}{\sigma^{2}}-1\right)
$$

Tem-se a correlação intraclasse amostral, com base na equação (12), calculada para uma amostra

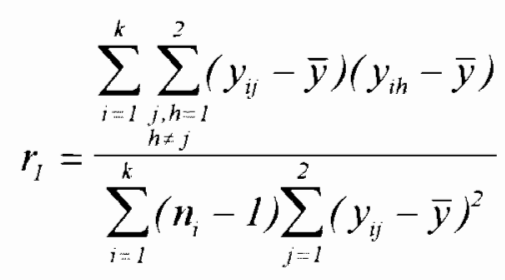

De (12) pode-se pensar em estimar as variâncias pela ANOVA. Quando isto é feito, obtém-se o estimador de $\rho, r_{(A N O V A)}$ cuja fórmula (apresentada no Anexo 5) é coincidente com a do estimador de máxima verossimilhança de $P$ (Dunn G 1992, Donner A 1986).

\subsection{2 - Limites de variação de $\rho_{I}$}

De (13) tem-se que

$\rho_{I}$ é, no máximo, igual a +1 . Isto ocorre quando $\sigma_{a}^{2}=\sigma^{2}$

$\rho_{I}$ é, no mínimo, $\frac{-1}{(n-1)}$, onde $n$ representa o número de indivíduos em uma classe (família). Isto ocorre quando toda variação existente é devida ao erro experimental, fazendo com que $\sigma_{a}^{2}=0$

Para dois individuos por família, o parâmetro, como definido em (13), pode assumir valores negativos, para $n=2$ seria no mínimo igual a -1 .

Fisher (1925) tece comentários sobre a ocorrência de valores negativos lembrando que no estudo de semelhança de individuos dentro de uma mesma família, não se espera 
espera encontrar valores negativos de $\rho_{l}$, embora estes possam ocorrer, por definição da medida. Ainda, segundo Fisher, é possível a ocorrência de valores negativos da correlação intraclasse quando o número de elementos na classe for fixo; por exemplo, em jogos de cartas, onde o número de naipes é limitado a 4 , a correlação entre $o$ número de cartas de naipes diferentes na mesma mão, é no mínimo, $-1 / 3$.

Tem-se entretanto que como $\rho_{l}$ varia entre $\frac{-1}{(n-1)} \mathrm{e}+1$, para $n$ grande, o limite inferior tende a zero, resultando em uma distribuição assimétrica de $\rho_{l}$.

\section{Vício e desvio padrão de $\boldsymbol{r}_{I}$}

O estimador de $\rho_{I}$, como apresentado em (9) ou (14) é viciado (Kendall e Stuart; 1947).

Fisher (1925) apresenta a fórmula do desvio padrão do coeficiente de correlação intraclasse ( $r_{l}$ ) para $n$ (número de pares) suficientemente grande e $k$ individuos em uma classe:

$$
\frac{(1-\rho)\{1+(n-1) \rho\}}{\sqrt{\frac{1}{2} n(n-1) k}}
$$

\subsection{3 - Comparação entre estimadores da correlação interclasse $(r)$ e da correlação intraclasse para pares repetidos $\left(r_{l}\right)$}

No caso de dois instrumentos de medida ou observadores, a correlação intraclasse para pares repetidos pode ser escrita como função da correlação interclasse e das diferenças entre as médias e desvios padrão das duas variáveis (Dunn, G.; 1992).

$$
r_{l}=\frac{\left\{\left(s_{1}^{2}+s_{2}^{2}\right)-\left(s_{1}-s_{2}\right)^{2}\right\} r-\left(\bar{x}_{1}-\bar{x}_{2}\right)^{2} / 2}{\left(s_{1}^{2}+s_{2}^{2}\right)+\left(\bar{x}_{1}-\bar{x}_{2}\right)^{2} / 2}
$$

onde $\overline{\mathrm{x}}_{1}$ e $\overline{\mathrm{x}}_{2}$ são os valores médios para as réplicas 1 e 2 , respectivamente, e $s_{1}$ e $s_{2}$ são os desvios padrão correspondentes. As duas correlações $r_{l}$ e $r$ serão iguais somente se $\bar{x}_{1}=\bar{x}_{2}$ e $s_{1}=s_{2}$; caso contrário $r_{l}<r$. 
Fisher (1925) comenta que, quando a correlação intraclasse é justificada pela ausência de subdivisão das observações em classes, é de se esperar que $r_{l}$ forneça uma estimativa mais acurada do verdadeiro valor do que qualquer outra possível correlação interclasse derivada do mesmo conjunto de dados, dado que a média e variância são calculadas com base em $2 n$ ' observações ao invés de $n$ '.

Segundo Fisher (1925), o contraste mais nítido entre a correlação interclasse e a correlação intraclasse refere-se ao limite de variação das medidas, dada a ocorrência irrestrita de valores negativos de $r(-1<r<+1)$, enquanto que a correlação intraclasse varia entre $\frac{-1}{\mathrm{n}-1}<r_{l}<+1$.

\subsection{4 - Transformação de $r$ em $z$}

Fisher (1925) propôs uma transformação $z$, de $r$, que tende para a normalidade muito mais rápido do que $r$, com variância independente de $\rho$. Esta transformação é como segue,

Para $r=\operatorname{tang} \mathrm{z}, z=\frac{1}{2} \log \frac{1+r}{1-r}, \rho=\operatorname{tang} \xi, \mathrm{e} \xi=\frac{1}{2} \log \frac{1+\rho}{1-\rho}$

Aplicando-se a transformação, tem-se que, se $r=0$, então $z=0$; quando $r=1, z=\infty$; para $r=-1, \mathrm{z}=-\infty$. Para pequenos valores de $r, z$ é quase igual a $r$, se $r$ se aproxima da unidade, $z$ aumenta infinitamente.

Tem-se que $z$ segue uma distribuição aproximadamente Normal, com média zero e variância

$$
\operatorname{var}(z)=\frac{1}{n^{\prime}-3}
$$

As vantagens da transformação de $r$, em $z$ são relativas à distribuição de $r$ e $z$, em amostras aleatórias. Diferentemente do que ocorre com o desvio padrão de $r$, o desvio padrão de $z$ independe do valor da correlação na população da qual a amostra foi retirada (equação 15). 
Em segundo lugar, a distribuição de $r$ não é normal tanto em pequenas como em grandes amostras. A distribuição de $z$ não é estritamente normal, mas tende à normalidade rapidamente com o aumento da amostra, independentemente do valor da correlação.

Finalmente, a distribuição de $r$ muda de forma, com a mudança de $\rho$. Em contrapartida, a distribuição de $z$ é de forma quase constante.

A transformação $z$ é, de forma análoga, aplicada à correlação intraclasse $\left(r_{l}\right)$. Neste caso é denominada $z_{l}$. Tem-se, assim,

$$
z_{I}=\frac{1}{2}\left[\log _{e}\left(1+r_{l}\right)-\log _{e}\left(1-r_{I}\right)\right]
$$

Sendo a variância estimada de $z_{l}$, para $2 n$ 'pares de observações, dada por

$$
\hat{\sigma}_{z_{3}}^{2}=\frac{1}{n^{\prime}-\frac{3}{2}}=\frac{2}{2 n^{\prime}-3}
$$

que é menor do que a variância para $z$, como era esperado, dado que o número de pares de observações é $2 n$ 'e não $n$ '.

$O$ vício existente na transformação $z$ persiste para $z_{I}$, possuindo, entretanto, fatores de correção diferentes.

Segundo Fisher (1925), para o valor amostral da correlação intrerclasse, positivo ou negativo, deve-se aplicar a correção $-\frac{\rho}{2\left(n^{\prime}-1\right)}$ ao valor médio de $z$.

Para a correlação intraclasse, o vício é sempre negativo e independe de $\rho$. A correção, neste caso é de,$+\frac{1}{2} \log _{e} \frac{n^{\prime}}{n^{\prime}-1}$, ou, aproximadamente, $+\frac{1}{2 n^{\prime}-1}$. 


\subsection{5 - Estimador de $\rho_{l}$ por ponto e por intervalo}

\section{A - $\rho_{I}$ estimado por ponto $\left(r_{l}\right)$}

De (14) tem-se $r_{I}=\frac{\sum_{i=I}^{k} \sum_{\substack{j, h=I \\ h \neq j}}^{2}\left(y_{i j}-\bar{Y}\right)\left(y_{i h}-\bar{Y}\right)}{\sum_{i=1}^{k}\left(n_{i}-1\right) \sum_{j=1}^{2}\left(y_{i j}-\bar{Y}\right)^{2}}$

\section{B - Intervalo de confiança para $\rho_{I}$}

Após a transformação $z_{I}=\frac{1}{2}\left[\log _{e}\left(1+r_{I}\right)-\log _{e}\left(1-r_{I}\right)\right]$, obtém-se o intervalo de confiança para $Z_{I}$

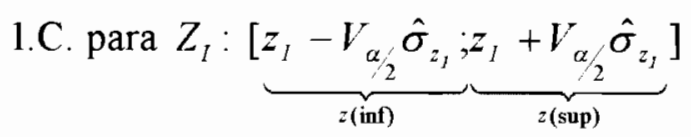

onde $V$ corresponde ao valor crítico da distribuição normal reduzida $\mathrm{N}(0,1)$, para um valor de $\alpha$ fixado.

A partir dos valores do limite inferior de $z_{l}[z(i n f)]$ e do limite superior de $z_{I}$, [z(sup)] obtém-se o intervalo de confiança para $\rho_{I}$. Assim,

I.C. para $\rho_{I}:\left[\frac{e^{2 z(\mathrm{inf})}-1}{e^{2 z(\mathrm{inf})}+1} \cdot \frac{e^{2 z(\mathrm{sup})}-1}{e^{2 z(\mathrm{sup})}+1}\right]$ 


\section{3 - CorrelaÇão intraclasse $\left(\rho_{I}\right)$ COMO FUnÇÃo de CoMPONENTES DE VARIÂNCIA}

\subsection{1 - Definição de $\rho_{I}$}

Considerando-se a existência de dois grupos de fatores que causam variação, Fisher (1925) utiliza a correlação intraclasse como uma medida que quantifica a importância relativa de um dos fatores. No caso de confiabilidade, as fontes de variação são: variação entre (devida à classes, que constitui o fator que é comum a todos os individuos) e variação dentro (devida a resultados discordantes entre as réplicas).

Esta medida fica, assim, associada a um modelo de efeitos aleatórios com um fator, considerado anteriormente, $y_{i j}=\mu+\alpha_{i}+e_{i j}$ para $i=1, \ldots, k ; \mathrm{j}=1, \ldots, \mathrm{n}_{\mathrm{i}}$, onde $k$ é número de classes, $n_{i}$ é o número de observações (réplicas) na classe $i$, sendo que para mesmo número de observações por classe, $n_{i}=n$.

O coeficiente de correlação intraclasse, como uma função dos componentes de variação, é dado por

$$
\rho_{I}=\frac{\sigma_{a}^{2}}{\sigma_{a}^{2}+\sigma_{e}^{2}}=\frac{\sigma_{a}^{2}}{\sigma^{2}}
$$

$\rho_{I}$, escrito segundo a fórmula (20), também pode ser escrito como o coeficiente de correlação momento-produto de Pearson, entre membros de uma mesma classe. Isto pode ser verificado considerando-se que a correlação entre elementos da classe $i$ é dada por

$$
\frac{\operatorname{Cov}\left(Y_{i j}, Y_{i h}\right)}{\sqrt{\operatorname{Var}\left(Y_{i j}\right)} \sqrt{\operatorname{Var}\left(Y_{i h}\right)}}=\frac{\operatorname{Cov}\left(Y_{i j}, Y_{i h}\right)}{\operatorname{Var}\left(Y_{i j}\right)}=E\left\{\left(y_{i j}-\mu\right)\left(y_{i h}-\mu\right)\right\} / \sigma_{y}^{2}=E\left(\alpha_{i}^{2}\right) / \sigma_{y}^{2}
$$

e, considerando-se as equações (3) e (4), tem-se que $\frac{\operatorname{Cov}\left(Y_{i j}, Y_{i h}\right)}{\operatorname{Var}\left(Y_{i j}\right)}=\frac{\sigma_{a}^{2}}{\sigma_{a}^{2}+\sigma_{e}^{2}}=\rho_{I}$

Escrever o coeficiente de correlação intraclasse como a correlação usual entre membros de uma mesma classe permite que esta medida estatística seja utilizada no estudo de confiabilidade (Bartko JJ 1966, Donner A e Kovol JJ 1980). 


\subsection{2.- Limites de variação de $\rho_{I}$}

$\rho_{I}$, definido em (20), é sempre positivo, variando entre 0 e +1 .

Quando a variabilidade devida a réplicas é muito pequena, a variabilidade total será quase toda explicada pela variabilidade entre classes e $\rho_{I}$ estará bem próximo de +1 . Neste caso pode-se dizer que existe alta confiabilidade dos dados e, como conseqüência, as observações estarão fortemente correlacionadas dentro das classes.

Se a variabilidade dentro de cada classe (devido a réplicas) for grande, quando comparada à variabilidade entre classes, $\rho_{I}$ tenderá para 0 , indicando baixa confiabilidade dos dados (Peres CA 1994)

\subsection{3- Estimador de $\rho_{I}$ por ponto e por intervalo}

\section{A - estimador por ponto}

Considerando-se a definição de $\rho_{I}(20)$, e os estimadores não viciados de $\sigma_{\mathrm{e}}^{2}$ e $\sigma_{\mathrm{a}}^{2}(5) \mathrm{e}(6)$, dados por $\hat{\sigma}_{a}^{2}=\frac{Q M A-Q M R}{n_{0}}$ e $\hat{\sigma}_{e}^{2}=Q M R$, tem-se

$\hat{\rho}_{I}=i c c=\frac{\hat{\sigma}_{a}^{2}}{\hat{\sigma}_{a}^{2}+\hat{\sigma}_{e}^{2}}=\frac{Q M A-Q M R}{Q M A+\left(n_{0}-1\right) Q M R}$

onde $n_{0}=n$ quando o modelo é balanceado e

$n_{0}=\left[N-\sum_{i=1}^{k} \frac{n_{i}^{2}}{N}\right] /(k-1)$

quando o modelo é não balanceado (número de réplicas diferentes por indivíduo)

O coeficiente de correlação intraclasse pode também ser escrito em função da razão de variâncias $F, \hat{\rho}_{1}=\frac{(F-1)}{\left(F+n_{0}-1\right)}$ onde $F=\frac{Q M A}{Q M R}$

Duas características importantes do estimador $\hat{\rho}_{I}$, dado em (21) são que ele é viciado (Kendall e Stuart 1947) e pode assumir valores negativos. Os valores negativos ocorrerão quando $Q M R>Q M A$. Neste caso, pode-se seguir algumas das soluções sugeridas por Searle (1971): 
i) aceitar o estimador negativo, apesar de sua natureza insatisfatória, e usá-lo como evidência de que o valor verdadeiro do componente é zero;

ii) aceitar o estimador negativo como evidência de que o valor verdadeiro do componente é zero, e como estimativa, utilizar o valor zero no seu lugar;

iii) interpretar o valor negativo como indicação de utilização de um modelo não adequado e reexaminar os dados com vistas a um novo modelo;

iv) questionar o método que conduziu ao estimador, utilizando outro procedimento, como por exemplo o de Bayes;

v) interpretar a estimativa negativa como indicação de número de observações insuficientes. Coletar mais dados e analisá-los separadamente ou em conjunto com os dados já coletados.

\section{B - Intervalo de confiança para $\rho_{I}$}

Quando o número de réplicas é o mesmo, para todos os indivíduos, o intervalo de confiança é dado por

$$
P\left(\frac{L_{i}}{1+L_{i}} \leq \rho_{I} \leq \frac{L_{s}}{1+L_{s}}\right)=1-\alpha
$$

onde

$$
\begin{aligned}
& \left\{\begin{array}{l}
L_{i}=\frac{1}{n}\left(\frac{Q M A}{Q M R} \frac{1}{F_{2}}-1\right) \\
L_{s}=\frac{1}{n}\left(\frac{Q M A}{Q M R} \frac{1}{F_{1}}-1\right)
\end{array}\right. \\
& \text { para } \mathrm{F}_{2}=\mathrm{F}_{\mathbf{k}-1, N-\mathbf{k}, 1-\alpha / 2} \text { e } \mathrm{F}_{1}=\mathrm{F}_{\mathbf{k}-1, N-\mathbf{k}, \alpha / 2}
\end{aligned}
$$


obtidos na tabela da distribuição $F$, para os graus de liberdade e nível de significância $\alpha$ especificados.

Quando o número de réplicas é diferente, o intervalo é calculado substituindo-se $n$ por $n_{0}$, definido na equação 22 (Neter J et al. 1988).

\section{4 - Comparação entre $r_{I}$ e $i c c$}

Considerando-se a definição da correlação intraclasse dada por $\rho_{I}=\frac{\sigma_{a}^{2}}{\sigma_{a}^{2}+\sigma_{e}^{2}}$, tem-se que este pode ser escrito como $\rho_{I}=\frac{1}{1+\sigma^{2} \sigma_{\sigma} / \sigma_{a}^{2}}$, fazendo com que o interesse maior recaia sobre os estimadores dos componentes de variância $\sigma_{a}^{2} e \sigma_{e}^{2}$. Uma vasta revisão dos estudos que abordam as propriedades dos estimadores destes componentes é apresentada por Khuri e Sahai (1985). Alguns achados relevantes para o presente estudo são mencionados a seguir:

i) em estudo de simulação, Swallow e Monaham (1984) encontraram que o estimador dado pela análise de variância teve uma boa performance quanto ao vício e erro quadrático médio, a menos que o número de elementos em cada classe fosse muito diferente;

ii) Donner e Koval (1980), em estudo relacionado a semelhança entre irmãos, simularam observações de uma distribuição normal multivariada, com diferentes números de indivíduos por família e compararam quatro estimadores, três dos quais eram $r_{i}, i c c$, e o estimador de máxima verossimilhança $\left(r_{M}\right)$. Os achados indicaram que o $r_{M}$ é um estimador mais acurado do que $i c c$ para pequenos e grandes valores de $\rho_{I}(\leq 0,1$ e $\geq 0,8)$ e que os dois estimadores eram igualmente eficientes para $\rho_{I}=0,3$ e 0,5 . Verificou-se, ainda, que $r_{I}$ teve um bom desempenho para $\rho_{I}=0$, com declínio rápido, na acurácia relativa (quociente entre o erro quadrático médio 
de $r_{l}$ e o erro quadrático médio de $i c c$ ), conforme $\rho_{I}$ aumentava. Concluíram que o estimador de máxima verossimilhança é preferível ao estimador pela ANOVA, para valores de $\rho_{l}$ maiores ou iguais a 0,5 . Para valores moderados $\left(\rho_{I}<0,5\right)$, os autores recomendam a utilização de icc. Neste estudo observou-se, ainda, que o vício máximo de $r_{I}$ era de 0,05 enquanto que o vício máximo para os outros estimadores foi de 0,02

iii) uma grande desvantagem do estimador de Pearson para pares repetidos ocorre quando as familias possuem tamanhos diferentes, sendo que as familias maiores terão mais peso no cálculo da medida, do que as famílias menores. Assim, uma familia de tamanho 2 estaria contribuindo com dois pares de valores, enquanto que outra, com 10 indivíduos estaria contribuindo, para a análise, com 90 pares de valores ( $n(n-1)$ vezes) representando uma contribuição 45 vezes a da anterior. Esta desvantagem pode ser contornada optando-se pelo estimador ponderado para pares repetidos proposto por Karlin S et al. (1981);

iv) Donner A (1986), vê como pouco indicado o uso do estimador $r_{I}$ a menos que os grupos sejam de igual tamanho;

v) $\mathrm{Na}$ situação onde os grupos são de igual tamanho, o estimador de máxima verossimilhança $\left(r_{M}\right)$ coincide com o estimador de Pearson para pares repetidos $\left(r_{l}\right)$ Se o número de famílias é grande, $r_{I}$ é virtualmente igual a icc (Donner A 1986);

vi) Alexander HW (1946), mostra que o valor numérico de $r_{I}$ é sempre menor que o valor numérico de $i c c$.

vii) A correlação intraclasse como função de componentes de variância está vinculada a um modelo onde o j-ésimo membro da i-ésima família pode ser descrito matematicamente como $x_{i j}=\mu+a_{i}+e_{i j}$, onde $\mu$ representa a média de todas as 
observações na população, os efeitos de familia $\left\{a_{i}\right\}$ são identicamente distribuídos com média 0 e variância $\sigma_{a}^{2}$, os erros $\left\{e_{i j}\right\}$ são identicamente distribuídos com média 0 e variância $\sigma_{e}^{2}$ e os $\left\{a_{i}\right\}$ e $\left\{\boldsymbol{e}_{i j}\right\}$ são independentes. A variância de $x_{i j}$ é dada por $\sigma_{x}^{2}=\sigma_{a}^{2}+\sigma_{e}^{2}$ e a correlação intraclasse é definida por $\sigma_{a}^{2} /\left(\sigma_{a}^{2}+\sigma_{e}^{2}\right)$. Estimando-se este parâmetro mediante a ANOVA, obtém-se o estimador $i c c=(Q M A-Q M R)(Q M A+(n-1) Q M R)$, para o mesmo número de indivíduos em uma classe.

O outro parâmetro, definido como $\operatorname{Cov}(X, Y) / \sigma_{X} \sigma_{Y}$, é baseado no "modelo" de correlação e assume que as observações (todos os possíveis pares) $x_{i /}$ distribuem-se ao redor da mesma média $\mu$ com mesma variância $\sigma^{2}$, de tal forma que duas observações de uma mesma classe possuem uma correlação comum, que é constante de família para família e independe do número de pessoas na família. (Snedecor e Cochran 1967).

A diferença entre os parâmetros leva a comportamentos diferentes quanto à sua adoção. Enquanto que o modelo de componentes de variância permite que as inferências sejam estendidas para um número populacional de famílias, o "modelo" de correlação comum apresenta-se mais apropriado se as inferências forem restritas às famílias da amostra (Donner e Koval 1980). 


\section{5 - Simulação Monte Carlo}

\section{Justificativa e estratégia de simulação}

Como visto anteriormente, ambos estimadores de $\rho_{I}$ são viciados; assim, a comparação empírica entre eles só pode ser feita mediante estudos de simulação que permitam o cálculo dos estimadores e a comparação destes com o parâmetro previamente fixado.

O parâmetro fixado para o estudo Monte Carlo foi o definido pela correlação de Pearson para pares repetidos, criando-se uma situação equivalente à do estudo de semelhanças entre irmãos e, neste caso, obtendo-se pares de valores sem distinção de classes. Para cada "família", gerou-se primeiramente um valor proveniente de uma distribuição $\mathrm{N}(0,1)$; o segundo passo consistiu em gerar um segundo valor correlacionado ao primeiro. Obteve-se, assim, $n$ pares independentes de valores correlacionados segundo uma correlação intraclasse pré definida.

A partir dos pares de valores gerados, para amostras de tamanho fixado, pôde-se, então, proceder ao cálculo das estimativas da correlação intraclasse e compará-las segundo algum critério. Neste trabalho, comparam-se o vício e o erro quadrático médio dos estimadores. A comparação é realizada utilizando-se medidas descritivas como valor mínimo e máximo, bem como pela razão entre o vício e o parâmetro e entre os erros quadráticos médios dos estimadores. Esta última é denominada por Donner A (1980) eficiência relativa do estimador, que neste trabalho é calculada pelo quociente entre o erro quadrático médio de $r_{I}$ e o erro quadrático médio de icc, adotando-se a mesma terminologia. 


\section{Simulação Monte Carlo}

O estudo de simulação, denominado estudo Monte Carlo, é um processo de amostragem artificial, utilizado, de forma geral, quando se quer referir ao uso de técnicas computacionais que permitem a geração de números pseudo-aleatórios com distribuição teórica conhecida (Dachs JNW 1988, Stamato JJ 1973).

Os números pseudo-aleatórios gerados devem possuir propriedades tais como procedimento de geração simples e curto, períodos com uma extensão razoável, repetibilidade e aceitação estatística medida por meio de testes estatísticos que comparam a distribuição teórica com a distribuição estimada.

Atualmente, os geradores de números pseudo-aleatórios utilizam uma variante do método proposto por Lehmer (in Dachs JNW 1988), onde são escolhidos quatro números: $\boldsymbol{X ( 0 )}$, que é um valor inicial (semente); $\boldsymbol{a}$, o multiplicador; $\boldsymbol{c}$, o incremento; e $\boldsymbol{m}$, o módulo (comprimento do ciclo)

Com base nestes números, obtém-se a seqüência de números pseudo-aleatórios, mediante a utilização da expressão

$$
X(n+1)=(a X(n)+c) \text { MOD } \mathrm{m}, \quad \text { para } \mathrm{n} \geq 0
$$

Neste trabalho, optou-se, para o estudo Monte Carlo, pela utilização do gerador de números pseudo-aleatórios KISS, existente no programa para microcomputadores, STATA (1996). O gerador utiliza números obtidos de um sistema de quatro equações iterativas, apresentadas no Anexo 6.

$\mathrm{O}$ gerador KISS produz números pseudo-aleatórios entre $[0,1)$, com período $\cong 2^{126}$. Para a geração de números aleatórios com distribuição $\mathrm{N}(0,1)$, utilizou-se a função invnorm(uniform()).

O estudo da distribuição dos valores gerados foi realizado mediante os teste $W^{\prime}$, de Shapiro-Francia, para normalidade, implementado no STATA (1996) pelo comando sfrancia - Shapiro-Francia test for normality. 


\section{Geração de pares de valores correlacionados}

Para o estudo Monte Carlo foram gerados $n(n=15,30$ e 45) pares de valores correlacionados segundo um coeficiente de correlação intraclasse fixado ( $\rho_{I}=0 ; 0,15$; $0,30 ; 0,45 ; 0,60 ; 0,75 ; 0,9)$, segundo os seguintes procedimentos:

i) geração de 1 valor pseudo-aleatórios $X \sim \mathrm{N}(0,1)$

ii) geração de 1 valor $Y \sim \mathrm{N}(0,1)$, correlacionados ao valor de $X$, da seguinte forma:

Para cada $X=$ valor aleatório $\sim \mathrm{N}(0,1)$, obteve-se

$Y=X \rho_{I}+Z \sqrt{1-\rho_{I}^{2}}$, onde $Z$ é o valor reduzido da variável aleatória $\mathrm{Y}$ condicionada a $X$, para um valor da correlação intraclasse fixada

iii) realização dos procedimentos em $i$ e $i i, n$ vezes, para $n=15,30$ e 45

iv) realização do procedimento iii 2.000 vezes, obtendo-se a distribuição amostral dos estimadores.

A geração dos pares de valores está baseada na distribuição normal bivariada onde $X, Y \sim N\left(\mu_{X}, \mu_{Y}, \sigma_{X}^{2}, \sigma_{Y}^{2}, \rho\right)$, correlacionadas segundo um coeficiente de correlação $\rho=\rho_{l}$, com função densidade de probabilidade conjunta $f(x, y)$ dada por

$$
f(x, y)=\frac{e^{-\frac{1}{2\left(1-\rho^{2}\right)}\left[\left(\frac{\left(x-\mu_{X}\right.}{\sigma_{X}}\right)^{2}-2 \rho\left(\frac{x-\mu_{X}}{\sigma_{X}}\right)\left(\frac{y-\mu_{Y}}{\sigma_{Y}}\right)+\left(\frac{y-\mu_{Y}}{\sigma_{Y}}\right)^{2}\right]}}{2 \pi \sigma_{X} \sigma_{Y} \sqrt{1-\rho^{2}}}
$$

Tem-se que, para um dado valor de $X$, a função densidade de probabilidade condicional $f(y x)$ é dada por

$$
f(y \mid x)=\frac{e^{\left.-\frac{1}{2} \mid \frac{y \times \mu \gamma r\left(\frac{\sigma}{\sigma x}\right)\left(x \mu_{x}\right)}{2 \pi \sqrt{1-\rho^{2}}}\right]^{2}}}{2 \pi \sqrt{1-\rho^{2}}},
$$


onde $Y_{x}$ é uma variável aleatória com média $\mu_{\mathrm{Y}}+\rho\left(\frac{\sigma_{\mathrm{Y}}}{\sigma_{\mathrm{X}}}\right)\left(\mathrm{x}-\mu_{\mathrm{x}}\right)$ e desvio padrão $\sigma_{Y} \sqrt{1-\rho^{2}}$

$$
\text { Padronizando-se } Y_{x} \text {, obtém-se } \frac{y_{X}-\left(\mu_{X}+\rho\left(\frac{\sigma_{Y}}{\sigma_{X}}\right)\left(x-\mu_{X}\right)\right)}{\sigma_{Y} \sqrt{1-\rho^{2}}}=Z \text {, }
$$

onde $Z \sim N(0,1)$, de onde se obtém $\mathrm{y}_{\mathrm{x}}=Z \sigma_{\mathrm{Y}} \sqrt{1-\rho^{2}}+\left(\mu_{\mathrm{Y}}+\rho\left(\frac{\sigma_{\mathrm{Y}}}{\sigma_{\mathrm{X}}}\right)\left(\mathrm{x}-\mu_{\mathrm{X}}\right)\right)$

Se $\mu_{X}=\mu_{Y}=0$ e $\sigma_{X^{\prime}}^{2}=\sigma_{Y}^{2}=1$, para valores fixados de $X$, obtém-se valores correlacionados de $Y$, ou seja $y_{x}=\rho x+Z \sqrt{1-\rho^{2}}$ (Mood et al. 1974).

\section{Programa estatístico utilizado no estudo Monte Carlo}

Para a geração dos pares de valores correlacionados, elaborou-se o programa principal, utilizando-se a linguagem de programação do programa para microcomputadores, STATA (1996), apresentado no Anexo 7.

O estudo Monte Carlo foi desenvolvido com o objetivo de produzir $n$ pares de valores $\{z 1, z 2\}$ distribuídos segundo uma distribuição Normal bivariada, com médias $\mathrm{e}$ variâncias iguais e valores correlacionados segundo um coeficiente de correlação intraclasse $\rho_{I}$. Optou-se por fixar o número de pares de valores em $n=\{15,30$ e 45$\}$ e os valores da correlação intraclasse $\rho_{I}$ em $\{0 ; 0,15 ; 0,3 ; 0,45 ; 0,6 ; 0,75 ; 0,9\}$. A combinação dos valores de $n$ e de $\rho_{I}$ produziu 21 configurações.

Cada rodada do programa principal envolveu o sorteio de 2.000 amostras de tamanho $n$ (pares de valores correlacionados), para uma dada configuração (por exemplo $n=15$ e $\rho_{I}=0,3$ ), produzindo a distribuição amostral de $r_{I}$ e $i c c$. 
Calcularam-se então, para cada configuração $\left(n, \rho_{I}\right.$ e 2.000 amostras $)$ o vício, o erro quadrático médio, a amplitude dos intervalos de confiança e o número de vezes que cada intervalo continha o verdadeiro valor da correlação fixada, para cada um dos estimadores

O quadro 2 apresenta a seqüência de procedimentos utilizados no estudo Monte Carlo, utilizando-se o programa STATA.

Quadro 2 - Procedimentos do estudo Monte Carlo e respectivos comandos no STATA

\begin{tabular}{|c|c|}
\hline procedimentos & comando no STATA \\
\hline $\begin{array}{l}\text { sorteio de } 100 \text { números aleatórios para semente } \\
\text { ativar o arquivo log (arquivo texto para guardar os resultados ) } \\
\text { carregar o programa principal } \\
\text { especificação de semente aleatória (\#) } \\
\text { realizar a simulação para determinada configuração ( } n \text { e Rho } \\
\text { fixados), com } 2000 \text { amostras } \\
\text { o programa principal produz, tendo n e Rho fixados } \\
\text { variável } z_{1}=1 \text { valor aleatório } \sim \mathrm{N}(0,1 \text { ) } \\
\text { variável } z_{2}=1 \text { valor aleatório } \sim \mathrm{N}(0,1 \text { ), correlacionados à } \\
z_{1} \\
\text { repetição da geração dos pares de valores segundo } n \\
\text { preparação dos pares repetidos } \\
\text { cálculo da correlação intraclasse } r_{I} \text { por ponto e intervalo } \\
\text { sub-rotina que calcula, para as } 2.000 \text { amostras } \\
\text { vicio, erro quadrático médio, amplitude do intervalo de } \\
\text { confiança co número de vezes que o intervalo contém o } \\
\text { parâmetro fixado }\end{array}$ & $\begin{array}{l}\text { set obs } 100 \\
\text { gen semente=uniform() } \\
\text { do C:DATAKarquivo.DO> } \\
\text { set seed \# } \\
\text { simul CENIOR3,reps }(2000) \text { d }\end{array}$ \\
\hline
\end{tabular}




\section{6 - CRITÉRIOS PARA ESCOLHA DO MELHOR ESTIMADOR}

Para a escolha do melhor estimador da correlação intraclasse, utilizaram-se, como critérios, o vício e o erro quadrático médio dos estimadores (Bussab WO, Morettin PA 1994).

\section{Vício}

Se $\theta$ é o parâmetro de interesse, o estimador $T$ será não viciado se sua esperança matemática for igual ao parâmetro, ou seja $E(T)=\theta$ (Anexo 2).

Para cada configuração ( $n$ e $\rho_{I}$ fixados), calculou-se a esperança matemática de cada estimador com base em suas distribuições amostrais. No STATA, isto foi feito mediante a sub-rotina CALCR\#\#, apresentada no Anexo 7.

\section{Erro Quadrático Médio}

O erro quadrático médio ( $E Q M)$ dos estimadores foi calculado com base nas distribuições amostrais de cada estimador, a partir da definição apresentada no Anexo 1, ou seja

$$
\operatorname{EQM}(T)=\operatorname{Var}(T)+\operatorname{Vies}^{2}(T), \text { onde }
$$

$\operatorname{Var}(T)$ é a variância do estimador e $\operatorname{Vies}^{2}(T)$ é o quadrado do viés do estimador. 


\section{4 - Resultados e Comentários}

\section{1 - Estudo Monte Carlo}

Utilizou-se para o desenvolvimento do estudo Monte Carlo um microcomputador modelo Pentium MMX, com velocidade de $166 \mathrm{Mhz}$ e memória de $32 \mathrm{Mb}$. O tempo médio para realização de uma simulação de 2.000 amostras para uma dada configuração ( $n$ e $\rho_{l}$ fixados) variou entre 7 e 12 minutos, observando-se maior tempo de processamento para valores maiores de $n$.

Realizou-se um estudo da distribuição dos valores gerados, cujos resultados são apresentados no Anexo 8

\section{2 - Estimadores de $\rho_{1}: r_{I}$ e $i c c$}

Mediante o estudo de simulação Monte Carlo foram obtidas estimativas do coeficiente de correlação intraclasse de Pearson para pares repetidos $\rho_{l}$ utilizando-se como estimadores a correlação de Pearson, para pares repetidos $\left(r_{l}\right)$, e a correlação intraclasse obtida pela técnica de análise de variância (icc). Para cada uma das 2.000 amostras de pares de valores gerados, foram estimados $r_{l}$ e icc. As tabelas 6 e 7 apresentam os valores médios, desvios padrão e valores mínimo e máximo de $r_{I}$ e $i c c$, respectivamente, para $n$ e $\rho_{l}$ fixados

Para cada configuração (n e $\rho_{I}$ fixados), foram obtidos os valores médios de $r_{I}$ e $i c c$, observando-se magnitudes bastante semelhantes. Os valores médios estimados de $r_{I}$ variaram entre $-0,72$ e $+0,97\left(n=15\right.$ e $\rho_{1}=0$ e $n=45$ e $\rho_{1}=0,9$; respectivamente). Para os mesmos valores de $n$ e $\rho_{l}$, observou-se, para icc, que os valores variaram entre 0,71 e $+0,97$. Observou-se, ainda, para ambos os estimadores, a ocorrência de estimativas negativas somente para $\rho_{l}$ igual a zero para os três tamanhos de amostra fixados, sendo que para $n=30$, apenas $r_{I}$ é negativo. 
Foram observados que, de forma geral, os valores médios de icc são sempre maiores do que os valores médios de $r_{l}$, para $n$ e $\rho_{l}$ fixados. As exceções foram observadas para os três valores de $n$ e $\rho_{I}=0$.

Tabela 6 - Simulação de 2.000 amostras de tamanho $n=15,30$ e 45 e coeficientes de correlação intraclasse $\rho_{l}=\{0,0,15 ; 0,30 ; 0,45 ; 0,60 ; 0,75 ; 0,9\}$. Média, desvio padrão e valores mínimo e máximo de $\boldsymbol{r}_{\boldsymbol{I}}$

\begin{tabular}{|c|c|c|c|c|c|}
\hline $\mathbf{n}$ & $\rho_{1}$ & média & desv.pad. & mínimo & máximo \\
\hline \multirow{7}{*}{15} & 0 & -0.0334344 & 0.2461647 & $-0.72+102$ & 0.7675644 \\
\hline & 0.15 & 0,1052931 & 0,2522432 & $-0,756291$ & 0,7697536 \\
\hline & 0.3 & 0.2481767 & 0.2388254 & -0.5510659 & 0.8452397 \\
\hline & 0.45 & 0.4000973 & $0.2186+16$ & -0.5455019 & 0,8727027 \\
\hline & 0.6 & 0,550783 & 0.1837469 & -0.2168968 & 0,9139484 \\
\hline & 0.75 & 0.7073135 & 0,1356034 & $-0,096527$ & 0,9609213 \\
\hline & 0.9 & 0,8782342 & 0.0664799 & 0,4086457 & 0,9826731 \\
\hline \multirow{7}{*}{30} & 0 & $-0,0141413$ & 0,1811207 & $-0,6279196$ & 0,5450183 \\
\hline & 0.15 & 0,1315562 & 0,1772918 & $-0,416548$ & 0,6117175 \\
\hline & 0.3 & 0,2740621 & 0,1699673 & $-0,363825$ & 0,7092349 \\
\hline & 0.45 & 0.4257376 & 0.1471719 & -0.0787091 & 0,8081201 \\
\hline & 0.6 & 0,5758132 & 0.1243855 & 0.0205929 & 0.857402 \\
\hline & 0.75 & 0.7297685 & 0,0876977 & 0,2333725 & 0,9260525 \\
\hline & 0.9 & 0,8888149 & 0,03938 & 0,6855208 & 0,9759331 \\
\hline \multirow{7}{*}{45} & 0 & $-0,0127084$ & 0.1496649 & $-0,4790654$ & 0,4717775 \\
\hline & 0.15 & 0,1406077 & 0,1456349 & $-0,3895059$ & 0,5996394 \\
\hline & 0,3 & 0.28455019 & 0,136821 & $-0,2256887$ & 0,6958768 \\
\hline & 0.45 & 0.4349972 & 0.1202941 & -0.0320657 & 0,7737036 \\
\hline & 0.6 & 0.5854884 & 0,097261 & 0.0249979 & 0.8441554 \\
\hline & 0.75 & $0.7376+88$ & 0.0686876 & 0,4015581 & 0,9016567 \\
\hline & 0.9 & 0,8936528 & 0,0310177 & 0,6560515 & 0,9658939 \\
\hline
\end{tabular}


Tabela 7 - Simulação de 2.000 amostras de tamanho $n=15,30$ e 45 e coeficientes de correlação intraclasse $\rho_{I}=\{0 ; 0,15 ; 0,30 ; 0,45 ; 0,60 ; 0,75 ; 0,9\}$. Média, desvio padrão e valores mínimo e máximo de icc

\begin{tabular}{|c|c|c|c|c|c|}
\hline $\mathbf{n}$ & $\rho_{l}$ & média & desv.pad. & mínimo & máximo \\
\hline \multirow{7}{*}{15} & 0 & $-0,0010425$ & 0,2463222 & $-0,7072793$ & 0,7813662 \\
\hline & 0.15 & 0,1370993 & 0,250632 & $-0,7411363$ & 0,7834413 \\
\hline & 0,3 & 0,2783407 & 0,2353051 & $-0,5265896$ & 0,854808 \\
\hline & 0,45 & 0,4270789 & 0,2135249 & $-0,5208159$ & 0,8806829 \\
\hline & 0.6 & 0,5732537 & 0,1775657 & $-0,1837886$ & 0,9194541 \\
\hline & 0,75 & 0,7235426 & 0,1297472 & $-0,0623176$ & 0,963479 \\
\hline & 0,9 & 0,885749 & 0,0628159 & 0,436971 & 0,9838189 \\
\hline \multirow{7}{*}{30} & 0 & 0,0022525 & 0,1811805 & $-0,6175428$ & 0,5568237 \\
\hline & 0,15 & 0,147646 & 0,176505 & $-0,4024402$ & 0,6222154 \\
\hline & 0,3 & 0.2891827 & 0,1685151 & $-0,3490282$ & 0,7175583 \\
\hline & 0.45 & 0,4391559 & 0,1451725 & $-0,0618424$ & 0,8139035 \\
\hline & 0,6 & 0.5867783 & 0,1221322 & 0,037529 & 0,8618268 \\
\hline & 0,75 & 0,73744686 & 0,0856662 & 0,2493355 & 0,9284292 \\
\hline & 0,9 & 0,8922964 & 0,0382348 & 0,6944017 & 0,9767261 \\
\hline \multirow{7}{*}{45} & 0 & $-0,0017243$ & 0,1496952 & $-0,4703613$ & 0.4804666 \\
\hline & 0,15 & 0,151367 & 0,145203 & $-0,3799327$ & 0,6067871 \\
\hline & 0,3 & 0,2945872 & 0,1359985 & $-0,2149979$ & 0,7016269 \\
\hline & 0.45 & 0,4439025 & 0,1191728 & $-0,0208373$ & 0,7781747 \\
\hline & 0,6 & 0,5927188 & 0,096694 & 0,0362237 & 0.8473543 \\
\hline & 0,75 & 0,7426772 & 0,0675919 & 0,41094 & 0.9037369 \\
\hline & 0,9 & 0,8958825 & 0,0304119 & 0,6624047 & 0,9666391 \\
\hline
\end{tabular}




\section{Comparação entre $r_{I}$ e icc}

Realizou-se a comparação, segundo $\rho_{I}$ e $n$, entre os valores médios de $r_{I}$ e icc mediante a utilização dos gráficos das duas medidas, da diferença entre elas e da razão entre o logaritmo natural do valor absoluto dos valores médios dos estimadores. As figuras $4 \mathrm{a}, 4 \mathrm{~b}$ e $4 \mathrm{c}$ apresentam os valores médios de $r_{I}$ e $i c c$, para $n$ e $\rho_{I}$ fixados.
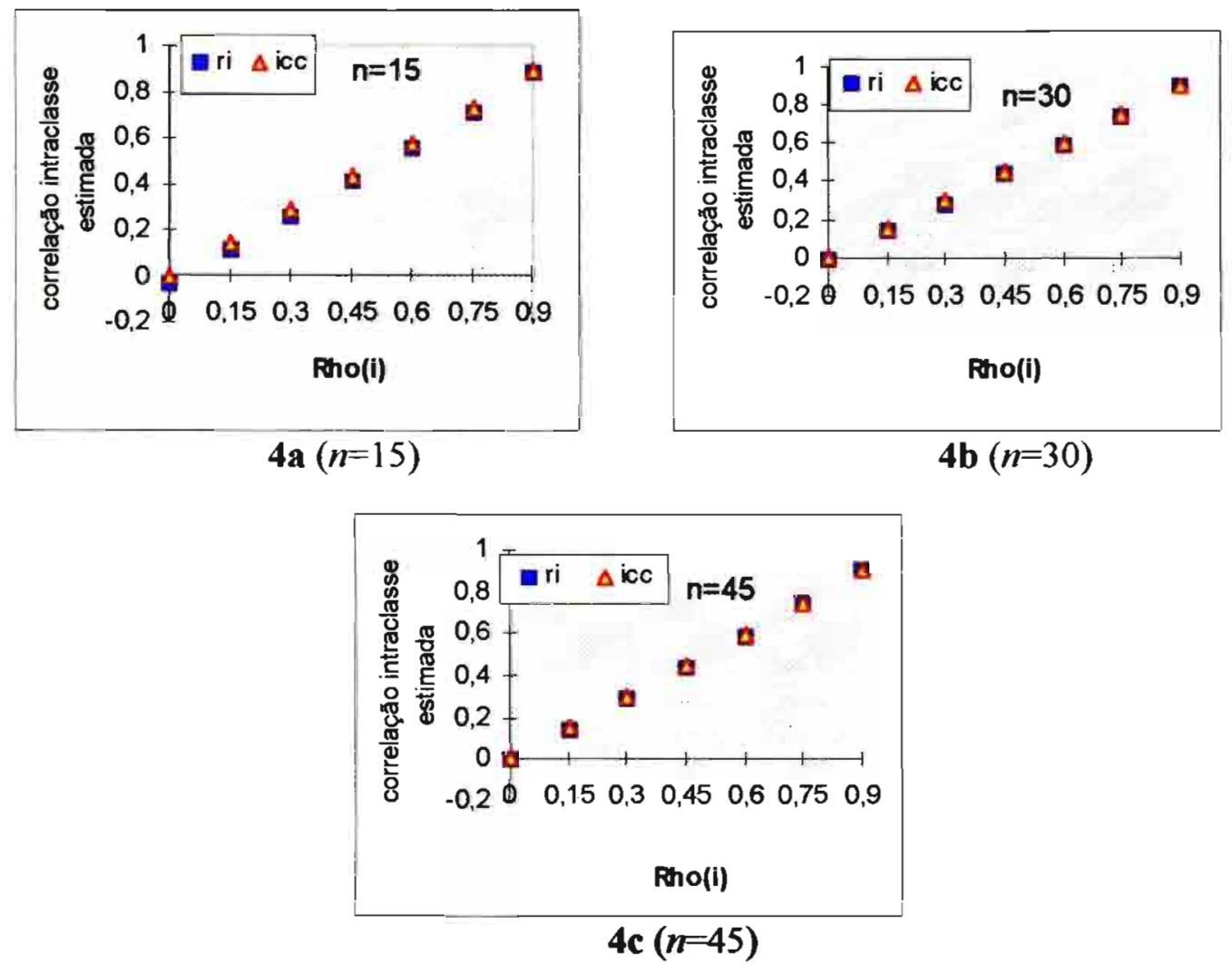

Figuras 4a, 4b e 4c- Simulação de 2.000 amostras de tamanho $n=15,30$ e 45 e coeficientes de correlação intraclasse $\rho_{I}=\{0 ; 0,1 ; 0,15 ; 0,30 ; 0,45 ; 0,60 ; 0,75 ; 0,9\}$.

Valores médios de $r_{I}$ e icc

As diferenças entre os valores médios das estimativas segundo $n$ e $\rho_{1}$ são apresentadas na figura 5 e Anexo 9. Observa-se que os valores médios das estimativas são iguais até a primeira casa decimal, passando a existir diferença entre eles, a partir da segunda casa decimal. Para $n=15$, as diferenças são maiores para $\rho_{I}$ menor ou igual a 
0,45 . Para $\mathrm{n}=30$ e 45 e $\rho_{l} \geq 0,90$, os valores médios de $r_{l}$ e $i c c$ se igualam até a segunda casa decimal.

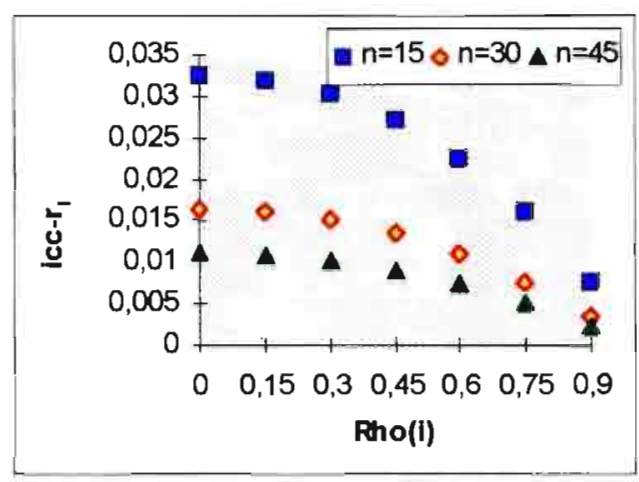

Figura 5 - Simulação de 2.000 amostras de tamanho $n=15,30$ e 45 e coeficientes de correlação intraclasse $\rho_{I}=\{0 ; 0,15 ; 0,30 ; 0,45 ; 0,60 ; 0,75 ; 0,9\}$. Diferença entre os valores médios de icc e $\boldsymbol{r}_{I}$

Para a comparação entre os valores médios dos estimadores, calculou-se, ainda, o quociente entre o logaritmo dos valores médios, absolutos, de icc e $r_{l}$, para $n$ e $\rho_{I}$ fixados, apresentados na figura 6. Observa-se que as razões tendem para 1 conforme $n$ e $\rho_{I}$ aumentam.

Considerando-se que os valores médios de icc são maiores que os valores médios de $r_{l}$, o quociente entre o logaritmo natural das estimativas em valores absolutos acaba sendo menor do que o valor um. Isto é observado para as amostras de tamanho $15,30 \mathrm{e}$ 45 e valores da correlação intraclasse iguais ou maiores que 0,15 . Para $\rho_{l}=0$, os valores médios de icc são menores do que os valores de $r_{I}$ e, neste caso, o quociente entre o logaritmo natural das estimativas em valores absolutos é maior do que o valor um. 


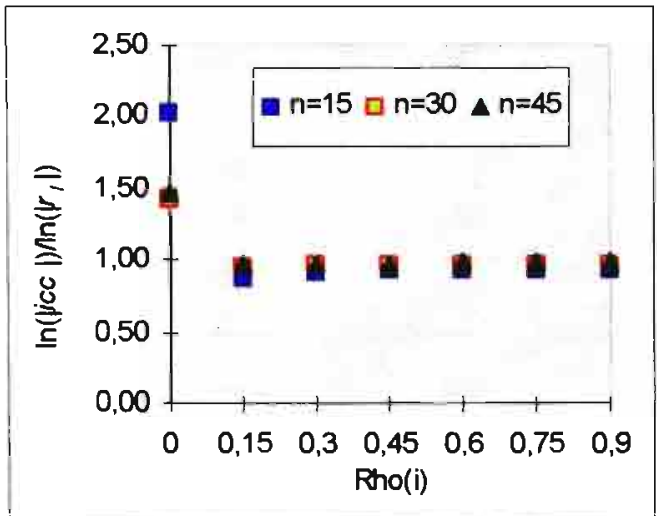

Figura 6 -Simulação de 2.000 amostras de tamanho $n=15,30$ e 45 e coeficientes de correlação intraclasse $\rho_{I}=\{0 ; 0,15 ; 0,30 ; 0,45 ; 0,60 ; 0,75 ; 0,9\}$.

Razão entre o logaritmo natural dos valores médios absolutos de icc e $\boldsymbol{r}_{\boldsymbol{I}}$

\section{Desvio padrão amostral de $\boldsymbol{r}_{I}$ e icc}

O desvio padrão de $r_{I}$, para $n$ e $\rho_{l}$ fixados, variou entre 0,246 e 0,310 ( $n=5$ e $\rho_{l}=0$ e $n=45$ e $\rho_{l}=0,9$, respectivamente). Para os mesmos valores de $n$ e $\rho_{I}$, foram observados valores do desvio padrão de icc variando entre 0,246 e 0,304 . Os desvios padrão de $r_{I}$ apresentam, quase na totalidade, magnitudes maiores que os desvios padrão de icc, a exceção ocorre para $\rho_{I}=0$, onde o desvio padrão de $r_{I}$ é menor que o desvio padrão de $i c c$

Para $n=15$, a diferença entre os desvios padrão aumenta até atingir um valor máximo quando $\rho_{I}=0,6 \mathrm{e}$, a partir deste valor, volta a diminuir. Para $n=30$ e 45 , as diferenças apresentam um comportamento bastante semelhante, com modesta tendência de aumento e queda a partir de $\rho_{I}=0,6$ (figura 7).

A figura 10 apresenta a razão entre os desvios padrão dos estimadores, para as 2.000 amostras. Observa-se, para os três valores de $\boldsymbol{n}$, um distanciamento do valor um, $\mathrm{e}$ portanto um aumento relativo do desvio padrão de $r_{l}$ em relação ao desvio padrão de $i c c$, conforme $\rho_{l}$ aumenta. A figura sugere que a velocidade de aumento da razão é maior para $n=15$. 


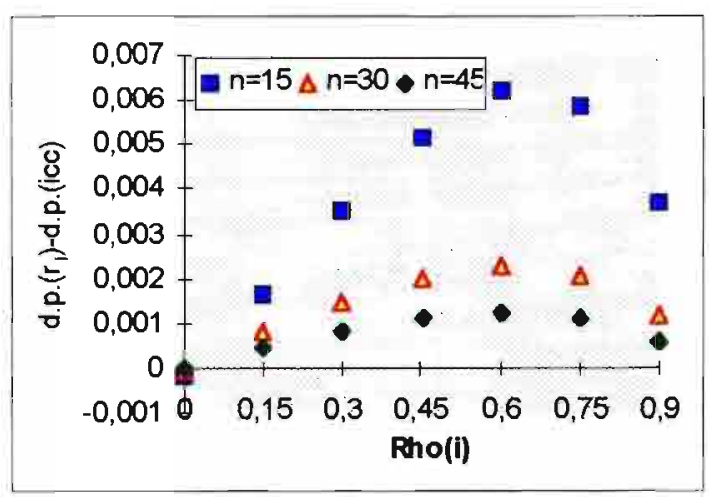

Figura 7 - Simulação de 2.000 amostras de tamanho $n=15,30$ e 45 e coeficientes de correlação intraclasse $\rho_{l}=\{0 ; 0,15 ; 0,30 ; 0,45 ; 0,60 ; 0,75 ; 0,9\}$. Diferença entre os desvios padrão de icc e $\boldsymbol{r}_{I}$

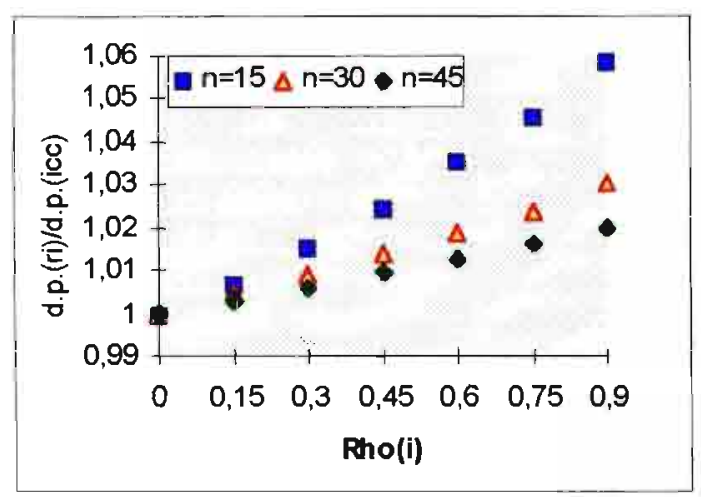

Figura 8 -Simulação de 2.000 amostras de tamanho $n=15,30$ e 45 e coeficientes de correlação intraclasse $\rho_{I}=\{0 ; 0,15 ; 0,30 ; 0,45 ; 0,60 ; 0,75 ; 0,9\}$. Razão entre os desvios padrão de icc e $\boldsymbol{r}_{I}$

\section{3 - Viés de $\boldsymbol{r}_{I}$ e de icc}

Os valores do viés de $r_{I}$ e de $i c c$ são apresentados no Anexo 10 e figuras $9 \mathrm{a}, 9 \mathrm{~b}$ e $9 c$. 


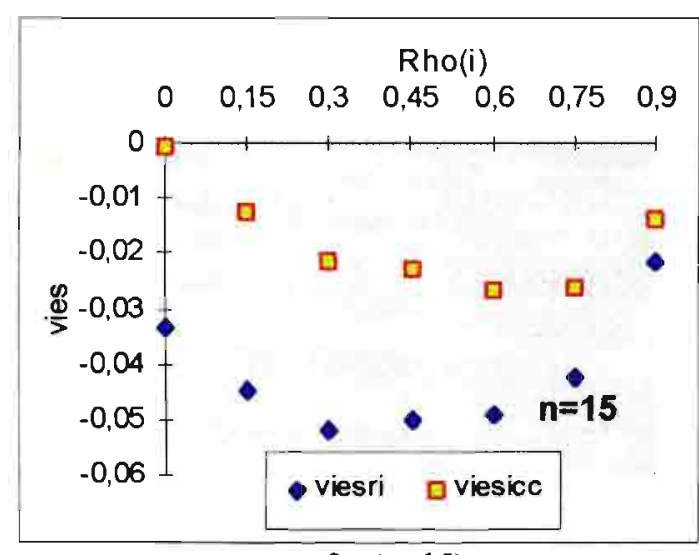

$9 \mathrm{a}(n=15)$

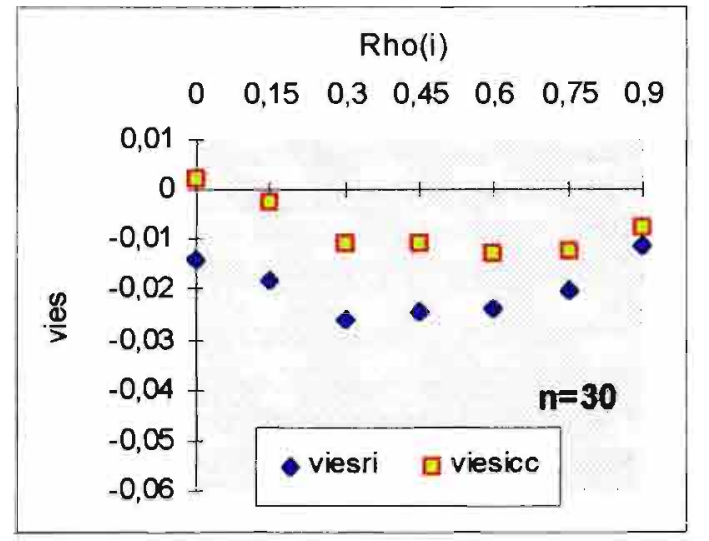

$9 \mathbf{b}(n=30)$

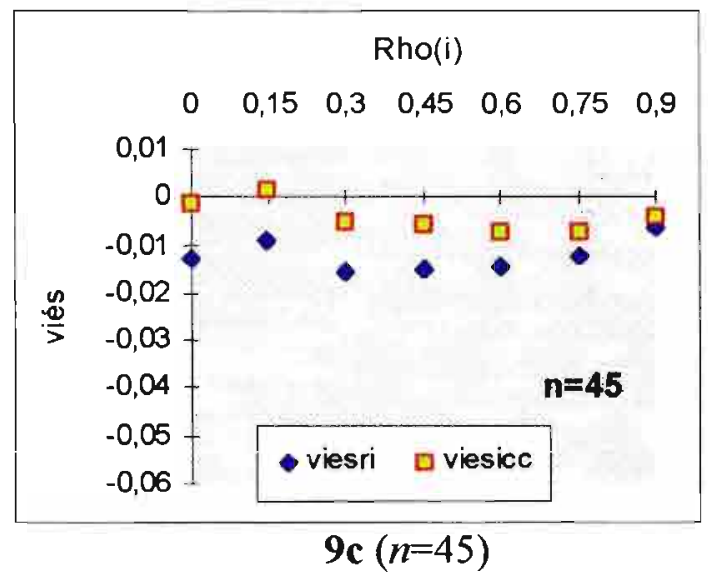

Figuras 9a, 9b e 9c - Simulação de 2.000 amostras de tamanho $n=15,30$ e 45 e coeficientes de correlação intraclasse $\rho_{I}=\{0 ; 0,15 ; 0,30 ; 0,45 ; 0,60 ; 0,75 ; 0,9\}$.

Valores do viés de $r_{I}$ (viesri) e do viés de icc (viesicc)

Os valores do viés de $r_{I}$ e de icc são, em quase sua totalidade, negativos. Observase a ocorrência de dois valores positivos para o viés de $i c c$ para $n=30$ e $\rho_{l}=0$ e para $n=45$ e $\rho_{I}=0,15$. Tem-se, ainda, que o viés de $i c c$ é sempre menor que o viés de $r_{I}$, para os três valores de $n$.

Para $n=15$ e 30 , os valores do viés de $r_{I}$ e $i c c$ parecem depender de $\rho_{I}$. As figuras 11 a e $11 \mathrm{~b}$ apontam para a ocorrência de valores menores do viés de $r_{I}$ e de icc, para valores extremos de $\rho_{1}$ (próximos de 0 e de 0,9 ). Para $n=45$ os viéses dos estimadores parecem não depender de $\rho_{l}$. 


\section{Avaliação do viés de $r_{I}$ e de icc}

Se os estimadores fossem não viesados, a razão entre o estimador e o parâmetro seria igual a um. Assim, calculou-se o quociente entre o viés de cada estimador e o valor do parâmetro, para $n=15,30$ e 45 . As figuras $10 \mathrm{a}$, 10b e $10 \mathrm{c}$ apresentam os quocientes, segundo a correlação pré fixada.

Observa-se que o tamanho da amostra parece influir no viés dos estimadores e, ainda que, à medida que $n$ aumenta, o quociente entre o estimador e o parâmetro parece se "estabilizar" mais rápido para icc do que para $r_{r}$.

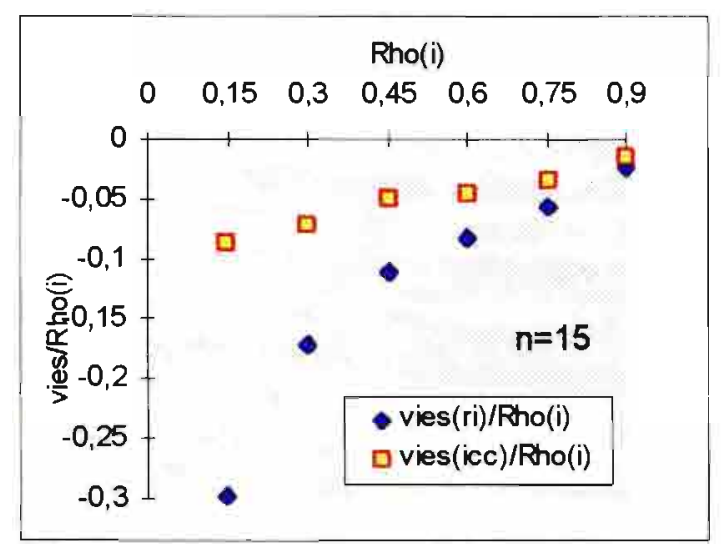

$10 \mathbf{a}(n=15)$

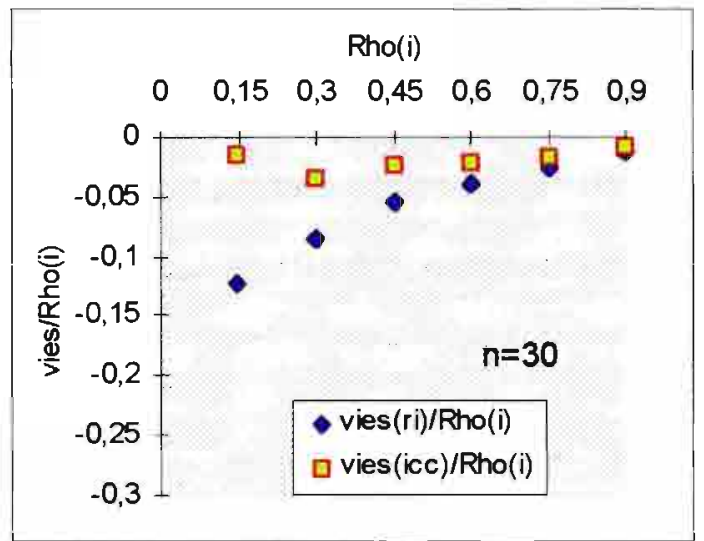

$10 \mathrm{~b}(n=30)$

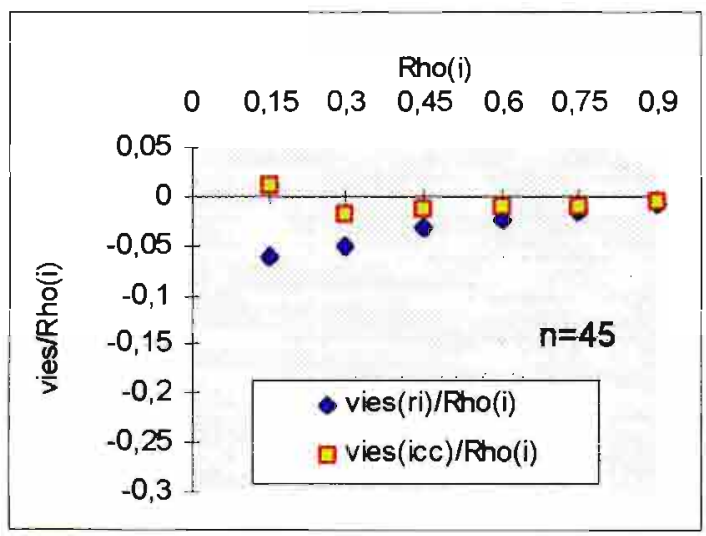

$10 \mathrm{c}(n=45)$ 


\section{4 - Erro Quadrático Médio de $r_{I}$ e de icc}

Os erros quadráticos médios de $r_{I}$ (eqmri) e de icc (eqmicc) são apresentados no Anexo 10 e figuras $11 \mathrm{a}, 11 \mathrm{~b}$ e $11 \mathrm{c}$.

Observa-se que o erro quadrático médio de $r_{l}$ é sempre maior que o erro quadrático médio de icc. Para $r_{l}$ os erros quadráticos médios variam entre 0,00100 e 0,06563 , para $n=45$ e $\rho_{I}=0,9$ e $n=15$ e $\rho_{I}=0,15$, respectivamente. Observa-se, para icc, que os erros quadráticos médios variam entre 0,00094 e 0,0011 , para $n=45$ e $\rho_{l}=0,9$ e $n=15$ e $\rho_{I}=0,15$, respectivamente.

Observa-se que os valores dos erros quadráticos médios de $r_{I}$ e de icc são iguais até a segunda casa decimal, para $n=15$ e $\rho_{I} \leq 0,75$, para $n=30$ e $0,3 \leq \rho_{I} \leq 0,6$ e $n=45$ e $\rho_{I} \geq 0,15$. Esta igualdade dos valores dos erros quadráticos médios ocorre até a terceira casa decimal para $n=15$ e $\rho_{I}=0,9$; para $n=30$ e $\rho_{I}=0 ; 0,15 ; 0,75$ e 0,9 ; para valores de $n=45$ e valores de $\rho_{I}=0 ; 0,30 ; 0,45 ; 0,60 ; 0,75$ e 0,90 .

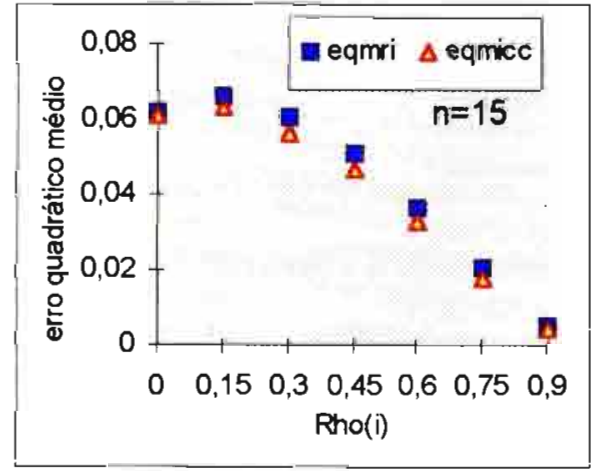

$11 \mathrm{a}(n=15)$

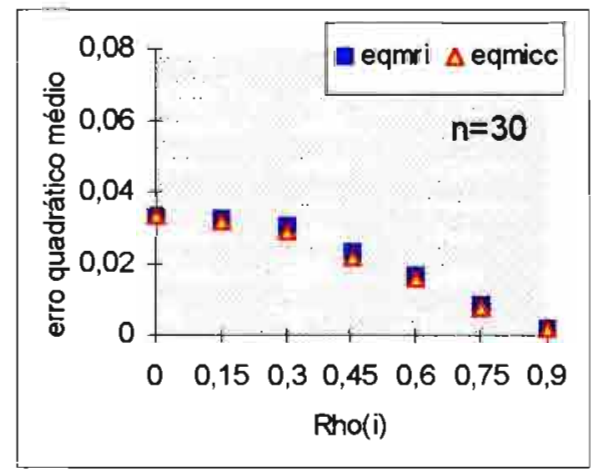

$11 \mathrm{~b}(n=30)$ 


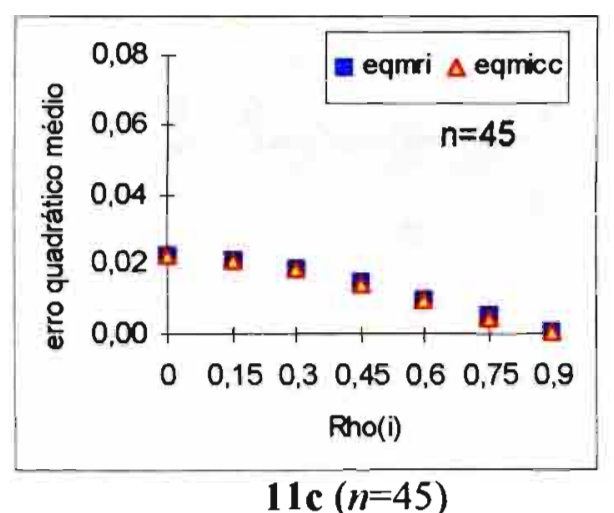

Figuras $11 \mathrm{a}, 11 \mathrm{~b}$ e $11 \mathrm{c}$ - Simulação de 2.000 amostras de tamanho $n=15,30$ e 45 e coeficientes de correlação intraclasse $\rho_{I}=\{0 ; 0,15 ; 0,30 ; 0,45 ; 0,60 ; 0,75 ; 0,9\}$.

Valores dos erros quadráticos médios de $r_{I}$ (eqmri) e de icc (eqmicc)

Os valores do erro quadrático médio para ambos os estimadores parecem depender dos valores de $n$ e $\rho_{I}$. Para $n=15$, e $\rho_{I} \leq 0,45$ observam-se valores próximos a 0,1 . Estes valores diminuem conforme $\rho_{l}$ aumenta.

Para $n \geq 30$, os erros quadráticos médios apresentam um padrão de queda mais suave se comparado com $n=15$. Para $n=45$, os valores dos erros quadráticos médios para ambos os estimadores são muito semelhantes e apresentam magnitudes menores para maiores valores de $\rho_{I}$.

As diferenças entre os erros quadráticos médios de icc e de $r_{I}$ são sempre positivas. A maior diferença é observada para $n=15$ e $\rho_{l}=0,45$. Para $n=15$, as diferenças dos erros quadráticos médios são maiores para valores de $\rho_{l}$ ao redor de 0,45 , apresentando um padrão bastante homogêneo de aumento, até o valor de $\rho_{l}=0,45 \mathrm{e}$ posterior queda, a partir deste valor. Conforme $n$ aumenta, a queda dos valores segundo $\rho_{I}$ fica mais suave. 


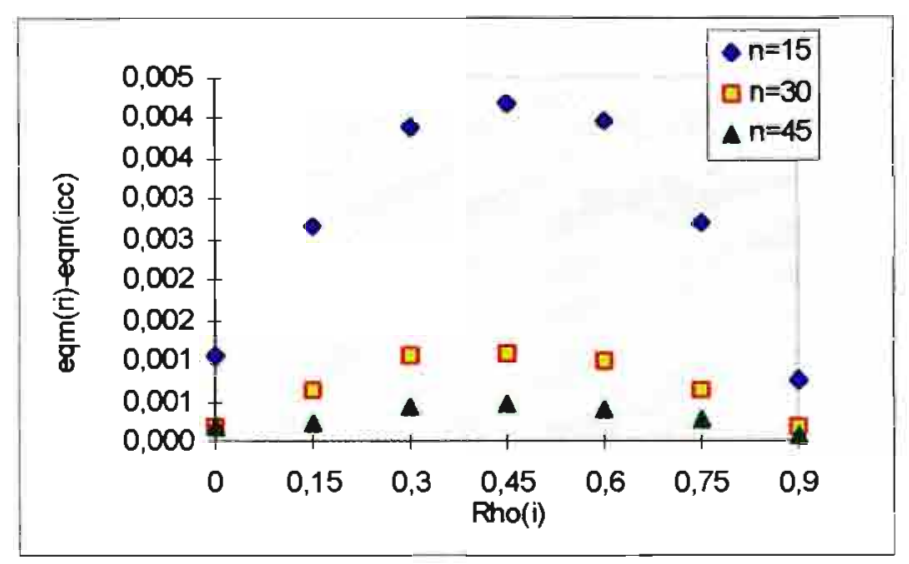

Figura 12 -Simulação de 2.000 amostras de tamanho $n=15,30$ e 45 e coeficientes de correlação intraclasse $\rho_{I}=\{0 ; 0,15 ; 0,30 ; 0,45 ; 0,60 ; 0,75 ; 0,9\}$.

Diferença entre os erros quadráticos médios de $r_{l}$ (eqmri) e de icc (eqmicc)

\section{Eficiência de icc}

A eficiência relativa de $i c c$ é dada pelo quociente entre o erro quadrático médio de $r_{I}$ e o erro quadrático médio de icc, como realizado por Donner (1980). Os valores da eficiência relativa são apresentados no Anexo 11 e na figura 13.

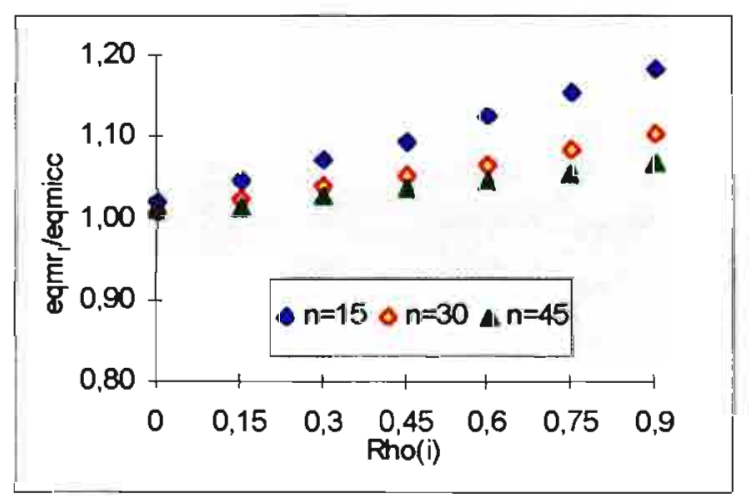

Figura 13 - Simulação de 2.000 amostras de tamanho $n=10,20,30$ e 40 e coeficientes de correlação intraclasse $\rho_{I}=\{0 ; 0,15 ; 0,30 ; 0,45 ; 0,60 ; 0,75 ; 0,9\}$. Valores do quociente entre o erro quadrático médio de $r_{I}$ (eqmri) e do erro quadrático médio de icc (eqmicc)

A eficiência relativa de icc (eqmri/eqmicc) é sempre maior do que o valor 1 , dado que o erro quadrático médio de icc é sempre menor que o erro quadrático médio de $r_{I}$. Para $n=30$ e 45 , observa-se uma eficiência relativa de icc bastante semelhante, que 
aumenta para valores maiores da correlação intraclasse. A figura apresentada sugere que para $n=15$, a eficiência de icc possui um aumento relativo mais rápido se comparada com $n=30$ e 45 .

\section{5 - ESTIMAC̣Ão de $\rho_{I}$ POR INTERVAlo}

\section{Amplitude média dos intervalos}

As amplitudes médias dos intervalos de confiança de $95 \%$ para $\rho_{I}$ foram obtidas calculando-se a média das diferenças entre os limites superior e inferior dos intervalos calculados para cada uma das 2.000 amostras, para $r_{I}$ e icc, respectivamente. Os resultados são apresentados nas figuras $14 \mathrm{a}$ e 14b, e no Anexo 12.

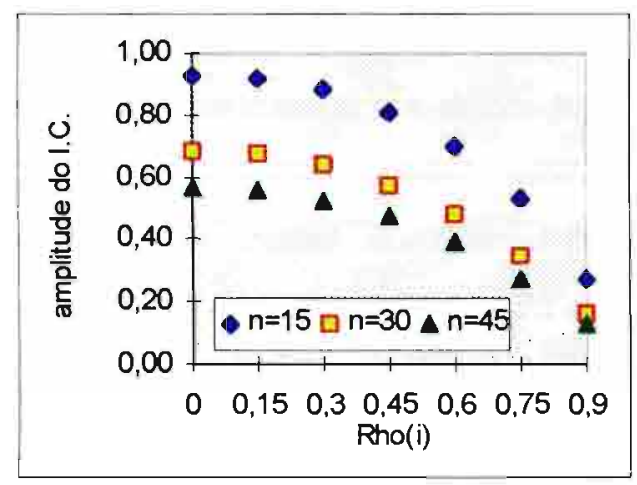

$14 a\left(r_{l}\right)$

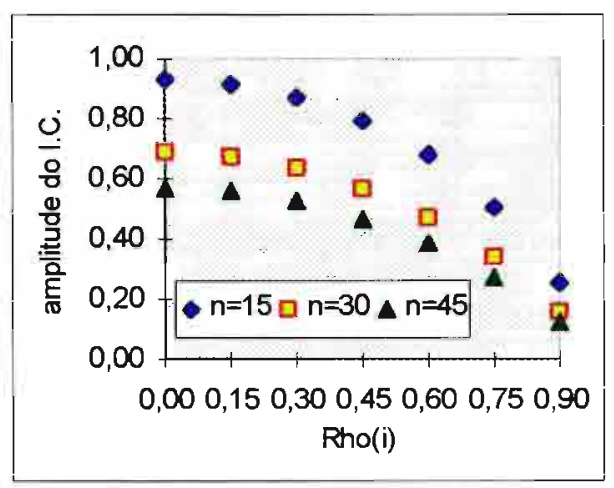

$14 \mathrm{~b}(\mathrm{icc})$

Figuras 14a e 14b - Simulação de 2.000 amostras de tamanho $n=15,30$ e 45 e coeficientes de correlação intraclasse $\rho_{I}=\{0 ; 0,15 ; 0,30 ; 0,45 ; 0,60 ; 0,75 ; 0,90\}$. Valores das amplitudes médias dos intervalos de confiança de $95 \%$ de $\rho_{I}$, estimados por $r_{I}$ e de icc

Observa-se que para todos os valores de $\rho_{I}$, exceto $\rho_{I}=0$, as amplitudes dos intervalos de classe são maiores quando estimadas por $r_{l}$. A ocorrência da maior amplitude média é observada quando $n=15$ e $\rho_{I}=0$ (para $r_{I}$, é de 0,928 e para $i c c$, é de 0,933 ). O valor mínimo da amplitude média, estimada por $r_{I}$ e $i c c$, ocorreu para $n=45$ e $\rho_{I}=0,9$ (apresentando os valores de 0,124 e 0,121, respectivamente). 
A figura 15 apresenta as diferenças entre as amplitudes médias para $n=15,30 \mathrm{e}$ 45. Observa-se que as diferenças dependem dos valores da correlação intraclasse, atingindo um máximo para $\rho_{I}=0,60$, para $n=30$ e 45 ; e $\rho_{I}=0,75$ para $n=15$.

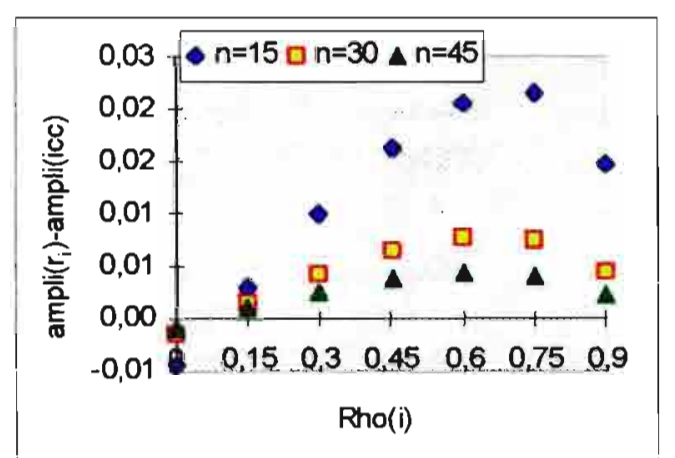

Figura 15 - Simulação de 2.000 amostras de tamanho $n=15,30$ e 45 e coeficientes de correlação intraclasse $\rho_{I}=\{0 ; 0,15 ; 0,30 ; 0,45 ; 0,60 ; 0,75 ; 0,90\}$. Diferença entre os valores das amplitudes médias dos intervalos de confiança de $95 \%$ de $\rho_{I}$, estimados por $r_{I}$ e de icc

\section{Intervalos de confiança de $95 \%$ para $\rho_{I}$}

Após a construção dos intervalos de confiança utilizando-se cada estimador, realizou-se a contagem do número de vezes que os intervalos de confiança abrangem o parâmetro. Os dados são apresentados nas figuras 16a, 16b e 16c e no Anexo 13.

Como esperado, perto de $95 \%$ dos intervalos abrangiam o parâmetro. Pode-se inferir, com base nesta observação, que os pares de valores foram gerados segundo um bom gerador.

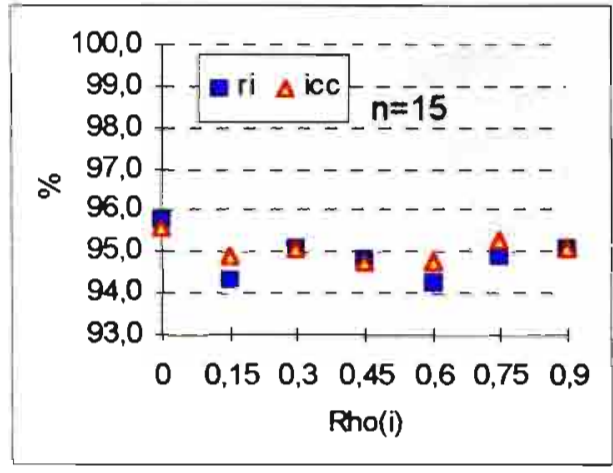

16a $(n=15)$

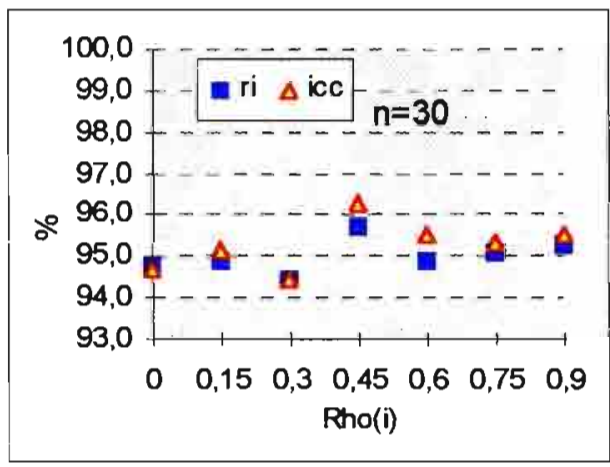

$16 \mathrm{~b}(n=30)$ 


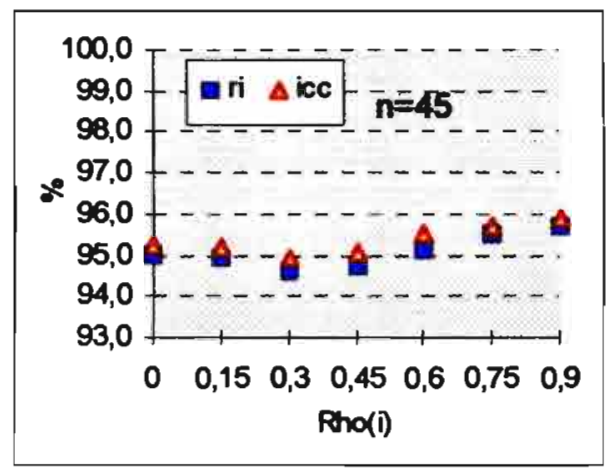

$16 c(n=45)$

Figuras 16a, 16b e 16c - Simulação de 2.000 amostras de tamanho $n=15,30$ e 45 e coeficientes de correlação intraclasse $\rho_{I}=\{0 ; 0,15 ; 0,30 ; 0,45 ; 0,60 ; 0,75 ; 0,90\}$. Percentual de vezes em que o parâmetro $\left(\rho_{1}\right)$ está contido no intervalo de confiança de $95 \%$.

Os quadros 3 e 4 apresentam um resumo das características dos parâmetros e dos estimadores a partir do estudo Monte Carlo 
Quadro 3 - Características teóricas dos parâmetros

Caracterís- Correlação intraclasse de Pearson para ticas

Modelo

$$
\text { "modelo" de correlação usual }
$$

mede a correlação entre observações de uma mesma classe. É calculada aplicando-se a correlação usual de Pearson, para o conjunto de pares repetidos
Parâmetro

$$
\rho_{I}=\frac{\operatorname{Cov}(X, Y)}{\sigma_{X} \sigma_{Y}}
$$

$$
\rho_{I}=\frac{\sigma_{a}^{2}}{\sigma_{a}^{2}+\sigma_{e}^{2}}
$$

Limites de variação

$$
\frac{-1}{(n-1)}<\rho_{I}<+1 \quad 0<\rho_{I}<+1
$$

$$
\sum_{i=I}^{k} \sum_{j, h=I}^{2}\left(y_{i j}-\bar{Y}\right)\left(y_{i h}-\bar{Y}\right)
$$

Estimador

$$
r_{I}=\frac{h \neq j}{\sum_{i=1}^{k}\left(n_{i}-I\right) \sum_{i=I}^{2}\left(y_{i j}-\bar{Y}\right)^{2}}
$$

$$
i c c=\frac{Q M A-Q M R}{Q M A+(n-1) Q M R}
$$

$$
\text { (viesado) }
$$

(viesado)

Intervalo de Confiança (I.C.) primeiramente faz-se a transformação de $r$ em $z$; calcula-se o I.C. para $Z$ e, a partir deste, o I.C. para $\rho_{I}$

$$
\begin{aligned}
& \text { I.C. para } Z \\
& \underbrace{\left[z_{I}-V_{\alpha / 2} \hat{\sigma}_{z_{J}}\right.}_{z(\text { inf })} ; \underbrace{\left.z_{I}+V_{\alpha / 2} \hat{\sigma}_{z_{J}}\right]}_{z \text { (sup) }} \\
& {\left[\frac{e^{2 z(\mathrm{inf})}-1}{e^{2 z(\mathrm{inf})}+1} \cdot \frac{e^{2 z(\mathrm{sup})}-1}{e^{2 z(\mathrm{sup})}+1}\right]}
\end{aligned}
$$

Correlação intraclasse como função de

$$
x_{i j}=\mu+a_{i}+e_{i j}
$$

$\left\{a_{i}\right\} \sim$ média 0 e variância $\sigma_{a}^{2}$

$\left\{e_{i j}\right\} \sim$ média 0 e variância $\sigma_{e}^{2}$

$\left\{a_{i}\right\}$ e $\left\{e_{i j}\right\}$ são independentes

$\operatorname{Var}\left(x_{i j}\right)=\sigma_{x}^{2}=\sigma_{a}^{2}+\sigma_{e}^{2}$

mede o quanto da variação total é devida à variação entre classes 
Quadro 4 - Características empíricas dos estimadores a partir da simulação de 2.000 amostras de pares correlacionados segundo coeficientes de correlação intraclasse e tamanho de amostras fixadas

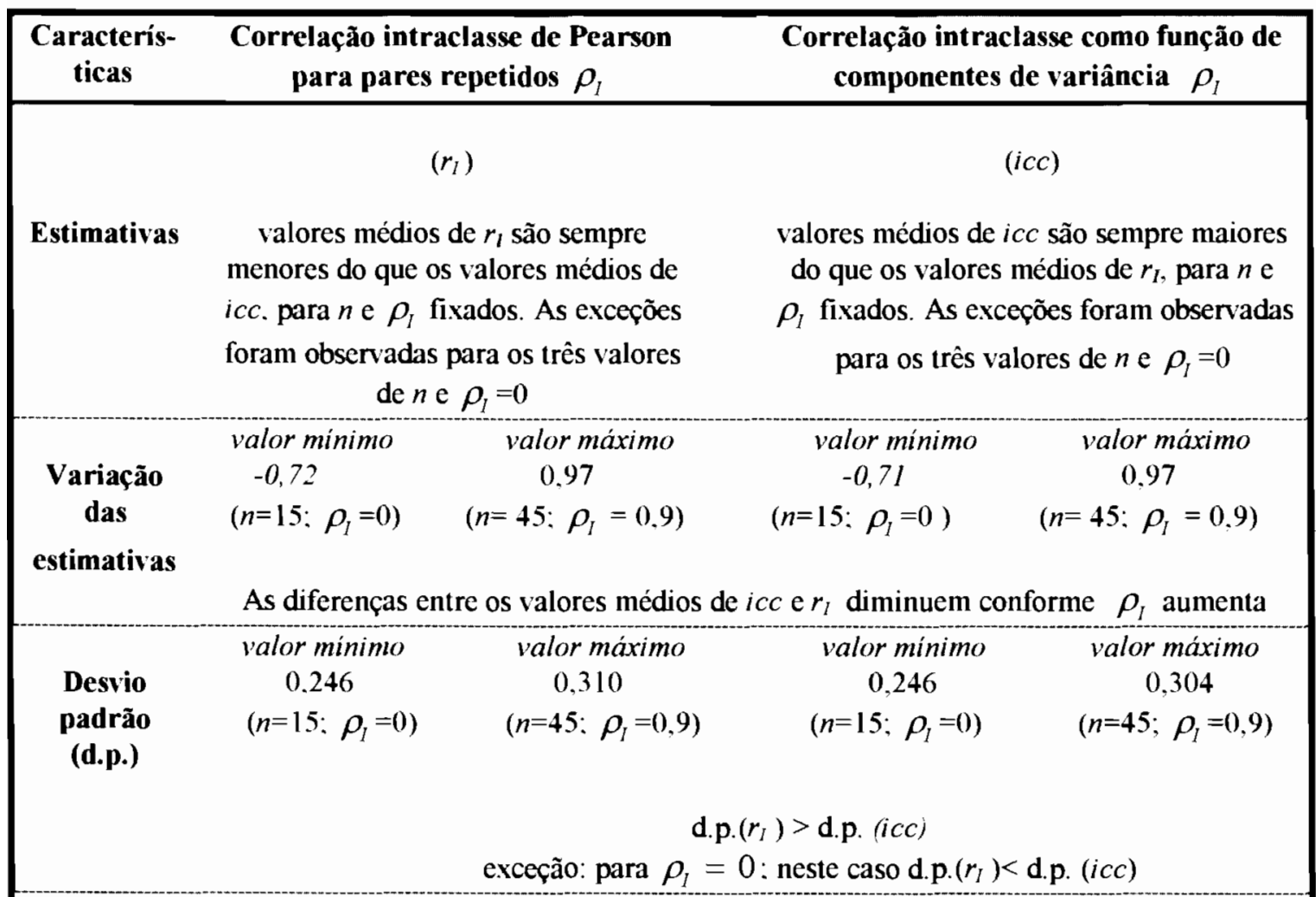

viéses de $r_{I}$ e de icc são, em quase sua totalidade, negativos.

Viés

O viés de icc é sempre menor que o viés de $r_{l}$, para os três valores de $n$.

O tamanho da amostra parece influir no viés dos estimadores. 
continuação

\begin{tabular}{|c|c|c|}
\hline \multirow{3}{*}{$\begin{array}{l}\text { Erro } \\
\text { quadrático } \\
\text { médio } \\
\text { (eqm) }\end{array}$} & \multicolumn{2}{|c|}{ O erro quadrático médio de $r_{I}$ é sempre maior que o erro quadrático médio de icc. } \\
\hline & $\begin{array}{cc}\begin{array}{c}\text { valor minimo } \\
0.00100\end{array} & \text { valor máximo } \\
\left(n=45 ; \rho_{I}=0.9\right) & \left(n=15 ; \rho_{I}=0.15\right)\end{array}$ & $\begin{array}{cc}\text { valor mínimo } & \text { valor máximo } \\
0,00094 & 0,0011 \\
\left(n=45 ; \rho_{I}=0,9\right) & \left(n=15 ; \rho_{I}=0,15\right)\end{array}$ \\
\hline & \multicolumn{2}{|c|}{$\begin{array}{l}\text { A igualdade dos valores dos erros quadráticos médios ocorre até a terceira casa decimal } \\
\text { para } n=15 \text { e } \rho_{I}=0,9 ; \text { para } n=30 \text { e } \rho_{I}=0 ; 0,15 ; 0,75 \text { e } 0,9 ; \text { para valores de } n=45 \\
\text { e valores de } \rho_{l}=0 ; 0,30 ; 0,45 ; 0,60 ; 0,75 \text { e } 0,90\end{array}$} \\
\hline Eficiência & \multicolumn{2}{|c|}{$\begin{array}{l}\text { Para } n=30 \text { e } 45 \text {. observa-se uma eficiência relativa de } i c c \text { bastante semelhante, que } \\
\text { aumenta para valores maiores da correlação intraclasse. Para } n=15 \text {, a eficiência de } i c c \\
\text { possui um aumento relativo mais rápido se comparada com } n=30 \text { e } 45 \text {. }\end{array}$} \\
\hline \multirow{2}{*}{$\begin{array}{l}\text { Intervalo } \\
\text { de } \\
\text { Confianca } \\
\text { (I.C) }\end{array}$} & \multicolumn{2}{|c|}{$\begin{array}{c}\text { Para todos os valores de } \rho_{I} \text {, exceto } \rho_{I}=0 \text {, as amplitudes dos intervalos de classe são } \\
\text { maiores para a correlação intraclasse de Pearson para pares repetidos }\end{array}$} \\
\hline & $\begin{array}{l}\text { A maior amplitude média é igual a } 0,928 \text { e } \\
\qquad \text { ocorre para } n=15 \text { e } \rho_{I}=0 \\
\text { O valor mínimo da amplitude média é igual } \\
\qquad \text { a } 0,124 \text { para } n=45 \text { e } \rho_{I}=0,9\end{array}$ & $\begin{array}{l}\text { A maior amplitude média é igual a } \\
0.933 \text { e ocorre para } n=15 \text { e } \rho_{I}=0 \\
\text { O valor mínimo da amplitude média é } \\
\text { igual a } 0.121 \text { para } n=45 \text { e } \rho_{I}=0.9 \text {. }\end{array}$ \\
\hline
\end{tabular}




\section{5 - DISCUSSÃo}

\section{Estudo de simulação Monte Carlo}

O gerador de números pseudo-aleatórios do programa de análise estatística STATA, segundo avaliação contida no presente estudo, demostrou ser bastante confiável. Testou-se, assim, a distribuição dos valores gerados, não rejeitando-se a hipótese de normalidade dos valores gerados (Anexo 8).

\section{Valores de $r_{I}$ e icc}

Para uma dada configuração ( $n$ e $\rho_{I}$ fixados), os valores gerados dos estimadores $r_{I}$ e icc não são iguais aos parâmetros, como esperado, dado que ambos são viciados (Fisher 1925).

Os valores médios de $i c c$ são maiores que os valores médios de $r_{l}$. A exceção ocorre para $\rho_{I}=0$. Este achado está em concordância com os resultados de Alexander (1946).

A diferença entre os estimadores diminui com o aumento de $n$ e $\rho_{I}$. Para $\mathrm{n}=30$ e 45 e $\rho_{I} \geq 0,90$, os valores médios de $r_{l}$ e $i c c$ se igualam até a segunda casa decimal.

\section{Viés de $r_{I}$ e icc}

Ambos os estimadores são viciados e possuem vícios negativos e com magnitudes diferentes, sendo que os vícios de $i c c$ são sempre menores que os vícios de $r_{I}$. Este resultado era esperado, tendo sido descrito por Fisher (1925).

Para $n=15$ e 30 , os valores do viés de $r_{l}$ e icc parecem depender de $\rho_{l}$. As figuras 11 a e 11b apontam para a ocorrência de valores menores do viés de $r_{l}$ e de icc, 
para valores extremos de $\rho_{l}$ (próximos de 0 e de 0,9 ). Para $n=45$ os viesses dos estimadores parecem não depender de $\rho_{l}$.

\section{Erro quadrático médio de $r_{I}$ e icc}

Os erros quadráticos médios de $i c c$ são sempre menores que os erros quadráticos médios de $r_{\boldsymbol{I}}$. A magnitude dos erros quadráticos médios de ambos os estimadores diminui conforme $n$ e $\rho_{I}$ aumentam.

Para $n=15$, a queda na magnitude do erro quadrático médio segundo $\rho_{I}$ é mais rápida para icc do que para $r_{l}$, quando comparada com as amostras de tamanho 30 e 45 . Isto indica que para tamanhos pequenos de amostra a utilização de icc é mais indicada, sob o ponto de vista da magnitude do erro.

\section{Eficiência de icc}

A eficiência relativa de icc (quociente entre o erro quadrático médio de $r_{I}$ e o erro quadrático médio de $i c c$ ) é sempre maior do que o valor 1 , dado que o erro quadrático médio de icc é sempre menor que o erro quadrático médio de $r_{I}$ Para $n=30$ e 45, observase uma eficiência relativa de icc bastante semelhante, que aumenta para valores maiores da correlação intraclasse.

\section{Amplitudes dos intervalos de confiança estimados por $\boldsymbol{r}_{I}$ e $i c c$}

Os intervalos de confiança de $95 \%$ para $\rho_{I}$, estimados por icc, revelaram possuir menor amplitude, quando se realiza a comparação com as amplitude médias dos intervalos estimados por $\boldsymbol{r}_{\boldsymbol{I}}$. 


\section{6 - Conclusões}

i) Pelo estudo Monte Carlo tem-se que os vícios dos estimadores ( $r_{I}$ e icc ) não são iguais, sendo que icc apresenta vícios menores que os vícios de $r_{I}$, para $n$ e $\rho_{I}$ fixados;

ii) os erros quadráticos médios de icc são sempre menores que os de $r_{I}$. A diferença entre os erros quadráticos médios diminui conforme $n$ e $\rho_{I}$ aumentam. Para tamanho de amostra grande ( $n$ igual ou maior que 40) os erros são praticamente iguais até a terceira casa decimal;

iii) os intervalos de confiança para a correlação intraclasse como função de componentes de variância possuem amplitudes menores do que os intervalos de confiança para a correlação intraclasse de Pearson para pares repetidos.

iv) a eficiência relativa de icc aumenta com o aumento da correlação intraclasse. A eficiência relativa de $i c c$ é semelhante quando o tamanho da amostra é grande ( $n$ igual ou maior que 30). É para valores pequenos de amostra ( $n$ igual ou menor que 15 ) que a eficiência relativa de $i c c$ é melhor.

v) o estimador icc é o melhor estimador da correlação intraclasse, se comparado com $r_{l}$, principalmente para valores de pequenos de tamanho de amostra ( $n$ igual ou menor que 15).

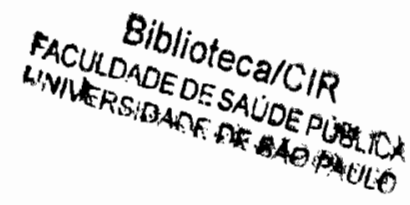




\section{REFERÊNCIAS BIBLIOGRÁFICAS}

Alexander HW. The estimation of reliability when several trials are available. Psychometrika 1946; 12: 79-99

Bartko JJ. The intraclass correlation coefficient as a measure of reliability. Psychol Rep 1966; 19: 3-11

Bussab WO, Morettin PA. Métodos quantitativos: estatística básica. $4^{\text {a }}$ edição. São Paulo: Atual Editora; 1994.

Burt C. Test reliability estimated by analysis of variance. Br J Statist Psychol 1955; 3: 103 -18 .

Carmines EG, Zeller RA. Reliability and validity assessment. Beverly Hills: SAGE Publications; 1979.

Caulcutt R, Boddy R. Statistics for analytical chemists. London: Chapman \& Hall; 1983.

Ching TH. Coeficiente de correlação intraclasse: planejamento com alocação ótima e aplicação no estudo de confiabilidade de medidas. São Paulo; 1995. [Dissertação de Mestrado - Istituto de Matemática e Estatística/USP].

Cochran WG. Errors of measurement in statistics. Technometrics; 1968; 10(4):637-665.

Dachs JNW. Estatística computacional: uma introdução em turbo pascal. Rio de Janeiro: Livros Técnicos e Científicos; 1988.

Donner A, Koval JJ. The estimation of intraclass correlation in the analysis of family data. Biometrics 1980; 36: 19-25.

Donner A. A review of inference procedures for the intraclass correlation coefficient in the one-way randon effects model. Int Stat Rev 1986; 54: 67-82.

Douglass CW. Evaluating diagnostic tests. Adv Dent Res 1993; 7 (2): 66-9.

Dunn G. Design and analysis of reliability studies. The statistical evaluation of measurement errors. $2^{\text {nd }} \mathrm{ed}$, London: Edward Arnold; 1992.

Fisher LD, Van Belle G. Biostatistics: a methodology for the health sciences. New York: John Wiley \& Sons; 1993. 
Fisher RA. Statistical methods for research workers. London: Oliver and Boyd; 1925.

Fleiss JL. The design and analysis of clinical experiments. Londosn: John Wiley \& Sons; 1986 .

Fletcher HR, Fletcher WS, Wagner HE. Epidemiologia clínica. $2^{\circ}$ edição, Porto Alegre: Artes Médicas; 1991.

Gimeno SGA, Souza JMP. Reprodutibilidade de informaçôes em estudo de fatores de risco para o diabetes mellitus insulino-dependente. Rev Saúde Pública 1997; 31: 508-11.

Karlin S, Cameron PE, Willians P. Sibling and parent-offspring correlation estimation with variable familiy age. Proc Nat Acad Sci USA 1981; 61: 302-15.

Keen KJ. Limiting the effects of single-member families in the estimation of the intraclass correlation. Biometrics 1996; 52: 823-32.

Kendall M, Stuart A. The advanced theory of statistics. Inference and relationship. $3^{\text {td }}$ ed. London: Griffin; 1947.

Khuri AI, Sahai H. Variance components analysis: a selective literature survey. Int Stat Rev $1985 ; 53: 279-300$.

Mood AM, Graybill FA, Boes DC. Introduction to the theory of statisties. $3^{\text {rd }}$ ed. Singapura: McGraw-Hill International Editions; 1974.

Moraes SA, Souza JMP. Reprodutibilidade dos valores glicêmicos em testes orais de tolerância à glicose e testes de tolerância a carboidratos. Rev. Bras. Medicina 1998; 55 : 887-94.

Neter J,WassermanW, Kutner MH. Applied linear statistical models: regression, analysis of variance, and experimental designs. $2^{\text {nd }}$ ed. New York: IRWIN; 1988.

Peres C A, Ching TH. Coeficiente de correlação intraclasse como medida de confiabilidade. In: Livro de Atas do $11^{\circ}$ SINAPE - Simpósio Nacional de Probabilidade e Estatística, Belo Horizonte. Universidade Federal de Minas Gerais - Departamento de Estatística. 1994; 114-9.s

Searle SR. Linear models. New York: John Wiley \& Sons; 1971.

Searle SR, Casella G, McCulloch CE. Variance components. New York: John Wiley \& Sons; 1992. 
Searle SR. Linear models. New York: John Wiley \& Sons; 1971.

Searle SR, Casella G, McCulloch CE. Variance components. New York: John Wiley \& Sons; 1992.

Silva NN. Amostragem probabilística. São Paulo: Edusp; 1998.

Snedecor GW, Cochran WG. Statistical methods. $6^{\text {th }}$ ed. Ames: The Iowa State University Press; 1967

Stamato JJ. Escolha de multiplicadores, através de testes estatísticos para a geração de números ao acaso em computadores eletrônicos. Ribeirão Preto; 1973. [Tese de doutorado. Ribeirão Preto/USP].

STATACORP. Stata statistical software: release 5.0 [computer program]. College Station: Stata Corporation; 1996.

Stigler SM. The history of statistics. The measurement of uncertainty before $1900.6^{\text {th }}$ ed. Cambridge (Mass): The Belknap Press of Harvard University Press; 1995.

Swallow WH, Monahan JF. Monte-Carlo comparison of ANOVA, MIVQUE, REML and ML estimators of variance components. Technometrics 1984; 26: 47-57.

Zar JH. Biostatistical analysis. $3^{\text {rd }}$ ed. Upper Saddle River, New Jersey: Prentice-Hall; 1996. 


\section{ANEXo 1 \\ DEFINIÇÃO DE ERRO, VÍCIO E ERRO QUADRÁTICO MÉDIO}

Erro

Considere-se um experimento onde é de interesse a obtenção da medida de comprimento de uma determinada caneta, utilizando-se um determinado instrumento de medida, em um determinado momento.

Seja, então,

$x$ - a observação obtida para a caneta;

$T$ - o "verdadeiro" valor do comprimento da caneta; $\mathrm{e}$

$e$ - o erro de mensuração associado à observação $x$

Estas quantidades estão relacionadas segundo as equações

$x=T \cdot e$ ou

$e=x-T$

sendo esta a equação que fornece a definição formal do erro de uma única observação.

Considerando-se observações repetidas para uma mesma caneta e um único instrumento de medida, têm-se os seguintes corolários, quando o número de observações repetidas, representado por $m$, para $m=1, \ldots, k$, aumenta (Burt C 1955)

i) o valor médio dos erros aleatórios tende para zero; matematicamente,

$$
\underset{k}{E}\left(e_{k}\right) \equiv \frac{1}{m} \sum_{k=1}^{m} e_{k} \rightarrow 0 ;
$$

ii) o valor esperado de uma observação tende para o valor médio $\left(\bar{x}=\sum_{k=1}^{m} x_{k}\right)$, que tende para o verdadeiro valor da medida; matematicamente,

$$
\underset{\mathrm{k}}{E}(x) \equiv \bar{x} \rightarrow T
$$

iii) os erros são independentes entre si, a covariància tende para zero; matematicamente,

$$
r_{e_{j} e_{j}} \equiv \underset{k}{E}\left(e_{j k} e_{j^{\prime} k}\right) \rightarrow 0
$$

v) a distribuição do erro tende para a distribuição Normal 
Vício

Parâmetro é o verdadeiro valor de uma característica de interesse, medida na população, e de forma geral, é raramente conhecido. O estimador é a medida estatística que descreve o parâmetro, em termos amostrais (Bussab WO, Morettin PA 1994).

Considere-se uma amostra $\left(X_{1}, X_{2}, \ldots, X_{n}\right)$ de uma variável aleatória que descreve uma característica de interesse de uma população. Seja $\theta$ um parâmetro que se deseja estimar.

Definição: Um estimador do parâmetro $\theta$ é qualquer função das observações $X_{1}, X_{2,}, \ldots, X_{n}$.

Definição: Seja $T=g\left(X_{1}, X_{2}, \ldots, X_{n}\right)$ um estimador de $\theta$; o estimador $T$ é dito estimador não viciado de $\theta$ se $E(T)=\theta$, para todo $\theta$.

$\mathrm{O}$ vício (ou viés) é dado por

$$
\text { Viés }=E(T)-\theta
$$

e indica a diferença entre a média do estimador e o parâmetro que se quer estimar.

\section{Erro Quadrático Médio}

Definição: Chama-se de erro quadrático médio (EQM) o valor

$$
\operatorname{EQM}(T)=E\left(e^{2}\right)=E(T-\theta)^{2}
$$

desta última equação tem-se

$$
\begin{aligned}
E Q M(T) & =E(T-\theta)^{2}=E(T-E(T)+E(T)-\theta)^{2} \\
& =E(T-E(T))^{2}+2 E[(T-E(T))(E(T)-\theta)]+E(E(T)-\theta)^{2}= \\
& =E(T-E(T))^{2}+E(E(T)-\theta)^{2},
\end{aligned}
$$

já que $E(T-E(T))=0$, então

$$
\begin{aligned}
& \operatorname{EQM}(T)=\operatorname{Var}(T)+\operatorname{Vies}^{2}(T) \\
& \underbrace{E[T-\theta]^{2}}_{\text {erro quadratico medio( } \mathrm{T})}=\underbrace{E[T-E(T)]^{2}}_{\text {variancia }(T)}+\underbrace{E(E(T)-\theta)^{2}}_{\text {vies }^{2}}
\end{aligned}
$$




\section{ANEXO 2}

\section{SENSIBILIDADE, ESPECIFICIDADE}

As medidas de sensibilidade e especificidade se baseiam em relações matemáticas entre as informações fornecidas por testes clínicos e laboratoriais e presença real de doença (Fletcher et al. 1991). A tabela 2.1 apresenta as relações entre os resultados de um teste (positivo ou negativo) e o diagnóstico verdadeiro (presente ou ausente).

Tabela 2.1 - Relação entre o resultado de um teste diagnóstico e a ocorrência da doença

\begin{tabular}{lcc}
\hline \multirow{2}{*}{ Teste } & \multicolumn{3}{c}{ Doença } \\
\cline { 3 - 3 } Positivo & $\mathrm{a}$ & $\mathrm{b}$ \\
Negativo & $\mathrm{c}$ & $\mathrm{d}$ \\
\hline total & $\mathrm{a}+\mathrm{c}$ & $\mathrm{d}+\mathrm{d}$ \\
\hline
\end{tabular}

Sensibilidade $(S)$ é definida como a proporção dos indivíduos com a doença que tem um teste positivo para a mesma. Utilizando-se a notação apresentada na tabela 2.1, tem-se que $S=\frac{a}{a+c}$

Especificidade $(E)$ é definida como a proporção dos indivíduos sem a doença que tem um teste negativo. Utilizando-se a notação apresentada na tabela A2.1, tem-se que $E=\frac{d}{b+d}$ 


\section{ANEXo 3}

\section{MODELO DE EFEITOS ALEATÓRIOS, PARA UM FATOR.}

O quadro 3.1 resume as características do modelo de efeitos aleatórios para um fator.

Quadro 3.1 - Caracteristicas do modelo de efeitos aleatórios para um fator.

\begin{tabular}{|cc|}
\hline Característica & Modelo de efeito aleatório \\
\hline equação do modelo & $y_{i j}=\mu+\alpha_{i}+e_{i j}$ \\
média de $\mathrm{y}_{\mathrm{ij}}$ & $E\left(y_{i j}\right)=\mu+\alpha_{i}$ \\
$E\left(y_{i j}\right)=\mu$
\end{tabular}

Fonte: Searle et al.(1992). 


\section{ANEXo 4 \\ DEFINIÇÃO DE CONFIABILIDADE EM TERMOS DE CONCORDÂNCIA}

Considerando-se que a concordância entre observações repetidas indicam a existência de confiabilidade, esta pode ser avaliada computando-se a correlação entre as duas séries de medições $\left(j\right.$ e $\left.j^{\prime}\right)$ obtidas de forma idêntica, para um instrumento especifico, utilizado sob condições experimentais idênticas (Burt C 1955). Tem-se, então

$$
r_{x^{\prime}}=\frac{\sum_{i} x_{i j} x_{i j^{\prime}}}{\sqrt{\left(\sum_{i} x_{i j}^{2} \sum_{i} x_{i j}^{2}\right.}} \text { para } i=1, \ldots, N
$$

Com base nos corolários relativos aos erros, apresentados no Anexo 1, tem-se que

$$
\sum x_{i j} x_{i j^{\prime}}=\sum\left(T_{1}+e_{i j}\right)\left(T_{1}+e_{i j^{\prime}}\right)=\sum T_{j}^{2}+\sum T_{i} e_{i j}+\sum T_{i} e_{i j^{\prime}}+\sum e_{i j} e_{i j^{\prime}}
$$

pelos corolários, quando $\mathrm{N}$ aumenta, a expressão acima tende para $\sum T_{i}^{2}$.

De forma semelhante, $\sum x_{i j}^{2} \rightarrow \sum T^{2}+\sum e_{i j}^{2}$, e $\sum x_{i j^{\prime}}^{2} \rightarrow \sum T_{i}^{2}+\sum e_{i j}^{2}$,

Pode-se ainda escrever que $\quad \sum e_{i j}^{2}=\sum e_{i i^{\prime}}^{2}=\sum e_{i}^{2}$

Com estas condições satisfeitas, pode-se escrever

$$
r_{x x^{\prime}}=\frac{\sum T_{i}^{2}}{\sum T_{i}^{2}+\sum e_{i}^{2}}=\frac{\sigma_{T}^{2}}{\sigma_{T}^{2}+\sigma_{e}^{2}}
$$




\section{ANEXo 5 \\ Correlação intraclasse de Pearson estimada pela ANOVA}

(Kendall e Stuart 1947, Dunn G 1992)

A correlação intraclasse de Pearson, para pares repetidos $\rho_{l}$ é dada por

$$
\rho_{l}=\frac{\operatorname{Cov}(X, Y)}{\sqrt{\sigma_{X}^{2}} \sqrt{\sigma_{Y}^{2}}}=\frac{\sum_{i=1}^{k} \sum_{j=1}^{n_{i}} \sum_{\substack{h=1, h \neq ., j \neq h}}^{n_{i}}\left(y_{y}-\mu\right)\left(y_{i h}-\mu\right)}{\sum_{i=1}^{k}\left(n_{i}-1\right) \sum_{j=1}^{n_{i}}\left(y_{y}-\mu\right)^{2}}
$$

que pode ser escrita como ${ }^{1}$

$$
\rho_{I}=\frac{\sum_{i=1}^{k} n_{i}^{2}\left(\mu_{i}-\mu\right)^{2}-\sum_{i=1}^{k} \sum_{j=1}^{n_{i}}\left(y_{i j}-\mu\right)^{2}}{\sum_{i=1}^{k}\left(n_{l}-1\right) \sum_{i=1}^{n_{i}}\left(y_{l j}-\mu\right)^{2}}
$$

A equação acima é formada por somas de quadrados dos desvios das observações em torno da média geral e das médias das classes em torno da média geral. Estas podem ser estimadas pela ANOVA, obtendo-se

$$
\begin{aligned}
r_{I} & =\frac{n S Q A-S Q T}{(n-1) S Q T}=\frac{n S Q A-(S Q A+S Q R)}{(n-1)(S Q A+S Q R)} \\
& =\frac{(n-1)(k-1) Q M A-k(n-1) Q M R}{(n-1)[(k-1) Q M A+k(n-1) Q M R]} \\
& =\frac{(k-1) Q M A-k Q M R}{(k-1) Q M A+k(n-1) Q M R}
\end{aligned}
$$

Sendo, a última fórmula, idêntica àquela do estimador de máxima verossimilhança da correlação intraclasse (momento produto) de Pearson, para pares repetidos.

\footnotetext{
${ }^{1}$ (o desenvolvimento de $i$ para $i i$ está apresentado na página 25 deste trabalho)
} 


\section{Anexo 6}

Equações geradoras de números pseudo-aleatórios, do gerador KISS (STATA 1996)

$$
\begin{aligned}
& x_{n}=69069 x_{n-1}+1234567 \quad \bmod 2^{32} \\
& y_{n}=y_{n-1}\left(I+L^{13}\right)\left(I+R^{17}\right)\left(I+L^{5}\right) \\
& z_{n}=65184\left(z_{n-1} \bmod 2^{16}\right)+\operatorname{int}\left(z_{n-1} / 2^{16}\right) \\
& w_{n}=63663\left(w_{n-1} \bmod 2^{16}\right)+\operatorname{int}\left(w_{n-1} / 2^{16}\right)
\end{aligned}
$$




\section{ANEXO 7}

\section{Programa computacional Para o estudo Monte Carlo}

Programa principal para $n=15$ e $\rho_{I}=0,3$ e 2.000 amostras

comandos

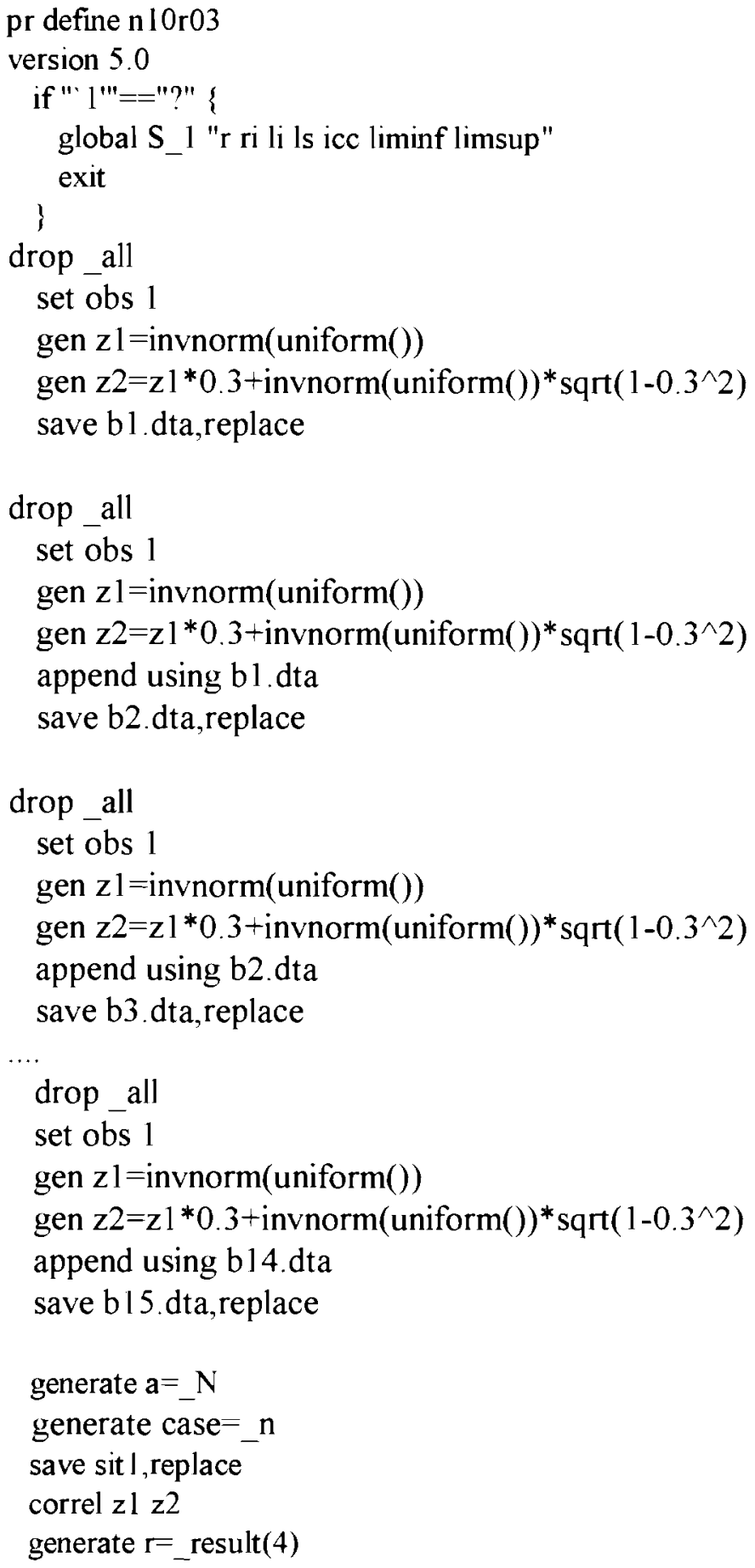

comentários

parte do programa onde os resultados são guardados para cada amostra

geração do primeiro par de valor correlacionado

geração do segundo par de valor correlacionado

geração do terceiro par de valor correlacionado

geração do décimo quinto par de valor correlacionado 
(continuação)

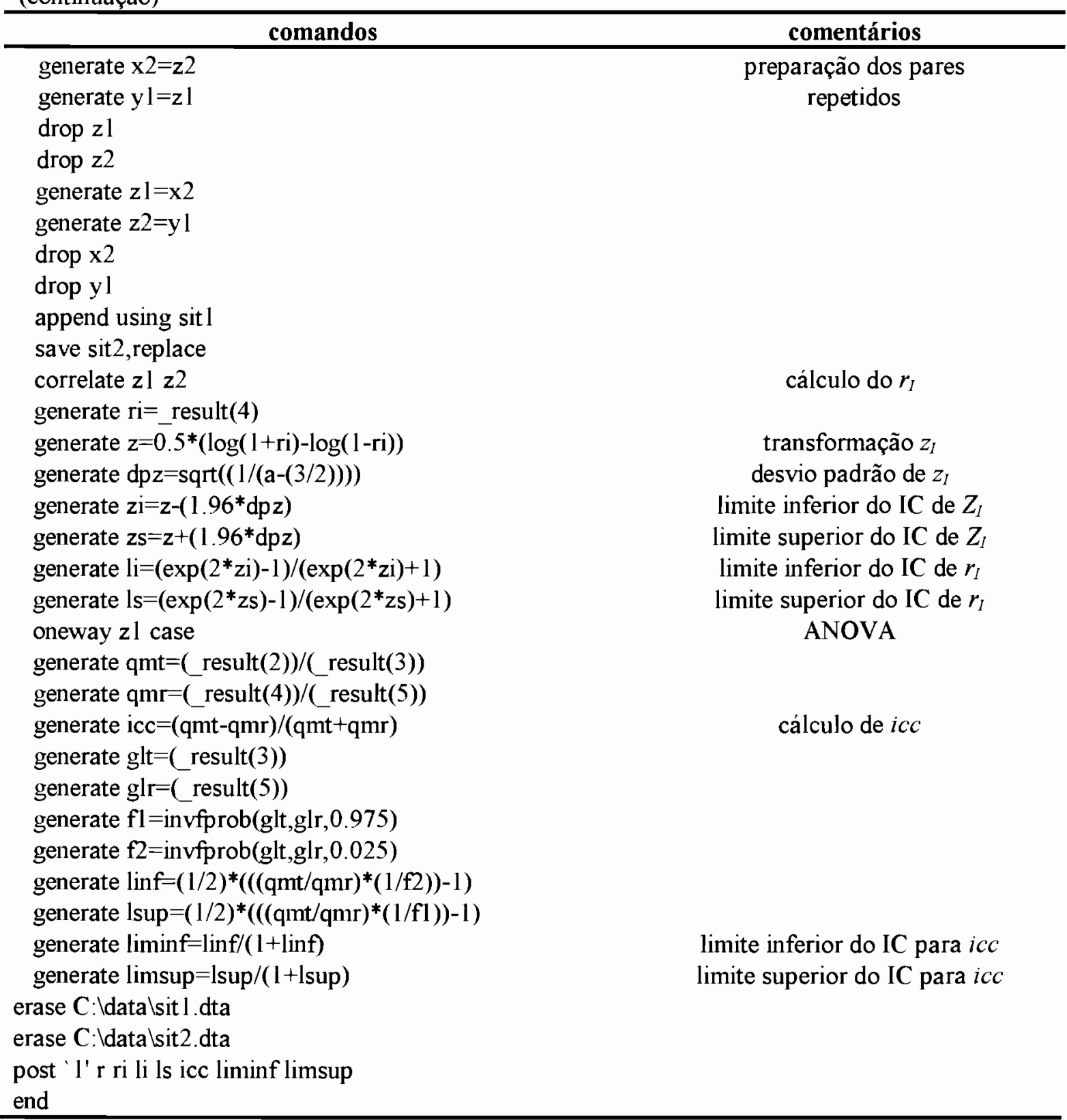


Sub-rotina CALCR para cálculo do vício e erro padrão (para $n=15$ e $\rho_{I}=0,3$ e 2.000 amostras)

comandos

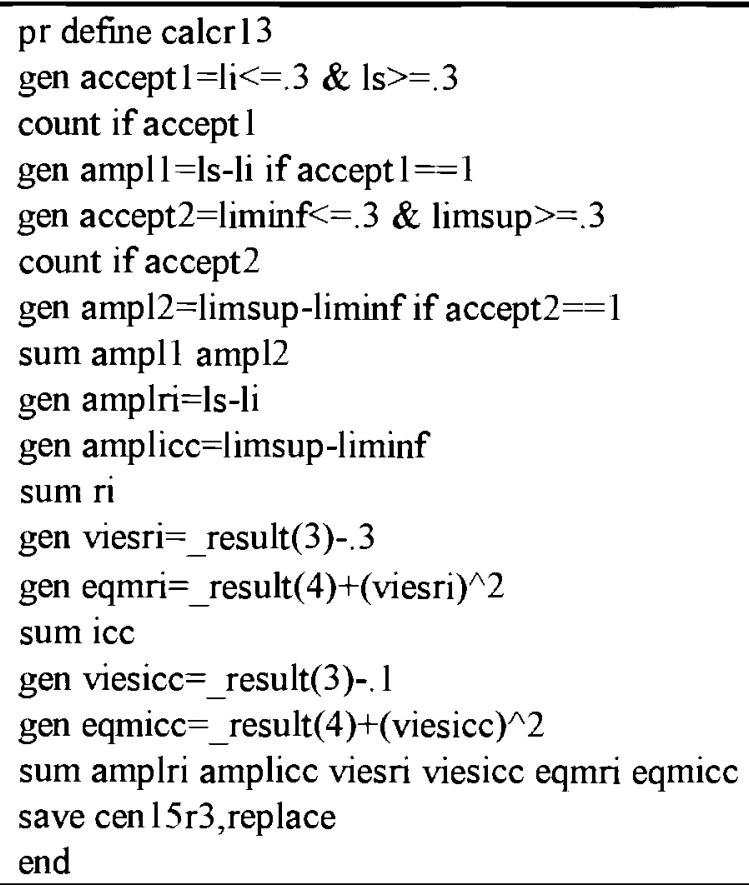

\section{comentários}

contagem do número de vezes que o intervalo de confiança para $r_{I}$ contém o parâmetro

contagem do número de vezes que o intervalo de confiança para icc contém o parâmetro

cálculo do vício de $r_{I}$ cálculo do erro quadrático médio de $r_{I}$ cálculo do vício de $r_{I}$ cálculo do erro quadrático médio de icc 


\section{ANEXO 8 \\ ESTUDO DA DISTRUIÇÃO DOS VALORES GERADOS}

O estudo da distribuição dos valores gerados foi realizada aplicando-se o teste de Normalidade, Shapiro-Francia, para pares de valores $\{z 1, z 2\}$ distribuídos segundo uma distribuição normal bivariada com mesma média e mesma variância, $\mathrm{N}\left(0,0,1,1, \rho_{I}\right)$, correlacionados $\left(\rho_{I}=0,0,50\right.$ e 0,8$)$. Os resultados do teste, para $n=10$ e 40 , são apresentados na tabela 8.1 .

Para cada configuração apresenta-se os valores gerados, o teste de normalidade , o gráfico de dispersão dos valores gerados e a correlação usual de Pearson, obtendo-se a correlação intraclasse de Pearson para pares repetidos.

Configuração 1: $\mathbf{n}=10, \rho_{I}=\mathbf{0}$

set abs 10

obs was 0, now 10

set seed 9711422

gen $z 1=i m u n o r m$ (uniform ())

gen $z 2=z 1 \star 0.0+i n \operatorname{morm}($ uniform ()$) \star \operatorname{sqr}\left(1-0.0^{\wedge} 2\right)$

valores gerados

\begin{tabular}{cccccc}
. list $\mathbf{z 1} \mathbf{z 2}$ & \multicolumn{2}{c}{} & \\
\hline \multicolumn{7}{c}{$\mathbf{z 1}$} & $\mathbf{z 2}$ & $\mathbf{z 1}$ & $\mathbf{z 2}$ \\
\hline 1. & -1.182999 & .6180825 & 6. & .2827041 & -.1006517 \\
2. & -1.075288 & .9163506 & 7. & .7341661 & .0568783 \\
3. & -.350171 & .060586 & 8. & .0358324 & -.5274458 \\
4. & -1.10264 & -1.318744 & 9. & -.1154405 & -1.319232 \\
5. & -.7449148 & -1.152147 & 10. & -.2845812 & .0621938 \\
\hline
\end{tabular}

teste de normalidade

- sfrancia 21 z2

Shapiro-Francia $W^{\prime}$ test for normal data

\begin{tabular}{r|ccccc} 
Variable & Obs & W' & $V^{\prime}$ & $z$ & Pr>z \\
z1 & 10 & 0.95826 & 0.698 & -0.568 & 0.71485 \\
$z 2$ & 10 & 0.92882 & 1.190 & 0.284 & 0.38808
\end{tabular}

gráfico de dispersāo dos valores gerados (zl e z2)

graph z1 z2, xlabel $(-2.0,-1.5,-1.0,-0.5,0.0,0.5,1.0)$ ylabel $(-1.0,-0.5,0.0,0.5,1.0)$ 

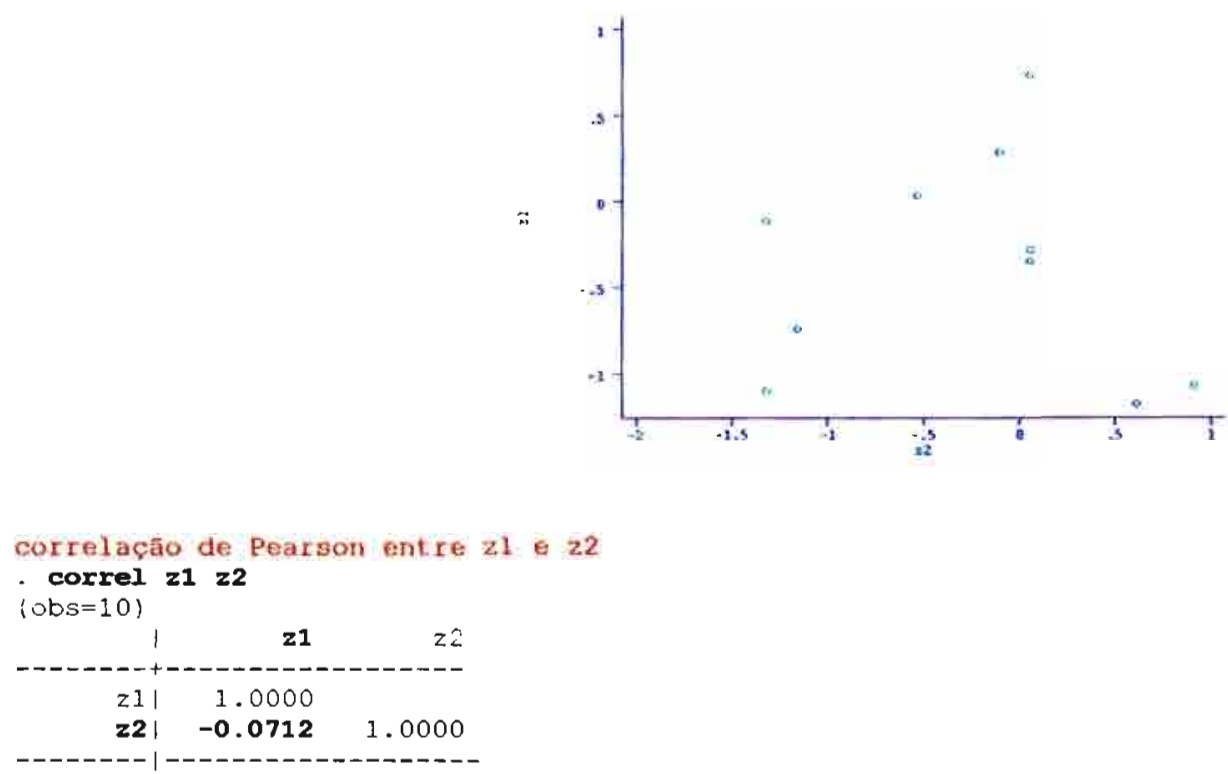

Configuração 2: $n=10, \rho_{I}=0,5$

- set obs 10

obs was 0 , now 10

set seed 8315064

gen $z 1=1$ nunorm (unt form ())

gen $z 2=z 1 * 0.5+1$ nvnorm(uniform ()$) \star \operatorname{sqrt}\left(1-0.5^{\wedge} 2\right)$

valores gerados

\begin{tabular}{|c|c|c|c|c|c|}
\hline & 21 & 22 & & $\mathbf{2 1}$ & $\mathbf{2 2}$ \\
\hline
\end{tabular}

teste de normalidade

- serancia $\geq 1 \quad 2$

Shapiro-Erancia $W^{\prime}$ test for normal data

Variable | Obs W' $\mathrm{V}^{\prime}$ $z \quad \operatorname{Pr}>z$

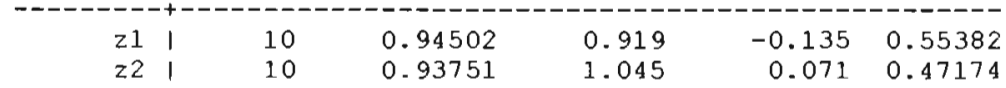

gráfico de dispersão dos valores gerados $(z 1$ e z2)

graph z1 z2, xlabel(-0.5,0.0,0.5,1.0,1.5,2.0) ylabel $(0.0,0.5,1.0,1.5)$ 

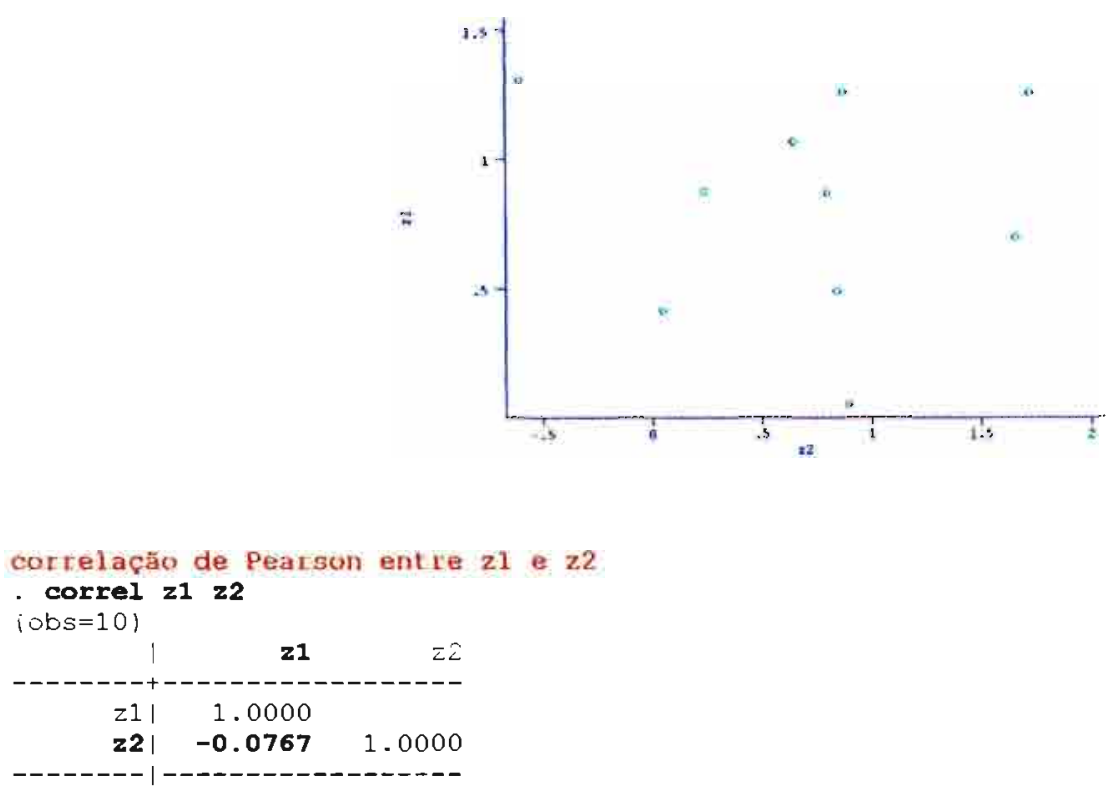

\section{Configuração 3: $n=10, \rho_{I}=0,8$}

- set abs 10

obs was 0 , now 10

set seed 3734917

gen $21=1$ nunorm (uniform())

gen $z 2=z 1 * 0.8+i n v n o r m(u n i \text { form }())^{\star} \operatorname{sqrt}\left(1-0.8^{\wedge} 2\right)$

valores gerados

list z1 22

\begin{tabular}{rrrrrr}
\hline \multicolumn{7}{c}{$\mathbf{z 1}$} & $\mathbf{z 2}$ & $\mathbf{z 1}$ & $\mathbf{z 2}$ \\
\hline 1. & .3012431 & 1.61327 & 6. & -.5068052 & .331127 \\
2 & -.5089676 & -1.489543 & 7. & -.85855 & -.9636325 \\
3. & 1.636532 & 1.014503 & 8. & .0294331 & -.4095795 \\
4. & .4900962 & 1.330274 & 9. & -.7756989 & -.6662866 \\
5. & .7371056 & 1.242351 & 10. & -.440271 & .6202074 \\
\hline
\end{tabular}

teste de normalidade

- sfrancia z1 z2

\begin{tabular}{|c|c|c|c|c|c|}
\hline Variable I & $\begin{array}{l}\text { Shap } \\
\text { Obs }\end{array}$ & $\begin{array}{r}\text { Erancia } \\
W\end{array}$ & $\begin{array}{c}\text { test } f \\
v^{\prime}\end{array}$ & $\begin{array}{r}r m a l \\
z\end{array}$ & Pr>z \\
\hline 211 & 10 & 0.91570 & 1.409 & 0.567 & 0.28532 \\
\hline$z 21$ & 10 & 0.95031 & 0.831 & -0.296 & 0.61631 \\
\hline
\end{tabular}

gráfico de dispersấo dos valores gerados (z1 e z2)

- graph z1 z2, xlabel $(-1.5,-1.0,-0.5,0.0,0.5,1.0,1.5,2.0)$ ylabel $(-1.0,-0.5,0.0$,

$>0.5,1.0,1.5,2.0)$ 


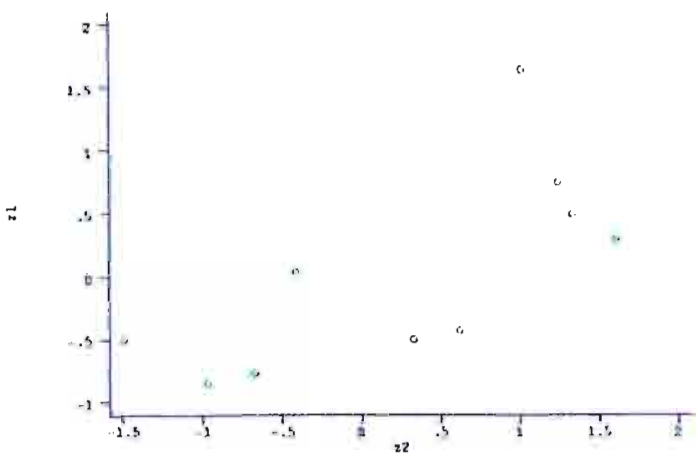

correlaço de pearson entre $z 1$ e $z 2$

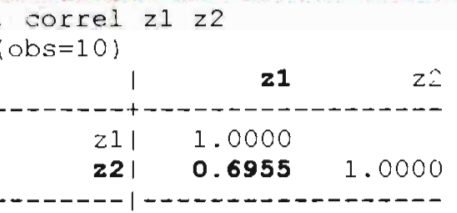

\section{Configuração 4: $n=40, \rho_{I}=0$}

\section{set abs 40}

obs was 0 , now 40

set seed 753731

gen $\mathrm{zl}=$ invnorm(uniform())

gen $z 2=z 1 * 0.0+1$ nvnorm (uniform ()$) * \operatorname{sqrt}\left(1-0.0^{\wedge} 2\right)$

valores gerados

\section{list $z 1=2$}

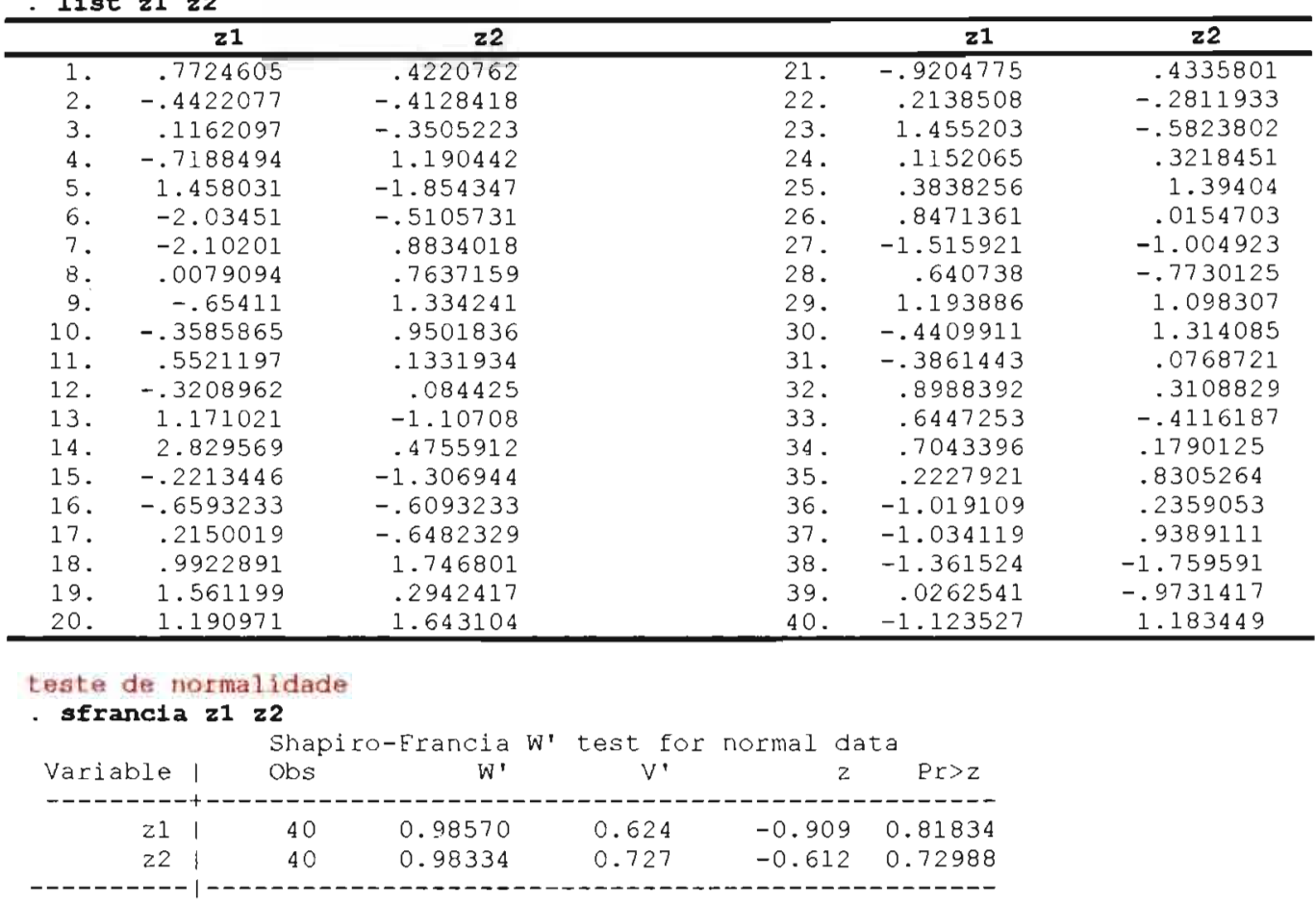

gráfico de dispersão dos valores gerados (21 e 22)

graph z1 z2, xlabel $(-2.0,-1.0,0.0,1.0,2.0)$ ylabel $(-2.0,-1.0,0.0,1.0,2.0,3.0)$

Anexos A - 14 


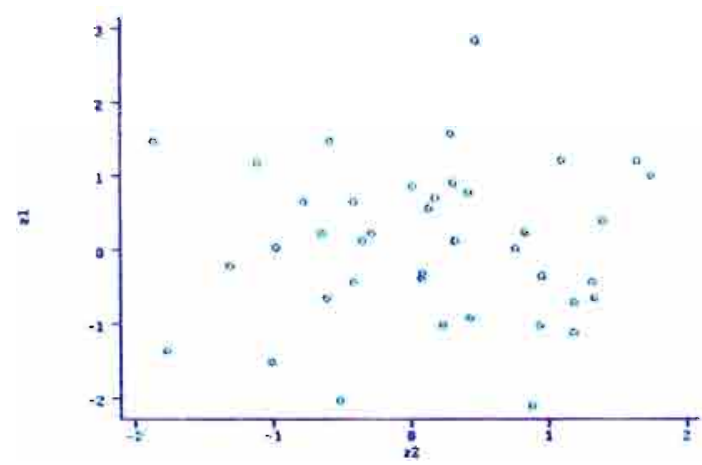

correlação de Pearson entre $z 1$ e $z 2$

- correl 2122

iobs $=40$ )

$\begin{array}{rrr}\text { | } & \mathbf{2 1} & \mathbf{z}< \\ z 1 \mid & 1.0000 & \\ \mathbf{2 2} \mid & \mathbf{0 . 0 1 1 4} & 1.0000\end{array}$

\section{Configuração 5: $\mathrm{n}=40, \rho_{I}=0,5$}

\section{set $a b s$}

obs was 0 , now 40

- set seed 3629161

gen 21-inunorm (uni form())

gen $z 2=z 1 * 0.5+i$ munorm (uniform ()$) * \operatorname{sgrt}\left(1-0.5^{\wedge} 2\right)$

valores gerados

\begin{tabular}{|c|c|c|c|c|c|}
\hline & $\mathrm{z1}$ & 22 & & 21 & 22 \\
\hline 1. & -.0633718 & .102894 & 21. & .341298 & -.0908163 \\
\hline 2. & .0772864 & -.4355544 & 22 . & 2.220693 & 2.03325 \\
\hline 3. & -1.197138 & -.5595763 & 23. & .634253 & .2708635 \\
\hline 4. & -2.05816 & -1.249224 & 24. & 2.116237 & 1.839841 \\
\hline 5. & -.6188348 & -.2273133 & 25. & -.4969674 & .4041592 \\
\hline 6. & -1.405683 & -.1515171 & 26. & -.2979644 & -.9424982 \\
\hline 7. & -.6279844 & .3758363 & 27. & .2205503 & -.1912663 \\
\hline 8. & -.0129603 & -1.174851 & 28. & 1.371361 & 1.446894 \\
\hline 9. & -.7917043 & 1.011786 & 29. & -.3636631 & -.1734827 \\
\hline 10. & 1.437868 & -.1420874 & 30. & 1.133421 & 1.50422 \\
\hline 11. & .5677435 & -1.769696 & 31. & 1.115786 & 1.099002 \\
\hline 12. & -.2123584 & 1.997941 & 32. & 1.189697 & .7835945 \\
\hline 13. & .9744481 & -.4550376 & 33. & -1.076169 & -1.027449 \\
\hline 14. & .1014771 & -1.088924 & 34. & -.230288 & -.3444999 \\
\hline 15. & -.6930944 & -.4510213 & 35. & 2.191619 & .7650678 \\
\hline 16. & 1.019753 & .8187997 & 36. & -1.244767 & -.7417473 \\
\hline 17. & -.1046399 & 1.097155 & 37. & .4028662 & .2367916 \\
\hline 18. & .9793368 & 1.391515 & 38. & .2515373 & .1729667 \\
\hline 19. & -.247563 & -.3318616 & 39. & -1.240507 & -.7003191 \\
\hline 20. & -.0699747 & -.3446531 & 40. & 1.21062 & .5569866 \\
\hline
\end{tabular}

teste de normalidade

- Sfrancta 2122

\begin{tabular}{|c|c|c|c|c|c|}
\hline \multirow[b]{2}{*}{ Variable | } & \multicolumn{2}{|c|}{ Shapiro-Francia } & \multicolumn{2}{|c|}{ test for normal } & data \\
\hline & Obs & $W^{\prime}$ & $V^{\prime}$ & $z$ & $\operatorname{Pr}>z$ \\
\hline 21 & 40 & 0.98437 & 0.682 & -0.736 & 0.76913 \\
\hline$z 21$ & 40 & 0.97922 & 0.907 & -0.187 & 0.57425 \\
\hline
\end{tabular}

qráfico de dispersäo dos valores gerados (zl e z2)

graph $21 \mathrm{z2}$, xlabel $(-2.0,-1.5,-1.0,-0.5,0.0,0.5,1.0,1.5,2.0)$ ylabel(-2.5, 
$-2.0,-1.0,0.0,1.0,2.0,3.0)$

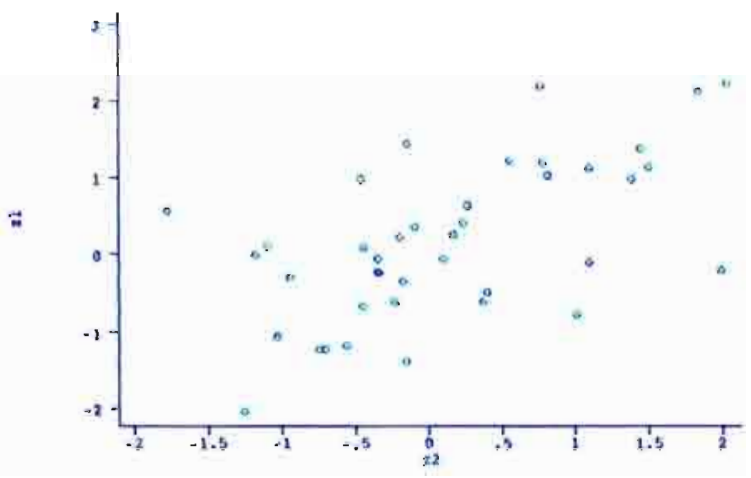

correlação de Pearson entre z.l e z.2

correl z1 z2

$(0 \mathrm{bs}=40\}$

\begin{tabular}{rrr} 
& $z 1$ & $z z$ \\
$z 1 !$ & 1.0000 & \\
$z 2 !$ & 0.5804 & 1.0000 \\
\hline
\end{tabular}

Configuração 6: $n=40, \rho_{1}=0,8$

- set abs 40

obs was 0 , now 40

set seed 7082457

- gen z1=inunorm(uniform())

gen $z 2=z 1 * 0.8+1$ nvnorm (uniform ()$) * \operatorname{scrt}\left(1-0.8^{\wedge} 2\right.$ )

valores gerados

\begin{tabular}{|c|c|c|c|c|c|}
\hline & $\mathbf{z} 1$ & 22 & & $\mathrm{z1}$ & $\mathrm{z2}$ \\
\hline 1. & .1931498 & .2642565 & 21. & -2.710783 & -2.501679 \\
\hline 2. & .804738 & -.0696982 & 22. & -.2128982 & -.1390005 \\
\hline 3. & -1.160713 & -.5515283 & 23. & .4613925 & -.3163403 \\
\hline 4. & 2.002946 & 1.410442 & 24. & -1.052658 & -.9871832 \\
\hline 5. & -.8513604 & -.4126154 & 25. & 1.795337 & .5605943 \\
\hline 6. & 1.826545 & 1.276437 & 26. & 3.020398 & 2.109524 \\
\hline 7. & .4520386 & 1.147922 & 27 . & -.5442978 & -.9464369 \\
\hline 8. & -.1686334 & -.4652099 & 28 . & .1236418 & .1913346 \\
\hline 9. & .3389046 & -.3112877 & 29. & -2.045961 & -1.508114 \\
\hline 10. & 1.205472 & 1.243243 & 30. & -2.099118 & -1.442944 \\
\hline 11. & .1672899 & .4504996 & 31. & -1.312404 & -.7903625 \\
\hline 12. & 2.339067 & 1.24111 & 32. & -2.188559 & -2.613187 \\
\hline 13. & -.0734075 & .3080218 & 33. & .303385 & -.0870731 \\
\hline 14. & .8387341 & -.2861967 & 34. & -.137172 & -.1292778 \\
\hline 15. & .4823111 & .5699558 & 35. & 1.497456 & .6906527 \\
\hline 16. & 1.802398 & 1.994224 & 36. & -2.101626 & -1.725944 \\
\hline 17. & -1.099019 & -.9486104 & 37. & -.6956264 & -1.607669 \\
\hline 18. & -.0409457 & -1.773921 & 38. & -1.482167 & -1.041233 \\
\hline 19. & -1.708178 & -1.130643 & 39. & 2.246663 & .0791562 \\
\hline 20. & .6816863 & .5134814 & 40. & .3027446 & .1819103 \\
\hline
\end{tabular}

teste de normal idade

- sfrancia $21 \mathrm{z2}$

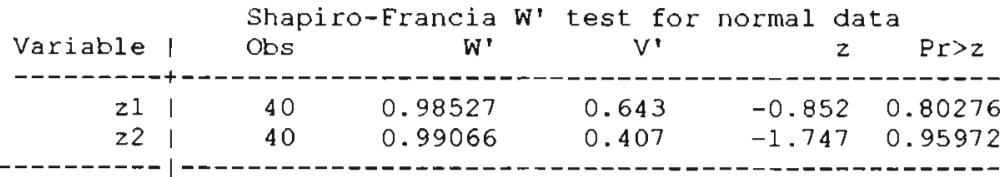

gráfico de dispersầ dos valores gerados (zl e z2)

graph z1 22 , xlabel $(-3.0,-2.0,-1.0,0.0,1.0,2.0,3.0)$ ylabel $(-3.0,-2.0$, 
$-1.0,0.0,1.0,2.0,3.0,4.0)$

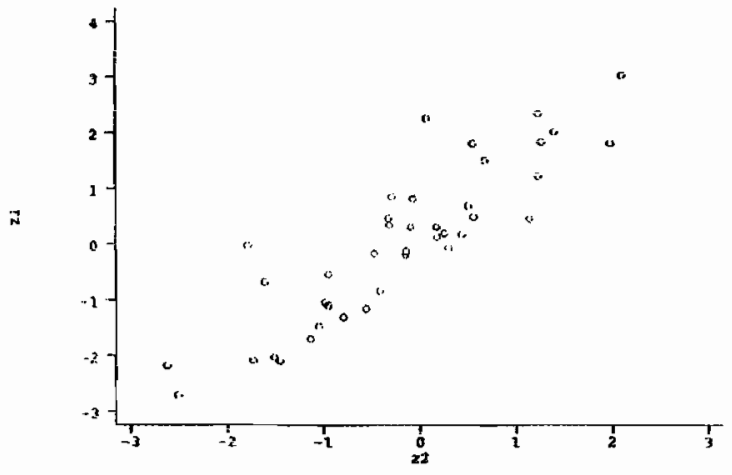

correlaçao de Pearson entre z1 e zz - correl z1 za $i 0 b s=40 ;$

\begin{tabular}{r|rr} 
& 21 & 22 \\
\hline $1 \mid$ & 1.0000 & \\
221 & $\mathbf{0 . 8 7 7 2}$ & 1.0000
\end{tabular}


Tabela 8.1 - Resultados do teste de Normalidade, Shapiro-Francia, para pares de valores gerados no estudo Monte-Carlo

\begin{tabular}{ccccc}
\hline valores & $\begin{array}{c}\text { tamanho } \\
\mathbf{d a} \\
\text { amostra } \\
\text { (n) }\end{array}$ & $\rho_{I}$ & $\mathbf{W}^{\prime}$ & $\mathbf{p}$ \\
$\mathbf{z 1}$ & 10 & 0 & & \\
& & 0,5 & 0,958 & 0,715 \\
& & 0,8 & 0,945 & 0,554 \\
$\mathbf{z 1}$ & 40 & 0 & 0,916 & 0,285 \\
& & 0,5 & 0,984 & 0,818 \\
& & 0,8 & 0,985 & 0,769 \\
$\mathbf{z 2}$ & 10 & 0 & 0,929 & 0,383 \\
& & 0,5 & 0,938 & 0,472 \\
& & 0,8 & 0,950 & 0,616 \\
$\mathbf{z 2}$ & 40 & 0 & 0,983 & 0,727 \\
& & 0,5 & 0,979 & 0,574 \\
& & 0,8 & 0,991 & 0,960 \\
\hline
\end{tabular}

Com base nos resultados do teste de normalidade de Shapiro-Francia (STATA, 1996), não se rejeita a hipótese de normalidade das distribuições de $z l$ e $z 2$, para amostras de tamanho 10 e 40 e valores de $\rho_{I}=\{0 ; 0,5 ; 0,8\}$ 


\section{ANEXo 9}

\section{DIFRENÇA ENTRE OS VALORES MÉDIOS DE $\boldsymbol{r}_{I}$ E icc}

As diferenças entre os valores médios de $r_{I}$ e de $i c c$ são apresentados na tabela 10.1

Tabela 9.1 - Simulação de 2.000 amostras de tamanho $n=15,30$ e 45 e coeficientes de correlação intraclasse $\rho_{I}=\{0 ; 0,15 ; 0,30 ; 0,45 ; 0,60 ; 0,75 ; 0,9\}$.

Diferenças entre os valores médios de $r_{I}$ e icc

\begin{tabular}{cccc}
\hline$\rho_{I}$ & $\mathbf{n = 1 5}$ & $\mathbf{n = 3 0}$ & $\mathbf{n = 4 5}$ \\
\hline 0 & 0,03239 & 0,01639 & 0,01098 \\
0,15 & 0,03181 & 0,01609 & 0,01076 \\
0,3 & 0,03016 & 0,01512 & 0,01004 \\
0,45 & 0,02698 & 0,01342 & 0,00891 \\
0,6 & 0,02247 & 0,01097 & 0,00723 \\
0,75 & 0,01623 & 0,00768 & 0,00503 \\
0,9 & 0,00751 & 0,00348 & 0,00223 \\
\hline
\end{tabular}




\section{AnEXo 10}

\section{VIÉS E ERRO QUADRÁTICO MÉdIO DE $\boldsymbol{r}_{I}$ E DE icc}

Os valores do viés de $r_{I}$ e de $i c c$ são apresentados na tabela 10.1

Tabela 10.1 - Simulação de 2.000 amostras de tamanho $n=15,30$ e 45 e coeficientes de correlação intraclasse $\rho_{I}=\{0 ; 0,15 ; 0,30 ; 0,45 ; 0,60 ; 0,75 ; 0,9\}$. Valores do viés de $r_{I}$

(viesri) e do viés de icc (viesicc)

\begin{tabular}{c|cc|cc|cc}
\hline$\rho_{I}$ & \multicolumn{2}{|c|}{$\mathbf{n = 1 5}$} & \multicolumn{2}{c|}{$\mathbf{n = 3 0}$} & \multicolumn{2}{c}{$\mathbf{n = 4 5}$} \\
\cline { 2 - 7 } & viesri & viesicc & viesri & viesicc & viesri & viesicc \\
\hline 0 & $-0,0334344$ & $-0,0010425$ & $-0,0141413$ & 0,0022525 & $-0,0127084$ & $-0,0017243$ \\
0,15 & $-0,0447069$ & $-0,0129007$ & $-0,0184438$ & $-0,002354$ & $-0,0093923$ & 0,001367 \\
0,3 & $-0,0518233$ & $-0,0216593$ & $-0,0259379$ & $-0,0108173$ & $-0,0154981$ & $-0,0054128$ \\
0,45 & $-0,0499027$ & $-0,0229211$ & $-0,0242624$ & $-0,0108441$ & $-0,0150028$ & $-0,0060975$ \\
0,6 & $-0,049217$ & $-0,0267463$ & $-0,0241868$ & $-0,0132217$ & $-0,0145116$ & $-0,0072812$ \\
0,75 & $-0,0426865$ & $-0,0264574$ & $-0,0202315$ & $-0,0125314$ & $-0,0123512$ & $-0,0073228$ \\
0,9 & $-0,0217658$ & $-0,014251$ & $-0,0111851$ & $-0,0077036$ & $-0,0063472$ & $-0,0041175$ \\
\hline
\end{tabular}

Os valores do erro quadrático médio de $r_{I}$ e de icc são apresentados na tabela 10.2

Tabela 10.2 - Resultados da simulação de 2.000 amostras de tamanho $n=15,30$ e 45 e coeficientes de correlação intraclasse $\rho_{I}=\{0 ; 0,15 ; 0,30 ; 0,45 ; 0,60 ; 0,75 ; 0,9\}$. Erros quadráticos médios de $r_{l}$ (eqmri) e de $i c c$ (eqmicc)

\begin{tabular}{c|cc|cc|cc}
\hline \multirow{2}{*}{$\rho_{1}$} & \multicolumn{2}{|c|}{$\mathbf{n = 1 5}$} & \multicolumn{2}{c|}{$\mathbf{n}=\mathbf{3 0}$} & \multicolumn{2}{c}{$\mathbf{n}=\mathbf{4 5}$} \\
\cline { 2 - 7 } & eqmri & eqmicc & eqmri & eqmicc & eqmri & eqmicc \\
\hline 0 & 0,0617149 & 0,0606757 & 0,0330047 & 0,0328314 & 0,0225611 & 0,0224116 \\
0,15 & 0,0656253 & 0,0629828 & 0,0317726 & 0,0311596 & 0,0212977 & 0,0210858 \\
0,3 & 0,0597232 & 0,0558376 & 0,0295617 & 0,0285144 & 0,0189602 & 0,0185249 \\
0,45 & 0,0502944 & 0,0461183 & 0,0222482 & 0,0211926 & 0,0146958 & 0,0142393 \\
0,6 & 0,0361852 & 0,0322450 & 0,0160568 & 0,0150911 & 0,0098001 & 0,0094027 \\
0,75 & 0,0202104 & 0,0175343 & 0,0081002 & 0,0074957 & 0,0048705 & 0,0046223 \\
0,9 & 0,0048933 & 0,0041489 & 0,0016759 & 0,0015212 & 0,0010024 & 0,0009418 \\
\hline
\end{tabular}


Os valores das diferenças entre os erros quadráticos médios de $r_{I}$ e de icc são apresentados na tabela 10.3 .

Tabela 10.3 - Simulação de 2.000 amostras de tamanho $n=15,30$ e 45 e coeficientes de correlação intraclasse $\rho_{l}=\{0 ; 0,15 ; 0,30 ; 0,45 ; 0,60 ; 0,75 ; .0,9\}$

Valores das diferenças entre o erro quadrático médio de $r_{I}\left(\right.$ eqmr $\left.r_{I}\right)$ e do erro quadrático médio de icc (eqmicc)

\begin{tabular}{cccc}
\hline$\rho_{l}$ & $\mathbf{n}=\mathbf{1 5}$ & $\mathbf{n}=\mathbf{3 0}$ & $\mathbf{n}=\mathbf{4 5}$ \\
\hline 0 & 0,00104 & 0,00017 & 0,00015 \\
0,15 & 0,00264 & 0,00061 & 0,00021 \\
0,3 & 0,00389 & 0,00105 & 0,00044 \\
0,45 & 0,00418 & 0,00106 & 0,00046 \\
0,6 & 0,00394 & 0,00097 & 0,00040 \\
0,75 & 0,00268 & 0,00060 & 0,00025 \\
0,9 & 0,00074 & 0,00015 & 0,00006 \\
\hline
\end{tabular}




\section{ANEXo 11}

\section{EFICIÊNCIA RELATIVA DE $i c c$}

A eficiência relativa de $i c c$ dada pelo quociente do erro quadrático médio de $r_{I}$ e do erro quadrático médio de $i c c$ são apresentados na tabela 11

Tabela 11 - Simulação de 2.000 amostras de tamanho $n=15,30$ e 45 e coeficientes de correlação intraclasse $\rho_{l}=\{0 ; 0,15 ; 0,30 ; 0,45 ; 0,60 ; 0,75 ; 0,90\}$.

Valores da eficiência relativa de icc

\begin{tabular}{cccc}
\hline$\rho_{I}$ & $\mathbf{n = 1 5}$ & $\mathbf{n = 3 0}$ & $\mathbf{n = 4 5}$ \\
\hline 0 & 1,0171 & 1,0053 & 1,0067 \\
0,15 & 1,0420 & 1,0197 & 1,0100 \\
0,3 & 1,0696 & 1,0367 & 1,0235 \\
0,45 & 1,0906 & 1,0498 & 1,0321 \\
0,6 & 1,1222 & 1,0640 & 1,0423 \\
0,75 & 1,1526 & 1,0806 & 1,0537 \\
0,9 & 1,1794 & 1,1017 & 1,0643 \\
\hline
\end{tabular}

Anexos A - 22 


\section{ANEXo 12}

\section{AMPLITUDES MÉdiAS DOS INTERVALOS DE CONFIANÇA Percentual de Vezes Que os intervalos abrangem O ParâMETro}

As amplitudes médias dos intervalos de confiança de $95 \%$ de confiabilidade, são apresentadas na tabela 12.1

Tabela 12.1 - Simulação de 2.000 amostras de tamanho $n=15,30$ e 45 e coeficientes de correlação intraclasse $\rho_{l}=\{0 ; 0,15 ; 0,30 ; 0,45 ; 0,60 ; 0,75 ; 0,9\}$. Valores das amplitudes médias dos intervalos de confiança para $\rho_{I}$

\begin{tabular}{ccccccc}
\hline & \multicolumn{2}{c}{$\mathbf{n}=\mathbf{1 5}$} & \multicolumn{2}{c}{$\mathbf{n = 3 0}$} & \multicolumn{2}{c}{$\mathbf{n = 4 5}$} \\
\cline { 2 - 7 }$\rho_{I}$ & $r_{l}$ & $i c c$ & $r_{l}$ & $i c c$ & $r_{I}$ & $i c c$ \\
\hline 0 & 0,928191 & 0,93257 & 0,68241 & 0,68395 & 0,56545 & 0,56635 \\
0,15 & 0,917751 & 0,91481 & 0,67248 & 0,67104 & 0,55559 & 0,55470 \\
0,3 & 0,882189 & 0,87221 & 0,63739 & 0,63325 & 0,52399 & 0,52158 \\
0,45 & 0,80794 & 0,79161 & 0,57355 & 0,56710 & 0,46729 & 0,46364 \\
0,6 & 0,695629 & 0,67503 & 0,47802 & 0,47030 & 0,38469 & 0,38041 \\
0,75 & 0,528118 & 0,50661 & 0,34494 & 0,33749 & 0,27252 & 0,26852 \\
0,9 & 0,264779 & 0,25007 & 0,16194 & 0,15742 & 0,12384 & 0,12153 \\
\hline
\end{tabular}


O número e percentual de vezes que os intervalos de confiança abrangem o parâmetro é apresentado na tabela 12.2 .

Tabela 12.2 - Simulação de 2.000 amostras de tamanho $n=15,30$ e 45 e coeficientes de correlação intraclasse $\rho_{I}=\{0 ; 0,15 ; 0,30 ; 0,45 ; 0,60 ; 0,75 ; .0,9\}$.

Número e percentagem de vezes que os intervalos de confiança de $95 \%$ abrangem o parâmetro $\rho_{I}$

\begin{tabular}{|c|c|c|c|c|c|c|c|c|c|c|c|c|}
\hline \multirow[b]{2}{*}{$\rho_{I}$} & \multicolumn{2}{|c|}{$\mathbf{r}_{1}$} & \multicolumn{2}{|c|}{ icc } & \multicolumn{2}{|c|}{$r_{1}$} & \multicolumn{2}{|c|}{ icc } & \multicolumn{2}{|c|}{$r_{1}$} & \multicolumn{2}{|c|}{ icc } \\
\hline & $\mathrm{s}$ & $\%$ & $\mathrm{~N}$ & $\%$ & s & $\%$ & $N$ & $\%$ & $v$ & $\%$ & $\mathbf{N}$ & $\%$ \\
\hline 0 & 1916 & 95,80 & 1912 & 95,60 & 1895 & 94,75 & 1894 & 94,70 & 1899 & 94,95 & 1905 & 95,25 \\
\hline 0,15 & 1886 & 94,30 & 1898 & 94,90 & 1898 & 94,90 & 1903 & 95,15 & 1898 & 94,90 & 1903 & 95,15 \\
\hline 0,3 & 1902 & 95,10 & 1902 & 95,10 & 1889 & 94,45 & 1889 & 94,45 & 1892 & 94,60 & 1898 & 94,90 \\
\hline 0,45 & 1896 & 94,80 & 1895 & 94,75 & 1914 & 95,70 & 1925 & 96,25 & 1895 & 94,75 & 1901 & 95,05 \\
\hline 0,6 & 1885 & 94,25 & 1895 & 94,75 & 1898 & 94,90 & 1910 & 95,50 & 1902 & 95,10 & 1909 & 95,45 \\
\hline 0,75 & 1898 & 94,90 & 1905 & 95,25 & 1902 & 95,10 & 1907 & 95,35 & 1909 & 95,45 & 1914 & 95,70 \\
\hline 0,9 & 1902 & 95,10 & 1901 & 95,05 & 1905 & 95,25 & 1911 & 95,55 & 1913 & 95,65 & 1917 & 95,85 \\
\hline
\end{tabular}




\section{ANEXo 13}

\section{Aplicação}

Foram utilizados como exemplo, dados obtidos por Gimeno SGA e Souza JMP (1997). O estudo tinha como objetivo avaliar, mediante um estudo de reprodutibilidade, a qualidade de dados de variáveis relacionadas a diabetes mellitus insulino-dependente.

Para a presente aplicação, foram selecionadas duas, entre as variáveis estudadas: comprimento da criança ao nascer $(\mathrm{cm})$ e idade da criança (dias), no momento da introdução do leite de vaca. Os dados foram coletados em dois momentos, para duas amostras de indivíduos; uma composta por portadores de diabetes mellitus insulinodependente (casos) e outra, composta por não portadores (controles). Neste exemplo serão utilizados os dados obtidos entre os controles.

Denominando-se $\mathrm{X}$ a observação obtida na primeira ocasião e $\mathrm{Y}$ a observação obtida na segunda ocasião, para cada variável, obtém-se

\section{VARIÁVEL COMPRIMENTO AO NASCER $\left(n_{\text {controle }}=36\right)$}

\section{a) coeficiente de correlação intraclasse de Pearson para pares repetidos $\left(r_{I}\right)$}

Após a construção dos pares repetidos $\{X, Y\}$ e $\{Y, X\}$ e, denominando-se o novo conjunto de pares de valores de $\left\{X, X^{\prime}\right\}$, calcula-se a correlação de Pearson, para o novo conjunto de dados.

$$
r_{I}=\frac{2 \sum_{i=1}^{72}\left\{\left(x_{i}-\bar{x}\right)\left(x_{i}^{\prime}-\bar{x}\right)\right\}}{\sum_{i=1}^{72}\left(x_{i}-\bar{x}\right)^{2}+\sum_{i=1}^{72}\left(x_{i}^{\prime}-\bar{x}\right)^{2}}=r_{I}=0,914191
$$

\section{Intervalo de confiança de $95 \%$}

transformação $z_{I}$

$$
z_{I}=\frac{1}{2}\left[\log _{e}\left(1+r_{I}\right)-\log _{e}\left(1-r_{I}\right)\right]=1,552465
$$




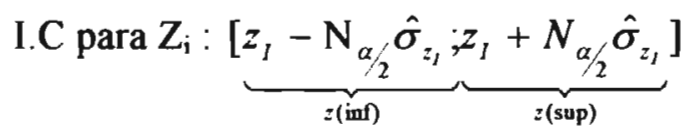

limite inferior de $z_{i}=1,218772$

limite superior de $z_{i}=1,886157$

variância de $z_{i}$

$$
\hat{\sigma}_{2,}^{2}=\frac{2}{2 n^{\prime}-3}=\frac{2}{2 \times 36-3}=0,028986
$$

$\mathrm{IC}$ para $\rho_{I}:\left[\frac{e^{2 z(\mathrm{inf})}-1}{e^{2 z(\mathrm{inf})}+1} ; \frac{e^{2 z(\mathrm{sup})}-1}{e^{2 z(\mathrm{sup})}+1}\right]$

I. C. $=(0,839292 ; 0,955037)$

A distribuição conjunta dos pontos $\left\{X, X^{\prime}\right\}$ é apresentada na figura 13.1. Observase que os valores de $r$ e $r_{I}$ são iguais e, ainda, que a correlação intraclasse $\left(r_{I}\right)$ é o coeficiente angular da reta de regressão.

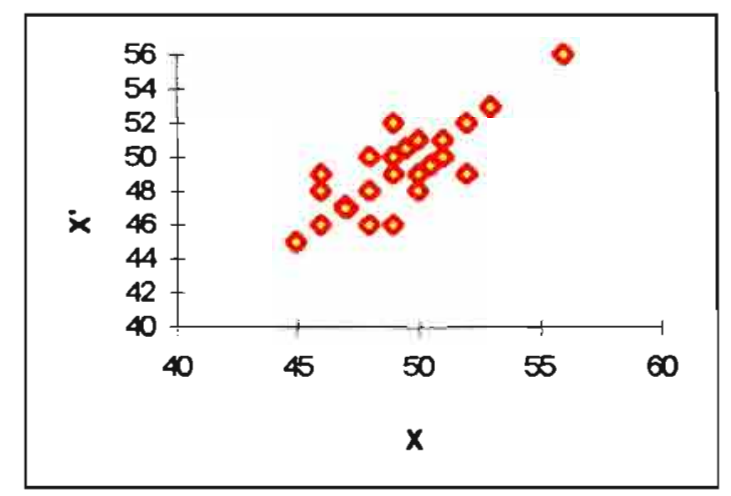

Figura 13.1 - Exemplo de aplicação, dispersão dos pontos $\left\{X, X^{\prime}\right\}$ variável comprimento ao nascer

Comentários: As séries de valores obtidos em duas ocasiões estão altamente correlacionadas indicando, que na pesquisa em questão, a variável comprimento ao nascer é confiável. 
b) correlação intraclasse como função de componentes de variância, estimados pela ANOVA (icc)

O modelo apropriado é o modelo de efeitos aleatórios, com um fator, dado pela equação

onde

$$
y_{l i}=\mu+\alpha_{i}+e_{l i}
$$

$y_{i l} \quad$ é a observação no indivíduo $i$, na ocasião $j(i=1, \ldots, 36 ; j=1,2)$;

$\mu$ é o comprimento médio ao nascer de crianças, na população de casos;

$\alpha_{i}$ é o efeito aleatório da criança $i, \alpha_{i} \sim \operatorname{Normal}\left(0, \sigma_{\alpha}^{2}\right)$;

$e_{i j}$ é o erro aleatório associado à observação $y_{i j}, e_{i l}-\operatorname{Normal}\left(0, \sigma_{e}^{2}\right)$

$n$ é o número de réplicas $(n=2)$

$\alpha_{i}$ e $e_{l l}$ são completamente independentes entre si.

Como

$$
\operatorname{var}\left(y_{! l}\right)=\sigma_{y}^{2}=\sigma_{\alpha}^{2}+\sigma_{e}^{2},
$$

o coeficiente de correlação intraclasse tem a forma

$$
\rho_{l}=\frac{\sigma_{a}^{2}}{\sigma_{a}^{2}+\sigma_{e}^{2}}
$$

Utilizando-se o STATA (1997), obtém-se as estimativas dos componentes de variância.

$$
\begin{aligned}
& \hat{\sigma}_{a}^{2}=\frac{Q M A-Q M R}{n} \text { e } \hat{\sigma}_{e}^{2}=Q M R, \text { resultando em } \\
& \hat{\rho}_{l}=i c c=\frac{\hat{\sigma}_{a}^{2}}{\hat{\sigma}_{a}^{2}+\hat{\sigma}_{e}^{2}}=\frac{Q M A-Q M R}{Q M A+(n-1) Q M R}
\end{aligned}
$$

Substituindo-se os valores dos Quadrados Médios, dados na tabela da ANOVA (tabela 13.1) obtém-se a estimativa para icc.

$$
i c c=\frac{10,1241379-0,10}{10,1241379+(2-1) 0,10}=0,9804384
$$


Tabelas 13.1 - Exemplo de aplicação

ANOVA com um fator aleatório, variável comprimento ao nascer

\begin{tabular}{|c|c|c|c|c|c|}
\hline Source & SS & $d f$ & MS & F & $>F$ \\
\hline $\begin{array}{l}\text { Between groups } \\
\text { Within groups }\end{array}$ & $\begin{array}{r}293.60 \\
3.00\end{array}$ & $\begin{array}{l}29 \\
30\end{array}$ & $\begin{array}{r}10.1241379 \\
.10\end{array}$ & 101.24 & 0.0000 \\
\hline Total & 296.60 & 59 & 5.02711864 & & \\
\hline
\end{tabular}

\section{Intervalo de Confiança}

O I.C. para $\rho_{l}$ é dado pela equação (23), ou seja,

$$
P\left(\frac{L_{i}}{1+L_{i}} \leq \rho_{I} \leq \frac{L_{s}}{1+L_{s}}\right)=1-\alpha,
$$

onde

$$
\left\{\begin{array}{l}
L_{i}=\frac{1}{n}\left(\frac{Q M A}{Q M R} \frac{1}{F_{2}}-1\right) \\
L_{s}=\frac{1}{n}\left(\frac{Q M A}{Q M R} \frac{1}{F_{1}}-1\right)
\end{array}\right.
$$

para $F_{2}=F_{k-1, N-k, 1-\alpha / 2}$ e $F_{1}=F_{k-1, N-k, \alpha / 2}$

Aplicando-se a fórmula acima tem-se

$$
\left\{\begin{array}{l}
L_{i}=\frac{1}{2}\left(\frac{10,1241379}{0,10} \frac{1}{1,948514}-1\right)=24,97912 \\
L_{s}=\frac{1}{2}\left(\frac{10,1241379}{0,10} \frac{1}{0,511584}-1\right)=97,949
\end{array},\right.
$$

e, substituindo-se os valores de $L_{i}$ e $L_{s}$ em (23), tem-se

$$
\text { I.C. }=(0,961508 ; 0,989894)
$$

Comentários: Pode-se observar que $\hat{\sigma}_{e}^{2}$ é bem pequeno quando comparado com o outro componente de variância $\left(\hat{\sigma}_{\alpha}^{2}\right)$, significando alta precisão da medida. A variância total é quase totalmente explicada pela variância entre individuos, podendo-se concluir que os dados de comprimento são confiáveis. 
VARIÁVEL IDAdE (DIAS) DA CRIANÇA NO MOMENTO dE INTROdUÇÃo do LEITE dE $\operatorname{VACA}\left(n_{\text {controle }}=38\right)$

a) coeficiente de correlação intraclasse de Pearson para pares repetidos $\left(\boldsymbol{r}_{I}\right)$

Após a construção dos pares repetidos $\{X, Y\}$ e $\{Y, X\}$ e, denominando-se o novo conjunto de pares de valores de $\left\{X, X^{\prime}\right\}$, calcula-se a correlação de Pearson, para o novo conjunto de dados.

$$
r_{l}=\frac{2 \sum_{i=1}^{76}\left\{\left(x_{i}-\bar{x}\right)\left(x_{i}^{\prime}-\bar{x}\right)\right\}}{\sum_{i=1}^{76}\left(x_{i}-\bar{x}\right)^{2}+\sum_{i=1}^{76}\left(x_{i}^{\prime}-\bar{x}\right)^{2}}=r_{l}=0,766833
$$

\section{Intervalo de confiança de $95 \%$}

transformação $z_{1}$

$$
z_{i}=\frac{1}{2}\left[\log _{e}\left(1+r_{l}\right)-\log _{e}\left(1-r_{l}\right)\right]=1,012595
$$

I.C para $Z_{\mathrm{i}}:[\underbrace{z_{1}-\mathrm{N}_{\alpha_{2}} \hat{\sigma}_{z_{i}} ;}_{z \text { (in) }} \underbrace{z_{l}+N_{\alpha_{2}} \hat{\sigma}_{z_{l}}}_{z \text { (sup) }}]$

limite inferior de $z_{i}=0,688174$

limite superior de $z_{i}=1,337017$

variância de $z_{i}$

$$
\hat{\sigma}_{i_{1}}^{2}=\frac{2}{2 n^{\prime}-3}=\frac{2}{2 \times 36-3}=0,027397
$$

IC para $\rho_{l}:\left[\frac{e^{2 z(\mathrm{in})}-1}{e^{2 z(\mathrm{in})}+1} \cdot \frac{e^{2 z(\mathrm{sup})}-1}{e^{2 z(\mathrm{sup})}+1}\right]$

I. C. $=(0,596808 ; 0,870954)$ 
A distribuição conjunta dos pontos $\left\{X, X^{\prime}\right\}$ é apresentada na figura 13.2. Observase que os valores de $r$ e $r_{l}$ são iguais e, ainda, que a correlação intraclasse $\left(r_{l}\right)$ é o coeficiente angular da reta de regressão.

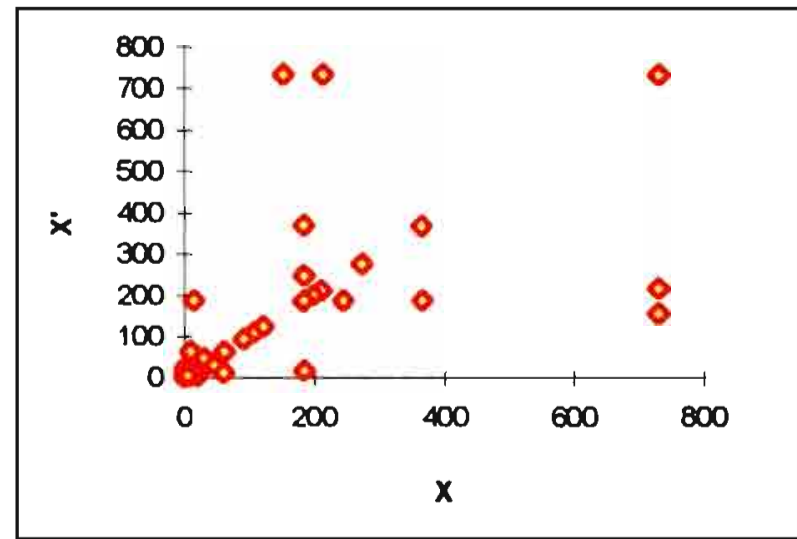

Figura 13.2 - Exemplo de aplicação, dispersão dos pontos $\left\{X, X^{\prime}\right\}$.

Variável idade da criança no momento de introdução do leite de vaca.

Comentários : As séries de valores obtidos em duas ocasiões estão moderadamente correlacionadas.

b) Correlação intraclasse como função de componentes de variância, estimados pela

\section{ANOVA (icc)}

O modelo apropriado é o modelo de efeitos aleatórios, com um fator, dado pela equação

onde

$$
y_{i j}=\mu+\alpha_{i}+e_{i j}
$$

$y_{i j}$ é a observação no individuo $i$, na ocasião $j(i=1, \ldots, 38 ; j=1,2)$;

$\mu$ é a idade da criança no momento da introdução do leite de vaca, na população de controles;

$\alpha_{i}$ é o efeito aleatório da criança $i, \alpha_{i} \sim \operatorname{Normal}\left(0, \sigma_{\alpha}^{2}\right)$;

$e_{i j}$ é o erro aleatório associado à observação $y_{i j}, e_{i j} \sim \operatorname{Normal}\left(0, \sigma_{e}^{2}\right)$

$n$ é o número de réplicas ( $\boldsymbol{n}=2)$

$\alpha_{i}$ e $e_{i j}$ são completamente independentes entre si 
Como

$$
\operatorname{var}\left(y_{i j}\right)=\sigma_{y}^{2}=\sigma_{\alpha}^{2}+\sigma_{e}^{2},
$$

o coeficiente de correlação intraclasse tem a forma

$$
\rho_{1}=\frac{\sigma_{a}^{2}}{\sigma_{a}^{2}+\sigma_{e}^{2}}
$$

Utilizando-se o STATA (1997), obtém-se as estimativas dos componentes de variância

$$
\begin{aligned}
& \hat{\sigma}_{a}^{2}=\frac{Q M A-Q M R}{n} \text { e } \hat{\sigma}_{e}^{2}=Q M R, \text { resultando em } \\
& \hat{\rho}_{I}=i c c=\frac{\hat{\sigma}_{a}^{2}}{\hat{\sigma}_{a}^{2}+\hat{\sigma}_{e}^{2}}=\frac{Q M A-Q M R}{Q M A+(n-1) Q M R}
\end{aligned}
$$

Substituindo-se os valores dos Quadrados Médios, dados na tabela da ANOVA (tabela 13.2), obtém-se a estimativa de icc.

$$
i c c=\frac{68586,909-8813,13158}{68586,909+(2-1) 8813,13158}=0,772271
$$

Tabela 13.2 - Exemplo de aplicação

ANOVA com um fator aleatório, variável idade da criança no momento de introdução do leite de vaca

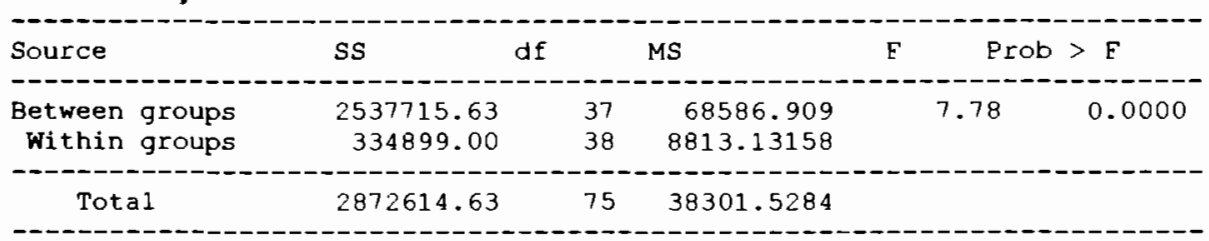

\section{Intervalo de Confiança}

O I.C. para $\rho_{l}$ é dado pela equação (23), ou seja,

$$
P\left(\frac{L_{i}}{1+L_{i}} \leq \rho_{I} \leq \frac{L_{s}}{1+L_{s}}\right)=1-\alpha,
$$

onde 


$$
\left\{\begin{array}{l}
I_{1}=\frac{1}{n}\left(\frac{Q M A}{Q M R} \frac{1}{F_{2}}-1\right) \\
I_{\mathrm{s}}=\frac{1}{n}\left(\frac{Q M A}{Q M R} \frac{1}{F_{1}}-1\right)
\end{array}\right.
$$

para $F_{2}=F_{k-1 . N \cdot k \cdot 1 \cdot \alpha / 2}$ e $F_{1}=F_{k-1, N-k, \alpha / 2}$

Aplicando-se a fórmula acima tem-se

$$
\left\{\begin{array}{l}
L_{t}=\frac{1}{2}\left(\frac{68586,909}{8813,13158} \frac{1}{1,912845}-1\right)=1,534235 \\
L_{s}=\frac{1}{2}\left(\frac{68586,909}{8813,13158} \frac{1}{0,521297}-1\right)=6,964418
\end{array},\right.
$$

e. substituindo-se os valores de $L_{l}$ e $L_{s}$ em (23), tem-se

$$
\text { I.C. }=(0,605404 ; 0,874442)
$$

Comentários: Pode-se observar que $\hat{\sigma}_{c}^{2}$ não é tão pequeno quando comparado com o outro componente de variância $\left(\hat{\sigma}_{\alpha}^{2}\right)$, significando que parte da variância total é explicada pela discordância entre os valores dentro de cada individuo. Esta variável possui, assim, confiabilidade moderada.

Quadro 13.1 - Resumo dos resultados, estimadores $r_{I}$ e $i c c$ e intervalos de confiança para as variáveis comprimento ao nascer e idade.

\begin{tabular}{|ccc|}
\hline Medida & comprimento ao nascer & idade da criança \\
\hline $\begin{array}{c}\text { correlação } \\
\text { intraclasse } \\
r_{I}\end{array}$ & 0,914 & 0,767 \\
I.C estimado por $r_{I}$ & $(0,839 ; 0,955)$ & $(0,596 ; 0,871)$ \\
$\begin{array}{c}\text { correlação } \\
\text { intraclasse } \\
\text { icc } \\
\text { I.C estimado por } \\
i c c\end{array}$ & 0,980 & 0,772 \\
\hline
\end{tabular}

Anexos A - 32 
Comentário: Ambos os estimadores produzem resultados bastante próximos. Para a variável idade da criança, estes são iguais até a segunda casa decimal. Para ambas as variáveis, o intervalo de confiança de $95 \%$ possui amplitude menor quando é utilizado $i c c$. 